INSTITUTO DE PESQUISAS ENERGÉTICAS E NUCLEARES

Autarquia associada à Universidade de São Paulo

DESENVOLVIMENTO DE RADIOTRAÇADORES ANGIOGÊNICOS PARA DIAGNÓSTICO DE GLIOMA: ESTUDO EM MODELO ANIMAL

ÉRICA APARECIDA DE OLIVEIRA

Tese apresentada como parte dos requisitos para obtenção do grau de Doutor em Ciências na Área de Tecnologia Nuclear - Aplicações

Orientadora:

Profa. Dra. Bluma Linkowski Faintuch

SÃO PAULO 
À minha família 


\section{AGRADECIMENTOS}

À Deus, inteligência suprema, que nos impulsiona a evolução, através da dinâmica da vida, onde todas as nossas ações geram reações. Aos amigos protetores pela influência benévola, auxílio e conforto que posso sentir a cada instante da minha vida.

Aos meus pais, por todos os esforços que fizeram para que eu tivesse a melhor educação possível, mesmo diante de todas as dificuldades e pelo apoio e ombro amigo em todos os momentos difíceis durante esses anos.

À minha orientadora Dra. Bluma Linkowski Faintuch, pelos importantes ensinamentos científicos, pela confiança, incentivo e amizade ao longo desses 5 anos em que realizei meu mestrado e doutorado.

Ao meu namorado e futuro marido Felipe de Souza Lima, pela paciência, compreensão e principalmente pelo amor, sempre presente nas palavras e gestos nos momentos em que eu mais precisava.

Aos colegas de laboratório, Ana Paula Funari, Angélica Bueno Barbezan, Aryel Heitor e Daniele Seo pela ajuda nos experimentos e pelo convívio amigável no dia-a-dia do laboratório.

À grande amiga Dra. Fernanda Faião Flores pelo apoio, incentivo e amizade sempre, tanto científico quanto pessoal. Você é o meu exemplo profissional!

Aos profissionais do Biotério do IPEN, especialmente a Maria Neide Ferreira Mascarenhas, pelos animais concedidos. 
À Dra. Ana Maria Moro e a Roselaine Campos Targino, do Instituto Butantan Laboratório de Biofarmacologia em células animais, pelo cultivo das células tumorais.

Ao Natanael Gomes da Silva, pela aquisição das imagens cintilográficas.

Ao Dr. Whitney Pope, do Departamento de Radiologia da Universidade da California, Los Angeles (UCLA) - EUA, por aceitar me receber como pesquisadora visitante e proporcionar a realização dos experimentos em Ressonância Magnética.

À Dra. Jelena Lazovic, ao Dr. Massoud Akhtari, ao Horacio Soto, à Lea Guo e a todos da Universidade da California, Los Angeles (UCLA) - EUA, pelos inúmeros ensinamentos e ajuda fundamental na realização dos experimentos.

Aos professores da pós-graduação pelos ensinamentos.

Ao Instituto de Pesquisas Energéticas e Nucleares - IPEN, pela infra-estrutura.

À Fundação de Amparo a Pesquisa do Estado de São Paulo - FAPESP, por ter concedido a bolsa de doutorado para realização do presente trabalho (processo no 2011/12405-0).

Enfim, a todos que de alguma maneira contribuíram para a execução desse trabalho, seja pela ajuda constante ou por uma palavra de amizade! 
"Jaliez a ciência nunca venha a ter todas as resposkas, mas jamais deixará de procurálas, e jamais tomará a caminho fácil em sua busca pelo conhecimento." 


\title{
DESENVOLVIMENTO DE RADIOTRAÇADORES ANGIOGÊNICOS PARA DIAGNÓSTICO DE GLIOMA: ESTUDO EM MODELO ANIMAL
}

\author{
Érica Aparecida de Oliveira
}

\begin{abstract}
RESUMO
A imagem molecular oferece a perspectiva de detectar doenças bem antes de os sintomas surgirem. A vasculatura tumoral é vital no crescimento do tumor e na disseminação de metástases, sendo assim alguns radiofármacos são dirigidos para a angiogênese. O glioma, tumor cerebral de baixa incidência porém alta mortalidade, requer um diagnóstico precoce para favorecimento da abordagem terapêutica. O objetivo desse estudo foi o desenvolvimento de novo radiofármaco para diagnóstico por imagem de glioma, baseado em peptídeos angiogênicos (GX1 e GX1-RGD) marcados com o radioisótopo tecnécio-99m. O desempenho dos conjugados peptídicos mostraram-se bastante parecidos em diversas avaliações. Eles foram radiomarcados com alta pureza radioquímica (>96\%) e estáveis em soro até pelo menos 4h. Ambos são hidrofílicos e com baixa ligação às proteínas plasmáticas. A biodistribuição em animais sadios demonstrou alta excreção renal e depuração sanguínea rápida para ambos os radiotraçadores. Nos estudos in vitro, o ${ }^{99 m}$ Tc-HYNIC-PEG $4-c(G X 1)$ apresentou picos de ligação aos $60 \mathrm{~min}$ e o 99mTc-HYNIC-E-[c(RGDfk)-c(GX1)]) aos $120 \mathrm{~min}$, nas células endoteliais HUVEC, usadas como controle, e nas células tumorais das linhagens U87MG e T98G. A captação tumoral nos animais foi mais acentuada para células U87MG, especialmente para o 99mTc-HYNIC-E-[c(RGDfk)-c(GX1)]) $(2,87 \pm 0,53 \%$ $\mathrm{Dl} / \mathrm{g})$ aos 60 min p.i., com boa visualização em imagens adquiridas por gamacâmara e micro-SPECT/CT. Estudos realizados com os peptídeos conjugados à nanopartículas magnéticas para visualização em ressonância magnética também demonstraram especificidade dos produtos em tecidos tumorais. O desempenho do ${ }^{99 m}$ Tc-HYNIC-E-[c(RGDfk)-c(GX1)]) foi superior que o do traçador GX1, quanto à captação no glioma humano, podendo ser considerado como um promissor radiofármaco para diagnóstico de gliomas.
\end{abstract}




\title{
DEVELOPMENT OF ANGIOGENIC RADIOTRACERS FOR GLIOMA DIAGNOSTIC: ANIMAL MODEL STUDY
}

\author{
Érica Aparecida de Oliveira
}

\begin{abstract}
Molecular imaging offers the prospect of detecting diseases well before the symptoms appear. The tumor vasculature is vital in the tumor growth and dissemination of metastasis, thus some radiopharmaceuticals are directed to angiogenesis. The glioma, a brain tumor of low incidence but high mortality, requires an early diagnosis for favoring therapeutic approaches. The aim of this study was the development of a new radiopharmaceutical for imaging diagnosis of glioma, based in angiogenic peptides (GX1 and RGD-GX1) radiolabeled with technetium-99m radioisotope. The peptidic conjugates showed very similar performance in several evaluation. They were radiolabeled with high radiochemical purity (>96\%) and are stable in the blood serum at least for four hours. Both are hydrofilic and had minimal binding to plasma protein. The biodistribution in healthy mice at many times, showed high renal excretion and fast blood clearance for both radiotracers. At in vitro studies, the 99mTc-HYNIC-PEG 4 $\mathrm{c}(\mathrm{GX} 1)$ exhibit binding peaks at $60 \mathrm{~min}$ and the $99 \mathrm{~m}$ Tc-HYNIC-E-[c(RGDfk)$c(G X 1)])$ at $120 \mathrm{~min}$, at HUVEC endotelial cells, used as control, and at tumor cell lines U87MG and T98G. The animal tumor uptake was more pronounced for U87MG cells, specially for ${ }^{99 m T c-H Y N I C-E-[c(R G D f k)-c(G X 1)]) ~}(2.87 \pm 0.53 \% \mathrm{DI} / \mathrm{g})$ at 60 min p.i., with good visualization in images acquired with gama-camara and micro-SPECT/CT. Studies performed with peptides conjugate to magnetonanoparticles for MRI visualization also demonstred the peptides specificity in tumor tissue.The 99mTc-HYNIC-E-[c(RGDfk)-c(GX1)]) performance was superior to the GX1 tracer, regarding the glioma uptake, and may be consider as a promisser radiopharmaceutical for glioma diagnosis.
\end{abstract}




\section{SUMÁRIO}

\section{Página}

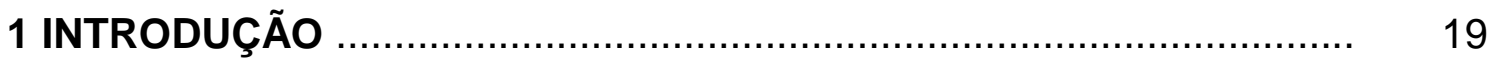

1.1 Medicina Nuclear............................................................................ 19

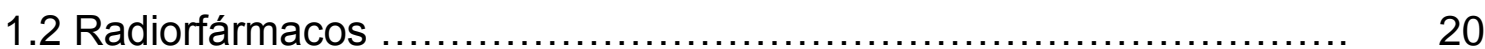

1.3 Biomoléculas radiomarcadas ........................................................... 22

1.4 Phage Display .......................................................................... 24

1.5 Peptídeo com a sequência RGD ………………………………... 26

1.6 Peptídeo com a sequência GX1 .................................................. 29

1.7 Câncer .................................................................................... 30

1.7.1 Tumores Cerebrais .................................................................

1.7.1.1 Glioma ...................................................................... 31

1.8 Relação entre Glioma, Angiogênese, Peptídeo RGD e Peptídeo GX1 33

1.9 Radioisótopo ${ }^{99 m} \mathrm{Tc}$ para imagem diagnóstica ................................... 36

1.9.1 Marcação de biomoléculas com ${ }^{99 m} \mathrm{Tc}$.............................................. 39

1.10 Agente quelante bifuncional ....................................................... 40

1.10.1 Agente 6-hidrazinonicotinamida (HYNIC) ………....................... 42

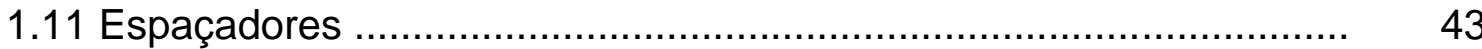

1.12 Considerações Finais ............................................................... 44

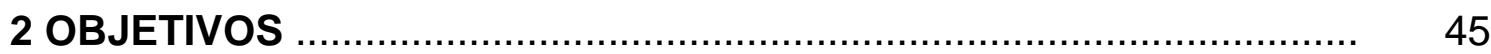

3 MATERIAIS E MÉTODOS …............................................................. 46

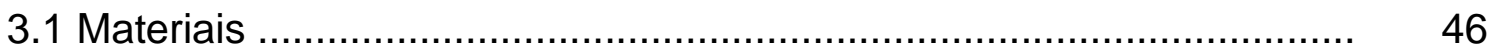

3.1.1 Equipamentos ................................................................... 46

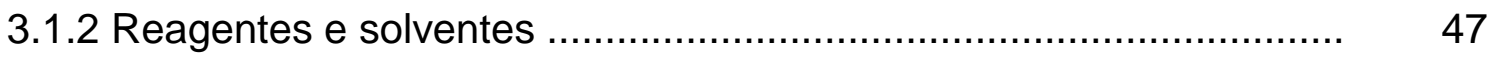

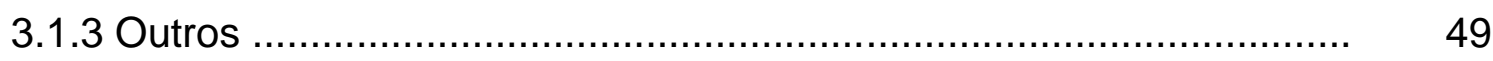


3.2.1 Marcação dos Conjugados Peptídicos GX1 e RGD-GX1 com Tecnécio-99m

3.2.2 Avaliação radioquímica dos conjugados radiomarcados

3.2.3 Análise da estabilidade dos produtos radiomarcados em soro humano

3.2.4 Determinação da lipofilicidade dos produtos radiomarcados

3.2.5 Determinação da ligação às proteínas plasmáticas

3.2.6 Biodistribuição em camundongos sadios

3.2.7 Cultivo celular

3.2.8 Ensaios in vitro de ligação às células

3.2.9 Inoculação das células tumorais nos animais

3.2.9.1 Inoculação subcutânea em camundongos imunodeprimidos

3.2.9.2 Inoculação intracranial em camundongos imunodeprimidos

3.2.9.3 Inoculação intracranial em ratos imunodeprimidos

3.2.10 Biodistribuição em camundongos portadores de tumor

3.2.11 Conjugação dos peptídeos com as nanopartículas magnéticas .....

3.2.12 Aquisição de imagens

3.2.12.1 Gama-câmara

3.2.12.2 Ressonância Magnética

3.2.12.3 SPECT/CT

3.2.13 Teste do Campo Aberto

3.2.14 Perfusão e Análise histológica 
4.1 Síntese dos conjugados peptídicos

4.2 Radiomarcação e avaliação radioquímica dos conjugados radiomarcados

4.3 Análise da estabilidade dos produtos radiomarcados em soro humano

4.4 Determinação da lipofilicidade dos produtos radiomarcados ............... $\quad 67$

4.5 Determinação da ligação às proteínas plasmáticas ............................. 68

4.6 Biodistribuição em camundongos sadios ………………………........ 69

4.7 Ensaios in vitro de ligação às células ................................................. 74

4.7.1 Células endoteliais humanas de cordão umbilical (HUVEC) ............. 74

4.7.2 Células tumorais de glioblastoma humano U87MG e T98G ............. 75

4.8 Biodistribuição em camundongos portadores de tumor ....................... 79

4.9 Imagens Cintilográficas por gama-câmara........................................... 84

4.10 Imagens de Ressonância Magnética …………................................ 88

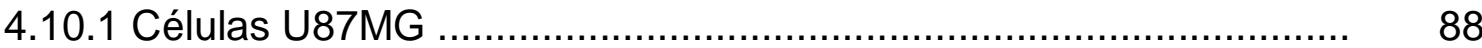

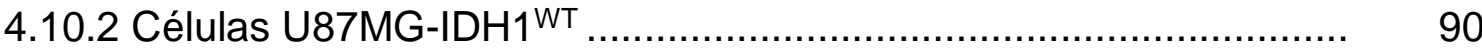

4.10.3 Células U87MG-IDH1 ${ }^{\mathrm{R} 132}$........................................................... 93

4.11 Imagens Cintilográficas por SPECT/CT ……….............................. 95

4.12 Teste do Campo Aberto ……........................................................ 97

4.13 Histologia ................................................................................... 100

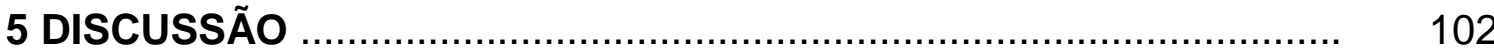

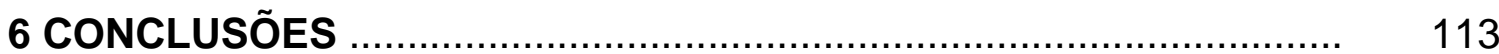

REFERÊNCIAS BIBLIOGRÁFICAS .................................................... 114 


\section{LISTA DE TABELAS}

Página

TABELA 1 -Ligação às proteínas plasmáticas do ${ }^{99 m}$ Tc-HYNIC-PEG 4 $c(G X 1)$ e ${ }^{99 m} T c-H Y N I C-E-[c(R G D f k)-c(G X 1)] \quad(n=3)$ em camundongos 68 Balb/c sadios

TABELA 2 - Biodistribuição do 99mTc-HYNIC-PEG4-c(GX1) e 99mTcHYNIC-E-[c(RGDfk)-c(GX1)] em camundongos Balb/c sadios (\%DI/g \pm 73 DP) $(\mathrm{n}=6)$

TABELA 3 - Porcentagem da dose total injetada dos radiomarcados 99mTc-HYNIC-PEG 4 -c(GX1) e 99mTc-HYNIC-E-[c(RGDfk)-c(GX1)] em 74 camundongos Balb/c sadios em diferentes tempos (\%DI)

TABELA 4 - Biodistribuição do ${ }^{99 m}$ Tc-HYNIC-PEG 4 -c(GX1) e do ${ }^{99 m} T c-$ HYNIC-E-[c(RGDfk)-c(GX1)] em camundongos SCID portadores de células tumorais de glioblastoma humano U87MG aos 60 e $120 \mathrm{~min}$ p.i. 80 $(\mathrm{n}=5)$

TABELA 5 - Biodistribuição do ${ }^{99 m}$ Tc-HYNIC-PEG 4 -C(GX1) e do ${ }^{99 m} T c-$ HYNIC-E-[c(RGDfk)-c(GX1)] em camundongos SCID portadores de células tumorais de glioblastoma humano T98G aos 60 e $120 \mathrm{~min}$ p.i. $(n=5)$ 


\section{LISTA DE FIGURAS}

Página

FIGURA 1 - Procedimento de seleção de afinidade ................................. 25

FIGURA 2 - Vasculatura e microambiente tumoral ................................ 34

FIGURA 3 - Receptores alvo em células tumorais, endoteliais ou em ambas

FIGURA 4 - Gerador de ${ }^{99} \mathrm{Mo} /{ }^{99 m} \mathrm{Tc}$

39

FIGURA 5 - Representação esquemática do desenho de um radiofármaco

FIGURA 6 - Molécula de HYNIC

FIGURA 7 - Molécula de polietilenoglicol com quatro subunidades de óxido de etileno

FIGURA 8 - Estrutura molecular do conjugado peptídico HYNIC-PEG4c(GX1); (A) GX1 cíclico; (B) PEG4; (C) HYNIC; Peso Molecular: 1290,2 ..

FIGURA 9 - Estrutura molecular do conjugado peptídico HYNIC-E[c(RGDfk)-c(GX1)]; (A) GX1 cíclico; (B) RGDfk cíclico; (C) HYNIC; Peso Molecular: 1755,9

FIGURA 10 - Cromatograma dos conjugados peptídicos (A) HYNICPEG 4 -C(GX1) e (B) HYNIC-E-[c(RGDfk)-c(GX1)]

FIGURA 11- Radiocromatograma do (A) ${ }^{99 m} T c-H Y N I C-P E G 4-C(G X 1) ;(B)$ 99mTc-HYNIC-E-[c(RGDfk)-c(GX1)] e (C) TcO

FIGURA 12 - Cromatograma dos conjugados peptídicos radiomarcados (A) ${ }^{99 \mathrm{mT}} \mathrm{Tc}-\mathrm{HYNIC}-\mathrm{PEG}{ }_{4} \mathrm{c}(\mathrm{GX} 1)$; (B) ${ }^{99 \mathrm{mT}} \mathrm{T}-\mathrm{HYNIC}-\mathrm{E}-[\mathrm{c}(\mathrm{RGDfk})-\mathrm{c}(\mathrm{GX} 1)] \ldots$

FIGURA 13 - Estabilidade em soro do ${ }^{99 m}$ Tc-HYNIC-PEG4-C(GX1) em (A) $1 \mathrm{~h} ;$ (B) $2 \mathrm{~h}$ e (C) $4 \mathrm{~h}$

FIGURA 14 - Estabilidade em soro do 99mTC-HYNIC-E-[C(RGDfk)$c(G X 1)]$ em (A)1h; (B) 2h e (C) 4h

FIGURA 15 - Perfil de ligação do ${ }^{99 m}$ Tc-HYNIC-PEG4-C(GX1) ao plasma intacto e às proteínas plasmáticas em camundongos Balb/c sadios

FIGURA 16 - Perfil de ligação do ${ }^{99 m}$ Tc-HYNIC-E-[c(RGDfk)-c(GX1)] ao plasma intacto e às proteínas plasmáticas em camundongos Balb/c sadios

FIGURA 17 - Depuração sanguínea em camundongos Balb/c sadios $(n=6)$ 
FIGURA 18 - Captação nos órgãos de excreção do ${ }^{99 m}$ TC-HYNIC-PEG4$c(G X 1)$ em camundongos Balb/c sadios $(n=6)$. A radioatividade nos intestinos foi avaliada após remoção do conteúdo luminal

FIGURA 19 - Captação nos órgãos de excreção do 99mTC-HYNIC-E[c(RGDfk)-c(GX1)] em camundongos Balb/c sadios $(n=6)$. A radioatividade nos intestinos foi avaliada após remoção do conteúdo luminal

FIGURA 20 - Ligação total, ligação específica e internalização às células HUVEC com o ${ }^{99 m T C-H Y N I C-P E G} 4-\mathrm{C}(\mathrm{GX} 1)$

FIGURA 21 - Ligação total, ligação específica e internalização às células HUVEC com o ${ }^{99 m T C-H Y N I C-E-[c(R G D f k)-c(G X 1)] ~}$

FIGURA 22 - Ligação total, ligação específica e internalização do ${ }^{99 m} T c-$ HYNIC-PEG4-C(GX1) às células U87MG

FIGURA 23 - Ligação total, ligação específica e internalização do ${ }^{99 m} T c-$ HYNIC-E-[c(RGDfk)-c(GX1)] às células U87MG

FIGURA 24 - Ligação total, ligação específica e internalização do ${ }^{99 m} T c-$ HYNIC-PEG 4 -C $(\mathrm{GX} 1)$ às células T98G

FIGURA 25 - Ligação total, ligação específica e internalização do ${ }^{99 m T C-}$ HYNIC-E-[C(RGDfk)-c(GX1)] às células T98G

FIGURA 26 - Razões tumor/órgão e tumor/tecidos em camundongos SCID para células U87MG ( $\mathrm{T}=$ Tumor; $\mathrm{S}=$ Sangue; $\mathrm{M}=$ Músculo; $\mathrm{O=Osso;} \mathrm{I=}$ Intestinos; F=Fígado; R= Rins) com os traçadores ${ }^{99 m T C-H Y N I C-P E G_{4}-}$ $c(G X 1)$ em 1h e 99mTc-HYNIC-E-[c(RGDfk)-c(GX1)] em 1 e $2 \mathrm{~h}$

FIGURA 27 - Captação dos radiotraçadores em tumor e em tumor bloqueado após a injeção em células tumorais de glioblastoma U87MG e T98G em camundongos SCID

FIGURA 28 - Razões tumor/órgão e tumor/tecidos em camundongos SCID para células T98G (T=Tumor; $\mathrm{S}=$ Sangue; $\mathrm{M=Músculo;} \mathrm{O}=\mathrm{O}$ sso; $\mathrm{I}=$ Intestinos; F=Fígado; $R=$ Rins) com os traçadores ${ }^{99 m T C-H Y N I C-P E G_{4}-}$ $c(G X 1)$ em $1 \mathrm{~h}$ e ${ }^{99 m}$ Tc-HYNIC-E-[c(RGDfk)-c(GX1)] em 1 e $2 \mathrm{~h}$

FIGURA 29 - Imagens cintilográficas obtidas após 1h da injeção de 99mTC-HYNIC-PEG 4 -C(GX1) em camundongos SCID portadores de células tumorais de glioblastoma U87MG (A) Sem bloqueamento ROI $5,21 \%$ (B) Com bloqueamento ROI 1,66\%

FIGURA 30 - Imagens cintilográficas obtidas após $1 \mathrm{~h}$ da injeção de 99mTc-HYNIC-E-[c(RGDfk)-c(GX1)] em camundongos SCID portadores de células tumorais de glioblastoma U87MG (A) Sem bloqueamento ROI $8,72 \%$ (B) Com bloqueamento $\mathrm{ROI}$ 0,78\% 
FIGURA 31 - Imagens cintilográficas obtidas após $2 \mathrm{~h}$ da injeção de 99mTc-HYNIC-E-[c(RGDfk)-c(GX1)] em camundongos SCID portadores de células tumorais de glioblastoma U87MG (A) Sem bloqueamento ROI $3,87 \%$ (B) Com bloqueamento ROI 0,65\%

FIGURA 32 - Imagens cintilográficas obtidas após 1h da injeção de 99mTc-HYNIC-PEG 4 -C(GX1) em camundongos SCID portadores de células tumorais de glioblastoma T98G (A) Sem bloqueamento ROI $1,21 \%$ (B) Com bloqueamento ROI 0,34\%

FIGURA 33- Imagens cintilográficas obtidas após $1 \mathrm{~h}$ da injeção de 99mTc-HYNIC-E-[c(RGDfk)-c(GX1)] em camundongos SCID portadores de células tumorais de glioblastoma T98G (A) Sem bloqueamento ROI $2,63 \%$ (B) Com bloqueamento ROI 0,33\%

FIGURA 34 - Imagens cintilográficas obtidas após $2 \mathrm{~h}$ da injeção de 99mTc-HYNIC-E-[c(RGDfk)-c(GX1)] em camundongos SCID portadores de células tumorais de glioblastoma T98G (A) Sem bloqueamento ROI $3,18 \%$ (B) Com bloqueamento ROI 0,38\%

FIGURA 35 - Imagem de ressonância magnética de camundongos NODSCID inoculados com células de glioblastoma humano U87MG e injetados com o contraste do conjugado NPM-HYNIC-PEG4-C(GX1); (A) Anatomia (RARE); Mapa de subtração em T2 (B) 0-15min; (C) 0-30min; (D) 0-1h; (E) 0-1h30; (F) 0-2h pós-injeção

FIGURA 36 - Imagem de ressonância magnética de camundongos NODSCID inoculados com células de glioblastoma humano U87MG e injetados com o contraste do conjugado NPM-HYNIC-E-[C(RGDfk)c(GX1)]; (A) Anatomia (RARE); Mapa de subtração em T2 (B) 0-15min; (C ) 0-30min; (D) 0-1h; (E) 0-1h30; (F) 0-2h pós-injeção

FIGURA 37 - Quantificação em T2 nos tumores dos animais portadores do tumor das células U87MG obtida através das imagens de ressonância magnética com os contrastes conjugados NPM-HYNIC$P E_{4}-c(G X 1)$ e NPM-HYNIC-E-[c(RGDfk)-c(GX1)]

FIGURA 38 - Imagem de ressonância magnética de camundongos NOD$S C I D$ inoculados com células de glioblastoma humano U87MG-IDH $1^{\mathrm{WT}} \mathrm{e}$ injetados com o contraste do conjugado NPM-HYNIC-PEG4-C(GX1); (A) Anatomia (RARE); Mapa de subtração em T2 (B) 0-15min; (C) 0-30min; (D) 0-1h; (E) 0-1h30; (F) 0-2h pós-injeção

FIGURA 39 - Imagem de ressonância magnética de camundongos NOD$S C I D$ inoculados com células de glioblastoma humano U87MG-IDH1WT e injetados com o contraste do conjugado NPM-HYNIC-E-[c(RGDfk)c(GX1)]; (A) Anatomia (RARE); Mapa de subtração em T2 (B) 0-15min; (C) 0-30min; (D) 0-1h; (E) 0-1h30; (F) 0-2h pós-injeção 
FIGURA 40 - Quantificação em T2 nos tumores dos animais portadores do tumor das células U87MG-IDH1 ${ }^{\mathrm{WT}}$ obtida através das imagens de ressonância magnética com os contrastes conjugados NPM-HYNIC$P E_{4}-c(G X 1)$ e NPM-HYNIC-E-[c(RGDfk)-c(GX1)]

FIGURA 41 - Imagem de ressonância magnética de camundongos NOD$S C I D$ inoculados com células de glioblastoma humano U87MG-IDH1 ${ }^{R 132}$ e injetados com o contraste do conjugado NPM-HYNIC-PEG 4 -C(GX1); (A) Anatomia (RARE); Mapa de subtração em T2 (B) 0-15min; (C) 030min; (D) 0-1h; (E) 0-1h30; (F) 0-2h pós-injeção

FIGURA 42 - Imagem de ressonância magnética de camundongos NOD$S C I D$ inoculados com células de glioblastoma humano U87MG-IDH1 ${ }^{R 132}$ e injetados com o contraste do conjugado NPM-HYNIC-E-[C(RGDfk)c(GX1)]; (A) Anatomia (RARE); Mapa de subtração em T2 (B) 0-15min; (C) 0-30min; (D) 0-1h; (E) 0-1h30; (F) 0-2h pós-injeção

FIGURA 43 - Quantificação em T2 nos tumores dos animais portadores do tumor das células U87MG-IDH1 ${ }^{R 132}$ obtida através das imagens de ressonância magnética com os contrastes conjugados NPM-HYNIC$\mathrm{PEG}_{4}-\mathrm{C}(\mathrm{GX} 1)$ e NPM-HYNIC-E-[c(RGDfk)-c(GX1)]

FIGURA 44 - Imagem de SPECT/CT de ratos Nude inoculados com células de glioma humano U87MG por cirurgia intracranial obtidas após 1h da injeção do 99mTc-HYNIC-E-[c(RGDfk)-c(GX1)]; (A) Corte transversal; (B) Corte sagital e (C) Corte coronal ...

FIGURA 45 - Imagem de SPECT/CT com bloqueamento de ratos Nude inoculados com células de glioma humano U87MG por cirurgia intracranial obtidas após $1 \mathrm{~h}$ da injeção do ${ }^{99 m T C-H Y N I C-E-[C(R G D f k)-~}$ c(GX1)]; (A) Corte transversal; (B) Corte sagital e (C) Corte coronal

FIGURA 46 - Representação gráfica do total de entradas dos ratos Nude portadores de glioblastoma submetidos ao teste em campo aberto para avaliação comportamental

FIGURA 47 - Representação gráfica da distância percorrida total em cm dos ratos Nude portadores de glioblastoma submetidos ao teste em campo aberto para avaliação comportamental

FIGURA 48 - Representação gráfica do rearing total dos ratos Nude portadores de glioblastoma submetidos ao teste em campo aberto para avaliação comportamental

FIGURA 49 - Representação gráfica do tempo total de rearing em segundos dos ratos Nude portadores de glioblastoma submetidos ao teste em campo aberto para avaliação comportamental

FIGURA 50 - Lâmina histológica com coloração de Nissl no aumento de $4 x$ do cérebro de rato Nude com glioma inoculado intracranialmente e utilizados na aquisição de imagens por SPEC/CT sem bloqueamento ..... 
FIGURA 51 - Lâmina histológica com coloração de Nissl a olho nu do cérebro de rato Nude com glioma inoculado intracranialmente e utilizados na aquisição de imagens por SPEC/CT sem bloqueamento

FIGURA 52 - Lâmina histológica com coloração de Nissl no aumento de $4 x$ do cérebro de rato Nude com glioma inoculado intracranialmente e utilizados na aquisição de imagens por SPEC/CT com bloqueamento .....

FIGURA 53 - Lâmina histológica com coloração de Nissl a olho nu do cérebro de rato Nude com glioma inoculado intracranialmente e utilizados na aquisição de imagens por SPEC/CT com bloqueamento 


\section{LISTA DE ABREVIATURAS}

\%DI Porcentagem de dose injetada

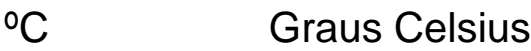

${ }^{111}$ In I Índio-111

125| lodo-125

${ }^{188} \mathrm{Re} \quad$ Rênio-188

${ }^{18} \mathrm{~F} \quad$ Flúor-18

${ }^{64} \mathrm{Cu} \quad$ Cobre-64

${ }^{68} \mathrm{Ga} \quad$ Gálio-68

${ }^{90} \mathrm{Y} \quad$ Ítrio-90

${ }^{99}$ Mo Molibdênio-99

99mTc Tecnécio-99 metaestável

$\mathrm{Bq} \quad$ Becquerel

BHE Barreira hematoencefálica

CLAE Cromatografia Líquida de Alta Eficiência

CNEN Comissão Nacional de Energia Nuclear

cpm Contagens por minuto

CT Tomografia Computadorizada

DMEM/F12 Meio de cultura de Eagle modificado/mistura nutriente de Ham F12

DNA Ácido desoxirribonucléico

DOTA Ácido 1,4,7,10-tetraazaciclododecano-1,4,7,10-tetraacético

DP Desvio padrão

DTPA Ácido dietilenotriaminopentaacético

EDDA Ácido N',N'-etilenodiaminodiacético

Gd Gadolíneo

GX1 Peptídeo com a sequência Cys-Gly-Asn-Ser-Asn-Pro-Lys-Ser-Cys 
HUVEC Células endoteliais de veia umbilical humana

HYNIC 6-hidrazinonicotinamida

IDH1 isocitrato desidrogenase-1

IPEN Instituto de Pesquisas Energéticas e Nucleares

ITLC-SG do inglês Instant Thin Layer Chromatography-Silica Gel, suporte para cromatrografia de camada delgada

MAG2 Mercaptoacetildiglicina

MAG3 Mercaptoacetiltriglicina

$\min \quad$ Minuto

MSME Do inglês multislice multi-echo

NAD Nicotinamida adenina dinucleótido

NADH Nicotinamida adenina dinucleótido hidreto

$\mathrm{Nal}(\mathrm{TI}) \quad$ lodeto de sódio tálio

NOD/SCID Do inglês non-obese diabetic - severe combined immunodeficiency

NPM Nanopartículas magnéticas

p.a. Para análise

p.i. Pós-injeção

PBS Tampão fosfato-salina

PEG polietilenoglicol

PET Tomografia por Emissão de Pósitron

$\mathrm{pH} \quad$ Potencial hidrogeniônico

RARE Do inglês Rapid Acquisition with Relaxation Enhancement

$\mathrm{R}_{\mathrm{f}} \quad$ Fator de retenção

RGD Peptídeo com a sequência arginina-glicina-ácido aspártico

ROI Do inglês Region of interest

RPMI Meio de cultura desenvolvido pelo Instituto Memorial Roswell Park 
SCID Do inglês severe combined immunodeficiency

SFB Soro fetal bovino

SPECT Tomografia Computatorizada por Emissão de Fótons

$\mathrm{T}_{1 / 2} \quad$ Tempo de meia-vida

T1 Tempo de relaxamento longitudinal

T2 Tempo de relaxamento transversal

TCA Ácido tricloroacético

TE Tempo de eco

TFA Ácido trifluoroacético

TNF-alfa Fator mutante humano recombinante de necrose tumoral alfa

tR Tempo de retenção

TR Tempo de repetição

USPIO Partículas de óxido de ferro ultra pequenas e super paramagnéticas

UV Ultravioleta visível

VIP Peptídeo intestinal vasoativo

xg Giros

aMSH Hormônio alfa-melanócito estimulante 


\section{INTRODUÇÃO}

\subsection{Medicina Nuclear}

A Medicina Nuclear é uma modalidade da medicina inserida na Radiologia, por ser predominantemente diagnóstica. As técnicas de imagem nuclear são amplamente utilizadas para aplicações clínicas devido a sua alta sensibilidade (Lee, Xie e Chen, 2010). Nela são realizados exames de imagem com a utilização de radiofármacos (Okarvi, 2004). Através dela, é possível obter um grande número de traçadores radioativos e rastrear múltiplas funções e mecanismos moleculares no corpo (Kitson e col., 2013).

A Medicina Nuclear teve seu pioneirismo em 1935, com o trabalho de George Hevesy que usou o fósforo-32 (originalmente produzido por F. Joliot e J. Curie em 1934), em estudos de biodistribuição em animais, e com Joseph Hamilton que fez tentativas para tratar pacientes com leucemia com sódio-24 em 1936 (Weiner e Thakur, 1995).

A medicina dispõe de métodos que permitem que determinadas doenças sejam diagnosticadas antes que se manifestem fisicamente no homem. Existe uma gradação no progresso da doença que pode ser identificado de acordo com o tempo que mostra as modificações morfoestruturais como um evento tardio, precedido pelas alterações funcionais (Mansi, 2009). Consequentemente, a imagem funcional, que é a representação das alterações patofisiológicas, pode ser mais precoce nas detecções das doenças quando comparado às imagens estruturais (Cascini e col., 2013). Além disso, imagens funcionais tem uma capacidade maior de avaliar o prognóstico e a relação com a terapia individualizadamente, sendo que mudanças patofisiológicas são preditores melhores sobre a evolução da doença e a efetividade da ação terapêutica (Cistaro e col., 2012).

Ainda mais interessante, é a possibilidade de estudar os mecanismos moleculares que subjazem a doença, permitindo a representação da alteração inicial patológica (Kitson e col., 2013). Através deles, é possível adquirir 
informação sensível e precisa, que cria a base para investigação nos primeiros níveis da doença, resultando em implicações terapêuticas favoráveis (Cascini e col., 2013). Por meio de cintilografias, são realizadas imagens dos sítios que expressam receptores específicos para as biomoléculas em questão, minimizando por outra parte, a exposição a outros órgãos (Obenaus, Edreira e Crudo, 1999).

A pesquisa nessa área tem feito grandes avanços no desenvolvimento de novos radiofármacos com a habilidade de melhorar o diagnóstico e as estratégias terapêuticas de várias doenças que afetam a população, e a mais importante delas é o câncer (Psimadas e col., 2013). Embora tenha o papel principal em diagnóstico clínico, a informação funcional tem que ser integrada à morfoestrutura (Cuccurullo e col., 2013). Desse modo, é possível melhorar a acurácia diagnóstica, um melhor entendimento do delineamento dos limites de estruturas anatômicas normais e patológicas, com um aumento significante da sensibilidade e especificidade (Cuccurullo, Cascini e Mansi, 2013).

Além disso, devido a melhores resoluções espaciais e/ou diferentes pressupostos subjacentes à imagem, técnicas morfoestruturais, como tomografias, ressonâncias magnéticas e ultrassonografias, também podem detectar anormalidades que não são visíveis em um estudo funcional (Cuccurullo, Cascini e Mansi, 2013).

\subsection{Radiofármacos}

Os radiofármacos, drogas que contém um radionuclídeo, são rotineiramente, usados na Medicina Nuclear. Um bom radiofármaco é aquele que apresenta uma farmacocinética ideal, caracterizada pelo baixo tempo de retenção no sangue e alta captação do órgão de interesse ou alta razão de captação órgão/tecido (Egli e col., 1999).

Uma parte significante dos avanços pode ser atribuída ao desenvolvimento de radiofármacos a partir de peptídeos radiomarcados. Eles são utilizados em diversas áreas de interesse, como oncologia, neurologia, 
cardiologia, na pesquisa de focos de infecção/inflamação e na pesquisa de trombose/aterosclerose. A aplicação em oncologia, para diagnóstico e tratamento de tumores específicos, representa, sem dúvida, a área mais estudada, com maior número de radiotraçadores desenvolvidos, alguns dos quais comercialmente disponíveis (Signore e col., 2001; Mukherjee et al., 2014).

A capacidade da biomolécula de reconhecer os receptores determinará a fixação do radiofármaco no tecido pretendido e não deverá ser alterada com a incorporação do radionuclídeo (Jurisson e col., 1993; Fichna e Janecka, 2003). A biodistribuição de radiofármacos pode ser determinada também pelas propriedades químicas e físicas ou pelas interações biológicas do produto (Fichna e Janecka, 2003). Para o diagnóstico, a radiação deve ser capaz de penetrar o corpo e ser detectada por um instrumento externo ao paciente.

Os radiofármacos podem ser divididos em duas classes: aqueles cuja biodistribuição é determinada exclusivamente pelas propriedades químicas e físicas, e aqueles cuja distribuição final é determinada por sua ligação a um receptor ou outras interações biológicas. Essa última classe é freqüentemente chamada de radiofármacos alvo-específicos (Liu e Edwards, 1999).

Os radiofármacos utilizados para diagnóstico estão classificados em radiofármacos de $1^{\underline{a} \text { g }}$ geração, $2^{\underline{a}}$ geração e $3^{\underline{a}}$ geração (Dilworth e Parrot, 1998). Os radiofármacos de $1^{\text {a }}$ geração estão relacionados a absorção, distribuição, metabolismo e excreção de complexos comuns de ${ }^{99 m}$ Tc. Os de $2^{\underline{a}}$ geração estão relacionados ao comportamento biológico destes radiofármacos pelas suas propriedades moleculares, tais como tamanho, carga e lipofilicidade. Já os de $3^{\text {a }}$ geração, são direcionados por moléculas biologicamente ativas, como, por exemplo, anticorpos e peptídeos, que se ligam a receptores celulares ou são transportados para o interior de determinadas células. A maior parte dos radiofármacos em uso clínico corresponde a radiofármacos de perfusão, mas atualmente são os radiofármacos específicos que detêm a atenção da investigação na área da química radiofarmacêutica.

A análise clínica de doenças neurológicas com a Medicina Nuclear está atualmente conectada com três categorias principais de estudos dos radiotraçadores: perfusão, metabolismo e receptores (Cascini e col., 2013). Uma vez que os radiofármacos tenham sido preparados e a pureza dos mesmos tenha 
sido determinada, o material é injetado no paciente e fornece informações sobre sua localização através da emissão de radiação, os quais são detectados em equipamento denominados gama câmara e SPECT (Tomografia por Emissão de Fótons) para os radioisótopos emissores de raios gama, e PET (Tomografia por Emissão de Pósitrons) para os emissores de pósitrons (Weiner e Thakur 1995).

\subsection{Biomoléculas Radiomarcadas}

Os primeiros relatos de anticorpos monoclonais radiomarcados surgiram no final da década de 1980 e início da década de 1990, com grande potencial para o diagnóstico de câncer (Morales e col., 2000). Porém os estudos demonstraram alguns incovenientes do radiotraçador como depuração sanguínea muito lenta, devido ao grande tamanho da molécula (150.000 daltons) e dificuldade de penetração na massa tumoral pouco perfundida (Xue e col., 1996).

Os peptídeos radiomarcados surgiram como uma alternativa aos anticorpos em forma de moléculas menores. Peptídeos são proteínas, que desempenham um papel crucial em quase todos os processos biológicos. São constituídas de aminoácidos ligados através de ligações peptídicas. A degradação e a reciclagem de aminoácidos é um processo constante e dinâmico. Novos métodos de sintetizar peptídeos de cadeia longa e em grande quantidade, assim como a sua purificação, caracterização e otimização, têm resultado em uma explosão de peptídeos potencialmente úteis e de interesse no desenvolvimento comercial (Weiner e Thakur, 2005; Song, Lee e Ban, 2012).

Em geral, peptídeos tem favorável farmacocinética e padrões de distribuição nos tecidos, como rápida depuração sanguínea em tecidos não-alvos. Alguns peptídeos tem boa permeabilidade que permitem rápido acesso aos tecidos e órgãos de interesse. Além disso, peptídeos geralmente apresentam baixa toxicidade e imunogenicidade, e são bastante flexíveis em modificações químicas e radiomarcações (Chen e Conti, 2010; Mukherjee e col., 2014).

Peptídeos regulatórios representam um grupo de diferentes famílias de moléculas conhecidas por agir em múltiplos alvos no corpo humano em concentrações extremamente baixas (Reubi, 1997). No entanto, esta classe de 
peptídeos controlam e modulam as funções de quase todos os órgãos chaves e processos metabólicos e sua ação é mediada por receptores de membrana específicos (Reubi, 2003; Veulens e Rodríguez, 2009).

Muitos peptídeos têm o papel de reguladores das funções e crescimento celulares, não apenas em condições normais, mas também em processos patológicos, como por exemplo, na qualidade de ligantes de receptores ou ainda interferindo na progressão do câncer (Weiner e Thakur, 2005). Um campo em constante crescimento é o de peptídeos dirigidos a tumores. Isso porque os receptores peptídicos se expressam frequentemente em vários cânceres primários humanos, muito mais do que em tecidos adjacentes à neoplasia (Weiner e Thakur, 2005).

A transformação neoplásica pode resultar em um aumento acentuado no número de receptores peptídicos que ocorrem fisiologicamente em um tecido. Sabe-se que a ativação oncogênica ou regulação epigenética e outros mecanismos compensatórios podem alterar a expressão do receptor peptídico (Reubi, 2003). Surgiram, portanto, os primeiros estudos com diversos peptídeos como o peptídeo vasoativo intestinal (VIP), análogos da somatostatina (lanreotide, octreotide, octreotate) radiomarcados com sucesso para a obtenção de imagens em pacientes com tumores (Riccabona e Decristoforo, 2003). Este sucesso deveu-se a alta afinidade dos mesmos com o receptor, boa internalização e retenção nas células, assim como a rápida eliminação de tecidos não-alvo (Heppeler e col., 2000).

Novos peptídeos foram sendo investigados como os com a sequência arginina-glicina-ácido aspártico (RGD), peptídeos liberadores de gastrina (análogos da bombesina), angiotensina, anexina, colecistoquinina e outros (Decristoforo e col., 2006; Korde e col., 2007; Kothari e col., 2007; Reubi, 2003; Zhang e col., 2004).

Em paralelo à procura genética por novos receptores peptídicos, buscam-se radiopeptídeos e peptídeos citotóxicos para uso potencial em alvos pré-definidos, e a otimização da captação pelo receptor é uma das maiores prioridades. O objetivo dessas pesquisas é o de obter maior efetividade no tratamento e/ou diagnóstico de enfermidades oncológicas. 
O desenvolvimento de agentes radiomarcados baseados na interação de ligante-receptor deve obedecer a etapas preliminares como estudos préclínicos, ainda que se façam restrições à extrapolação dos dados para resultados favoráveis em humanos. Ainda assim, estes parâmetros pré-clínicos são essenciais para predizer a chance de sucesso ou falha nas futuras aplicações. Os peptídeos têm sido radiomarcados com diferentes radioisótopos para uso diagnóstico e em menor grau para terapia (Weiner e Thakur, 2005; Okarvi, 2008).

\subsection{Phage Display}

Uma técnica emergente para descoberta de peptídeos alvo-específicos envolve a triagem de bibliotecas de phage display. A técnica phage display tem sido empregada com a finalidade de identificar ligantes através de interações moleculares e de igual maneira obter informações sobre a relação receptor-ligante (Deutscher, 2010; Ueberberg and Schneider, 2010).

Através da tecnologia phage display, muitos peptídeos alvo-específicos para tumores tem sido descobertos, com potencial para detectar tumores in vivo e levar agentes anticancerígenos especificamente ao local do tumor. Atualmente, muitos peptídeos específicos para tumores estão sendo testados para diagnósticos e terapias em várias fases de ensaios clínicos (Gautam e col., 2014).

A técnica de phage display foi usada pela primeira vez por George Smith em 1985. Demorou bastante tempo para apreciarem o potencial dessa nova ferramenta, mas o número crescente de publicações relatando o seu uso atesta a versatilidade dessa técnica para muitas aplicações, incluindo mapeamento de epítopos, o isolamento de proteínas de alta afinidade, engenharia proteíca e descoberta de drogas (Castel e col., 2011).

Phage Display é baseado na expressão de moléculas de interesse (peptídeos ou proteínas) como uma fusão com a terminação amino ou carboxil da proteína presente na superfície do bacteriófago (Smith, 1985; Souriau e col., 1998). Isso faz com que seja possível expor proteínas/peptídeos combinatórios de bibliotecas na superfícies de fagos recombinantes. As proteínas/peptídeos expostos são então selecionados por um procedimento de seleção por afinidade, 
baseado na habilidade delas de se ligarem a um alvo específico, como um anticorpo, uma enzima, um receptor, um ácido nucléico ou outra molécula nãoproteíca (Souriau e col., 1998). O processo de seleção consiste em muitos ciclos repetitivos, cada um composto por captura, lavagem e eluição em etapas, para enriquecimento progressivo e amplificação da população do fago carregando moléculas com alta afinidade para o alvo. Essas moléculas são então, testadas individualmente, para avaliar suas atividades ou habilidades para efetuar a função desejada, permitindo assim, a triagem de vasta sequência, promovendo meios de melhorar a afinidade peptídica e gerar peptídeos únicos que se liguem a qualquer alvo dado (FIG. 1) (Castel e col., 2011; Deutscher, 2010).

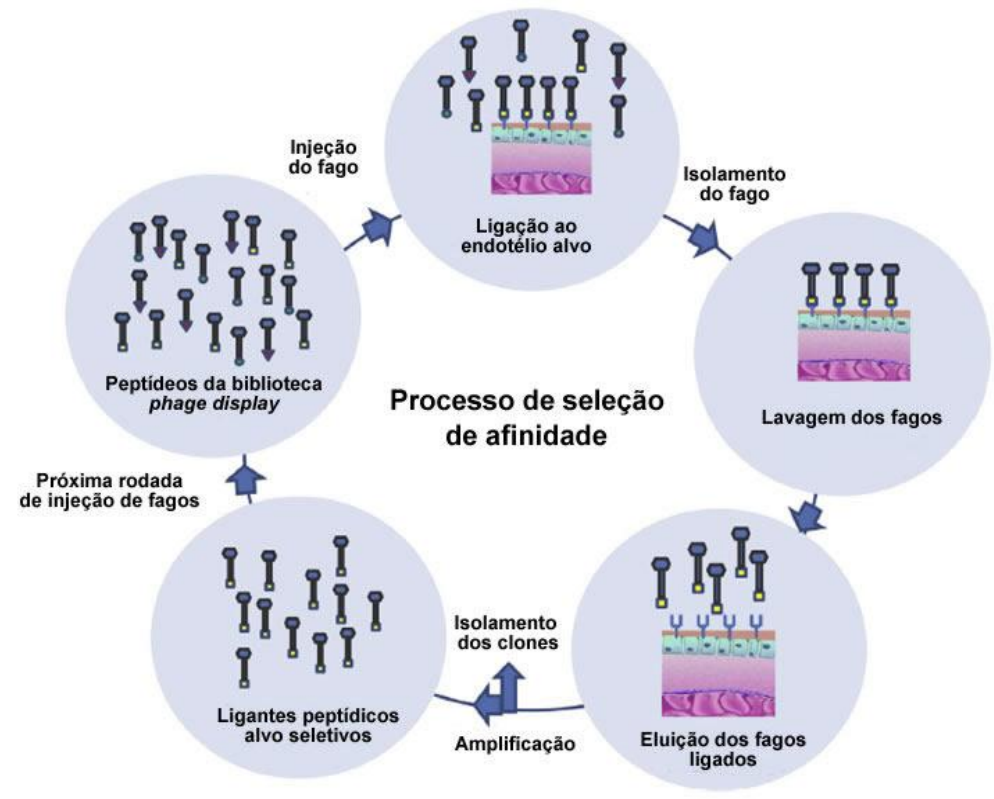

FIGURA 1 - Procedimento de seleção de afinidade. Um ciclo típico do processo de seleção por afinidade começa com a injeção intravenosa de um peptídeo da biblioteca phage display e incubação com o alvo. Após a remoção do alvo e homogeinização, os fagos que não se ligaram são lavados, enquanto que os fagos que permaneceram ligados são eluídos da molécula alvo e amplificados (Adaptado de D'Onofrio e col., 2014)

Após o processo de seleção de afinidade, é necessário o sequenciamento do DNA, para identificar os aminoácidos ligantes, além de análises imunohistoquímicas, imagem in vivo e espectrometria de massa para 
validar o peptídeo e seu alvo correspondente (Castel e col., 2011; Sugahara e col., 2009; Zurita e col., 2004).

Então, a partir dessa técnica foram selecionados os dois peptídeos utilizados nesse estudo e descritos a seguir.

\subsection{Peptídeo com a sequência RGD}

A sequência arginina-glicina-ácido aspártico (RGD), específico na adesão celular a partir do receptor inibidor da angiogênese, foi descoberta na fibronectina, por Pierschbacher e Ruoslahti (1984). Smith e Cheresh (1988) identificaram o receptor da integrina $\alpha_{v} \beta_{3}$ através do phage display.

A família de integrinas é composta por 25 membros identificados e são heterodímeros de 19 subunidades $\alpha$ e 8 subunidades $\beta$ (Desgrosellier e Cheresh, 2010). São proteínas de adesão celular que controlam a ligação à membrana extracelular. As integrinas são moléculas de glicoproteínas, receptores da transmembrana celular não covalentes e exercem atividades variadas dentro e fora da célula, proporcionando comunicação efetiva entre as células e o meio que as envolve, de modo bidirecional. Seus ligantes possuem papel crítico em processos fisiológicos, incluindo ligação às células, proliferação, remodelação óssea e cicatrização de feridas. Além disso, as integrinas podem contribuir em eventos patológicos, como trombose, aterosclerose, invasão tumoral, angiogênese e metástases, infecções por microorganismos e disfunções imune (Liu e col., 2008; Zhou e col., 2011a). As integrinas tem sido propostas como alvos moleculares para tratamento de câncer, trombose e outras doenças nas últimas duas décadas, e o papel das integrinas tem sido extensivamente revisado (Desgrosellier e Cheresh, 2010; Zhou e col., 2011a).

Entre os 25 membros da família de integrinas, a integrina $\alpha_{v} \beta 3$ é a mais estudada, pelo seu papel em crescimento tumoral e angiogênese (Zhou e col., 2011a). A integrina $\alpha_{v} \beta_{3}$ é geralmente expressa em baixos níveis em células epiteliais e células endoteliais maduras, mas é altamente expressada em tumores, incluindo osteosarcomas, neuroblastomas, glioblastomas, melanomas, 
carcinomas de mama, pulmão e próstata (Albelda e col., 1990; Falcioni e col., 1994; Gasparini e col., 1998; Meitar e col., 1996; Schnell e col., 2008; Sengupta e col., 2001).

Foi relatado que a integrina $\alpha_{v} \beta_{3}$ é superexpressa não somente em células tumorais, mas também em células endoteliais da neovasculatura tumoral. A superexpressão da $\alpha_{v} \beta_{3}$ em células endoteliais ativadas pode modular a adesão celular e migração durante a angiogênese tumoral e sua expressão em células de carcinoma potencializa metástases pela facilitação da invasão e movimento das células tumorais através dos vasos sanguíneos. Também foi demonstrado que o nível de expressão de $\alpha_{v} \beta_{3}$ se correlaciona bem com o potencial de metástase e agressividade de muitos tumores (Meitar e col., 1996; Zitzmann e col., 2002).

Enquanto algumas integrinas seletivamente reconhecem uma simples proteína ligante na membrana celular (exemplo, $\alpha_{5} \beta_{1}$ reconhece primeiramente a fibronectina), outras podem se ligar a vários ligantes (exemplo, integrina $\alpha_{v} \beta 3$ ligase a vibronectina, fibronectina, fibrinogênio, colágeno denaturado ou proteolisado e outras proteínas da matriz) (Jin e Varner, 2004).

Uma integrina $\alpha_{v} \beta 3$ não ligada, e presumivelmente bloqueada, pode promover apoptose em células endoteliais vasculares. Stupack e col. (2001) demonstraram que o domínio citoplasmático $\beta_{3}$ da subunidade da integrina liga-se a caspase-8 e ativa-a. A integrina $\alpha_{v} \beta_{3}$ também pode ser um alvo para fatores anti-angiogênicos, angiostatina, endostatina, antitrombina e anastelina (Yi e Ruoslahti, 2001). O peptídeo RGD liga-se à integrina $\alpha v \beta 3$ e/ou em outras integrinas, por exemplo, $\alpha_{v} \beta_{3}, \alpha_{5} \beta_{1}$ e $\alpha_{11} \beta \beta_{3}$ (Jin e Varner, 2004).

Os peptídeos sintéticos de sequência RGD antagonistas da integrina $\alpha_{v} \beta_{3}$ foram subsequentemente mostrados como inibidores do crescimento da nova vasculatura e regressão efetiva em cobaias portadoras de tumores, levando o tumor a inanição por falta de suplemento sanguíneo. A maioria das integrinas, incluindo as unidades $\alpha_{v} \beta 3$, reconhecem a sequência Arg-Gly-Asp (RGD) (Dijkgraaf e col., 2007).

Peptídeos lineares RGD mostraram-se altamente susceptíveis a degradação devido a reação do resíduo ácido aspártico com a estrutura do peptídeo. Além das pesquisas terem evoluído de RGD linear para RGD cíclico, 
estudos recentes foram realizados com moléculas RGD dímeras, tetrâmeras e octâmeras, demonstrando uma maior afinidade de ligação e maior captação tumoral (Dijkgraaf e col. 2007; Li e col., 2007; Liu e col.; 2008, Liu e col.; 2011). A avaliação quanto a influência do tamanho da molécula de RGD direcionada a diagnóstico e terapia foi comentada por Wester e Kesller em 2005. Já foi demonstrado que a ciclização dos peptídeos RGD via ligantes, como ponte dissulfeto, tioéter, e anéis aromáticos rígidos, frequentemente leva ao aumento da afinidade de ligação e seletividade no receptor (D'Andrea e col., 2006; Gottschalk e Kessler; 2002).

O peptídeo RGD já foi radiomarcado com vários radioisótopos como ${ }^{99 m T c},{ }^{111} \mathrm{In},{ }^{68} \mathrm{Ga},{ }^{125} \mathrm{I},{ }^{18} \mathrm{~F},{ }^{90} \mathrm{Y}$ e ${ }^{64} \mathrm{Cu}$ (Alam e col., 2014; Chen e col., 2004a; 2004b; 2004c; Decristoforo e col., 2008; Dikkgraaf e col., 2007; Liu e col., 2008; Liu e col., 2011; Wu e col., 2005). Eles têm sido explorados como radiofármacos para diagnóstico para avaliação da atividade angiogênica em tumores sólidos, assim como monitorar a resposta de tumores a terapias anti-angiogênicas e alvo para integrinas (Battle e col., 2011, Beer e col., 2007 and Gaertner e col., 2012). O RGD já foi estudado em diversas células tumorais como de melanoma, pulmão, mama e glioblastoma (Schottelius e Wester, 2009).

Estudos com RGD associado a outros peptídeos, formando heterodímeros como Bombesina-RGD, RGD-aMSH (Hormônio alfamelanócito estimulante) e mais recentemente RGD-ATWLPPR foram realizados para melhorar a afinidade de ligação às células, através da habilidade de se ligar a dois receptores diferentes (Li e col., 2008; Liu e col., 2009; Wu e col., 2014; Yang e col., 2009, 2010).

Nanopartículas acopladas com o peptídeo RGD foram extensivamente estudadas para imagens alvo específicas de câncer usando pontos quânticos (Cai e col., 2006), nanopartículas de óxido de ferro (Lee e col., 2008, Benezra e col., 2011) e nanopartículas de ouro (Kim e col., 2011).

Progressos significantes tem sido feitos no uso para imagem de tumor por SPECT ou PET. Dentre o radiotraçadores avaliados em vários modelos préclínicos em animais portadores de tumor, o ${ }^{18} \mathrm{~F}$-galacto-RGD, $\left[{ }^{18} \mathrm{~F}\right]$-fluciclatide, ${ }^{18} \mathrm{~F}$ RGD-K5, [ $\left.{ }^{18} \mathrm{~F}\right] \mathrm{FPPRGD2},{ }^{68} \mathrm{Ga}-\mathrm{NOTA}-\mathrm{RGD}$ e o $\left[{ }^{18} \mathrm{~F}\right] \mathrm{AH} 111585$ estão atualmente 
sob investigação clínica para imagens não-invasivas da expressão de $\alpha v \beta 3$ em pacientes com câncer (Beer e col., 2007, 2008; Beer, Schwaiger, 2011; Cai e Conti, 2013, Kenny e col., 2008).

\subsection{Peptídeo com a sequência GX1}

Através de uma busca in vivo na biblioteca de peptídeos phage display, foi identificado previamente um peptídeo composto por 9 aminoácidos, Cys-GlyAsn-Ser-Asn-Pro-Lys-Ser-Cys, nomeado GX1, que se liga especificamente a vasculatura de câncer gástrico humano (Chen e col., 2009; Hui e col., 2008; Zhi e col., 2004). Estudos de marcação imunohistoquímica, ensaio imunoenzimático (ELISA) e imunofluorescência confirmaram a atividade alvo do peptídeo CGNSNPKSC (GX1), indicando que o GX1 pode ser usado como um novo marcador vascular para cânceres humanos (Hui e col., 2008; Zhi e col., 2004).

Embora seu receptor continue desconhecido, Hu e col. (2014) sugerem que a integrina $\alpha 3 \beta 1$ como um possível receptor, baseado em estudos de espectometria de massas. Essa elucidação irá permitir o entendimento completo dos efeitos anti-angiogênicos mediados pelo GX1. O peptídeo GX1 já foi radiomarcado com sucesso com ${ }^{64} \mathrm{Cu}$ em células de glioblastoma U87MG e se mostrou um radiotraçador promissor para imagens de vasculatura tumoral (Chen e col., 2012a). Também já foi radiomarcado com o ${ }^{99 m}$ Tc em células de carcinoma gástrico humano SGC7901 com alta eficiência e atividade específica para imagem diagnóstica da angiogênese tumoral (Hu e e col. 2014; Hui e col., 2008).

Há poucos relatos na literatura sobre estudos com esse peptídeo. Além dos já citados, o peptídeo GX1 também já foi conjugado com corantes fluorescentes para obtenção de imagens fluorescentes ópticas de tumor gástrico (Hu e col., 2014; Xin e col., 2013) e para imagens de fluorescência de infravermelho em células de glioblastoma (Chen e col., 2012b). Chen e col. (2009) conjugaram o peptídeo GX1 com o fator mutante humano recombinante de necrose tumoral alfa (TNF-alfa) e demonstraram seletividade para sítios tumorais alvos, aumento significante da atividade anti-tumoral do fator TNF-alfa e diminuição da toxicidade sistêmica. 


\subsection{Câncer}

Cânceres são doenças genéticas resultantes de mutações acumuladas no DNA. Essas mutações estão associadas ao descontrole de funções essenciais como a proliferação, diferenciação e morte celular, gerando células cujo DNA apresenta-se instável (Melo, Junqueira e Chammas, 2003). Hanahan e Weinberg (2000) classificaram essas características em seis grupos: autossuficiência quanto aos fatores de crescimento, insensibilidade a fatores inibitórios de proliferação, evasão de apoptose, potencial replicativo infinito, invasão tecidual e metástase, e angiogênese sustentada.

O desenvolvimento e a progressão do câncer são fenômenos complexos e difíceis de elucidas, contudo os avanços em biologia molecular são contínuos e lançam luz em certos tipos de malignidade (Nishino et al., 2012). Uma detecção precisa e rápida de tumores é crucial para definir a base molecular da patogênese do câncer, prevenindo complicações e implementando abordagens terapêuticas com sucesso (Achilefu, 2004).

Câncer é a maior causa de morbidade e mortalidade no mundo todo, sendo responsável por aproximadamente uma de quatro mortes nos Estados Unidos (Siegel e col., 2013). Isso devido a falta de testes para diagnóstico precoce e a falta de disponibilidade de drogas alvo-específicas para tumores. Muitas restrições da quimioterapia convencional, como a instabilidade da droga em circulação, distribuição tecidual inapropriada e toxicidade em células sadias poderiam ser melhoradas através de drogas específicas (Choi e col., 2014).

\subsubsection{Tumores Cerebrais}

Os tumores cerebrais representam um grande desafio tanto para aqueles que recebem como para aqueles que fornecem o diagnóstico. Localizados, geralmente, em regiões de difícil acesso, resistentes à radiação, à quimioterapia e à cirurgia de remoção e oferecendo um grande risco às funções 
desempenhadas pelo cérebro, estes tumores são um apelo constante a novas estratégias de diagnóstico e de tratamento mais eficazes.

O diagnóstico é feito por estudos de imagem (ressonância magnética e tomografia axial computorizada), seguido de biópsia e análise histológica. Considera-se a histologia do tumor determinante no diagnóstico e nas decisões terapêuticas em gliomas, no entanto, por vezes, é um método subjetivo e variável (Eoli e col., 2006). A microscopia eletrônica mostra lesões infiltrativas no tecido cerebral que rodeia o tumor, característica que está sempre presente nos glioblastomas (Laws Jr e Shaffrey, 1999).

Tanto a cirurgia como a radioterapia podem ser efetivas, no entanto a aplicação pode ser limitada devido a proximidade com regiões importantes para a função cerebral (Ong e col., 2009). Apesar do desenvolvimento das técnicas de neuro-imagem, do aperfeiçoamento das técnicas cirúrgicas, da melhoria nas metodologias histológicas e do aumento progressivo do conhecimento na biologia molecular dos tumores, o diagnóstico dos gliomas cerebrais malignos ainda permanece difícil e subjetivo (Riemenschneider e col., 2010).

Atualmente, a maioria das drogas usadas contra o câncer não conseguem diferenciar entre células saudáveis e tumorais, levando à uma toxicidade sistêmica e efeitos colaterais adversos (Gautam e col., 2014). Por isso, nos últimos anos, têm-se estudado intensivamente formas mais eficazes de diagnóstico e, para isso, esforços têm sido feitos de forma a clarificar as alterações genéticas/moleculares associadas com 0 desenvolvimento e progressão de gliomas humanos.

\subsubsection{Glioma}

O termo glioma é usado para tumores originados em células da glia: astrocitomas, glioblastomas, oligodendrogliomas e ependimomas (Goldman e Pirotte, 2011). Os dois primeiros são os mais comuns. Gliomas são tumores cerebrais primários em adultos e incluem uma variedade de tipos histológicos e morfologias (Laperriere, Zuraw e Cairncross, 2002). 
Estes tumores podem também variar desde neoplasias com células pequenas e uniformes até células gigantes e multiformes, justificando assim o termo multiforme para designar os glioblastomas. Devido ao rápido crescimento, provocam extensas áreas de destruição do tecido nervoso, causando edema e necrose (Guedes, 2010).

Glioblastomas são tumores cerebrais altamente agressivos, que tem origem astrocítica ou oligodendrócita. Apesar de recentes melhoras no campo das cirurgias de resecção, a radioterapia e quimioterapia alquilante, a média de sobrevida ainda é menor que 6 meses em análises de base populacional (Ohgaki e Kleihues, 2009). Gliomas, e particularmente glioblastoma multiforme, são os tumores cerebrais primários mais frequentes com alta malignidade e pobre prognóstico em adultos, sendo sua incidência estimada em 3-4/100.000/ano. A média de sobrevivência de pacientes com glioblastoma multiforme é de $35 \%$ depois de um ano e menos de $5 \%$ dos pacientes vivem mais de 5 anos (Ostrom e col., 2013).

O prognóstico sombrio do glioblastoma tem muitas razões. Além do padrão de crescimento infiltrado, glioblastomas são caracterizados por um fenótipo imunossupressivo. Além disso, as células de glioblastomas são resistentes a diferentes estímulos apoptóticos. A classificação da Organização Mundial da Saúde de 2007 (Louis e col., 2007), reconhece três principais tipos histológicos de glioma difuso de baixo grau, grau II: astrocitoma difuso, oligoastrocitoma e oligodendroglioma. Astrocitoma difuso tende a progredir a tipos histológicos mais malignos, como astrocitoma anaplásico (grau III) e eventualmente glioblastoma secundário (grau IV), visto que a progressão de oligodendrogliomas a oligodendrogliomas anaplásicos é menos previsível.

A maioria dos glioblastomas (grau IV) afeta pacientes idosos e se manifesta rapidamente após um histórico clínico curto e sem evidências de lesão precursora maligna: estes são designados glioblastomas primários. Em contraste, glioblastomas secundários se desenvolvem em pacientes jovens através da progressão de astrocitoma difuso (grau II) ou astrocitoma anaplásico (grau III) (Louis e col., 2007). Glioblastoma (GBM, grau IV astrocitoma) é a forma mais maligna de tumores de cérebro, caracterizada por intensa proliferação, quimioresistência, invasão e recorrência (Ohgaki e Kleihues, 2009). 
Gliomas tendem a ser altamente vascularizados, uma característica que é crítica para o seu crescimento. Tem sido muito explorado o aumento da vasculatura de gliomas para a localização e diagnóstico destes tumores por angiografia e estudos contrastados que usa como vantagem a permeabilidade dos vasos. A proliferação vascular é um importante marcador na classificação histológica de gliomas (Daumas-Duport, 1992). O grau de vascularização tem sido mostrado como correlacionado com a classificação do tumor e sua agressividade, presumivelmente porque tumores com uma rápida taxa de crescimento requer um aumento de nutrientes e oxigênio (Plate e Mennel, 1995).

\subsection{Relação entre Glioma, Angiogênese, Peptídeo RGD e Peptídeo GX1}

O fenômeno de angiogênese, formação de novos vasos sanguíneos, é fundamental no desenvolvimento do corpo humano e em alguns processos fisiológicos (Dobrucki e Sinusa, 2007).

Os vasos sanguíneos podem se desenvolver na embriogênese mediante dois tipos de processos: a vasculogênese que consiste no processo de diferenciação inicial de células mesenquimais em hemangioblastos (precursores das células endoteliais e sanguíneas); e a angiogênese, formação de novos vasos sanguíneos a partir de vasos pré-existentes. A angiogênese é um processo necessário tanto para a embriogênese como para o crescimento somático, cicatrização, regeneração de órgãos e tecidos, crescimento do corpo lúteo e do endotélio. Consiste em uma cascata de processos que se resume basicamente na degradação da matriz extracelular, proliferação e migração das células endoteliais (capilares). O desenvolvimento dos vasos sanguíneos pode gerar a angiogênese patológica auxiliando, por exemplo, o crescimento de tumores. A hipótese de que o crescimento de tumores e metástases são dependentes de angiogênese foi primeiramente proposta por Judah Folkman em 1971 (Folkman, 1971; Folkman, 1995). Esta hipótese é hoje em dia apoiada por extensas evidências experimentais. 
Quando há um desequilíbrio, devido tanto a uma maior ou menor regulação de mediadores anti-angiogênicos, a angiogênese é induzida (Brack, Dinkelborg e Neri, 2004). A formação de novos vasos sanguíneos é essencial no suprimento de oxigênio e nutrientes à proliferação de células do tumor. Tumores sólidos em fase precoce de crescimento recebem seus nutrientes por difusão passiva (Cai, Ghambi e Chen, 2005).

As células tumorais podem obter nutrientes e oxigênio por difusão passiva na distância aproximada de 0,2 a 0,5mm levando a um crescimento tumoral de aproximadamente 2 a $3 \mathrm{~mm}^{3}$, contendo alguns milhões de células. A taxa de crescimento de células em tumores sem neovascularização fica em equilíbrio com a sua taxa de mortalidade. Os novos vasos sanguíneos suprem as células tumorais e remove os produtos de seu metabolismo (FIG. 2). Ao contrário da angiogênese vista em tecidos normais, a angiogênese tumoral apresenta vasos vazantes, diâmetros irregulares, paredes finas, fluxo sanguíneo aberrante e áreas de necrose. Também são observadas diferenças com relação à expressão de moléculas de superfície das células endoteliais dos vasos sanguíneos tumorais e normais (Melo, Junqueira e Chammas, 2003; Folkman, 1995).

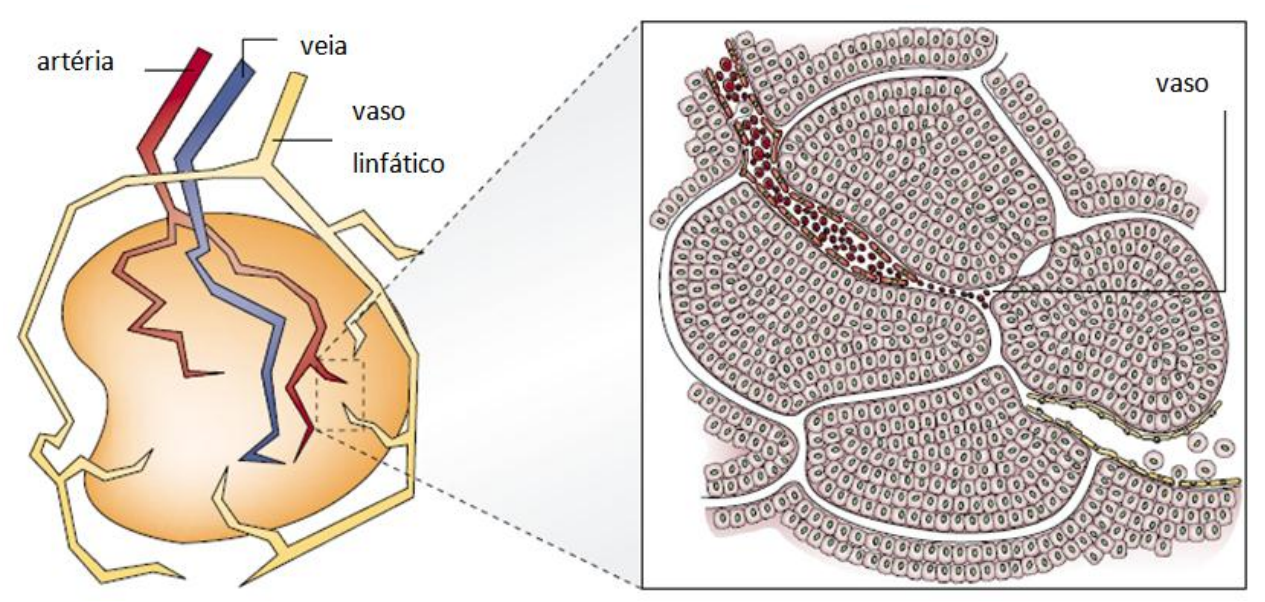

FIGURA 2 - Vasculatura e microambiente tumoral (Ruoslahti, 2002)

A imagem molecular não-invasiva da angiogênese deverá prover informações valiosas sobre a caracterização de tumores sólidos em termos de 
perfusão de tumores e consequentemente focando um tratamento eficaz (Cai, Ghambi e Chen, 2005). Vale ressaltar que tumores são microambientes heterogêneos que apresentam, além do tecido tumoral, as células estromais (fibroblastos, adipócitos, células da musculatura lisa, do sistema imune e inflamatórias) e que juntos, participam do processo de progressão tumoral (Hanahan e Weinberg, 2000).

Há uma forte razão para o uso de terapias anti-angiogênicas para esses tumores, como eles são altamente vascularizados, proliferação microvascular ou necrose (ou ambos) é um critério essencial no diagnóstico de glioblastoma, e vários estudos confirmaram que bloqueando a angiogênese tumoral, o crescimento do tumor é inibido (Jain e col., 2007; Plate e col., 1993; Plate, Scholz e Dumont, 2012).

Gliomas malignos são caracterizados por um componente angiogênico robusto e, embora não seja uma doença metastática, exibe um padrão localmente invasivo. A regulação da invasão e da angiogênese parece ser estreitamente interdependente: a cooptação de vasos sanguíneos através de células de glioma infiltrantes é um instrumento para a invasão do glioma maligno e um precursor para a neovascularização (Jain e Carmeliet, 2012; Plate, Scholz e Dumont, 2012; Zerrouqi e Van Meir, 2011)

A identificação de sequências de peptídeos, como Arg-Gly-Asp (RGD) e Cys-Gly-Asn-Ser-Asn-Pro-Lys-Ser-Cys (GX1) do phage display, foi de importante contribuição no campo das drogas-alvo e obtenção de imagens, dirigidas a neovascularização tumoral. Estudos realizados demonstraram que células de glioma apresentam receptores para o peptídeo de sequência RGD (Shi e col., 2009a; Shi e col., 2009b; Wu e col., 2007; Chen e col., 2004a; 2004c), assim como o peptídeo GX1 demonstrou captação na vasculatura tumoral (Zhang e col., 2006).

As sequências curtas de peptídeos são atrativas porque são passíveis de síntese em larga escala, modificações químicas e não são imunogênicas (Kok e col., 2002). Com isso, a busca por identificar peptídeos que reconheçam especificamente células tumorais e vasculaturas tumorais vem ocorrendo ao longo dos anos (Gautam et al., 2014). 
A utilização de uma molécula heterodímera, contendo o peptídeo RGD e o peptídeo GX1 favorece a ligação com o alvo, no caso o glioma, devido a habilidade de se ligar ao mesmo tempo a dois sítios receptores, e consequentemente uma melhor visualização do tumor por imagem molecular (FIG. 3).

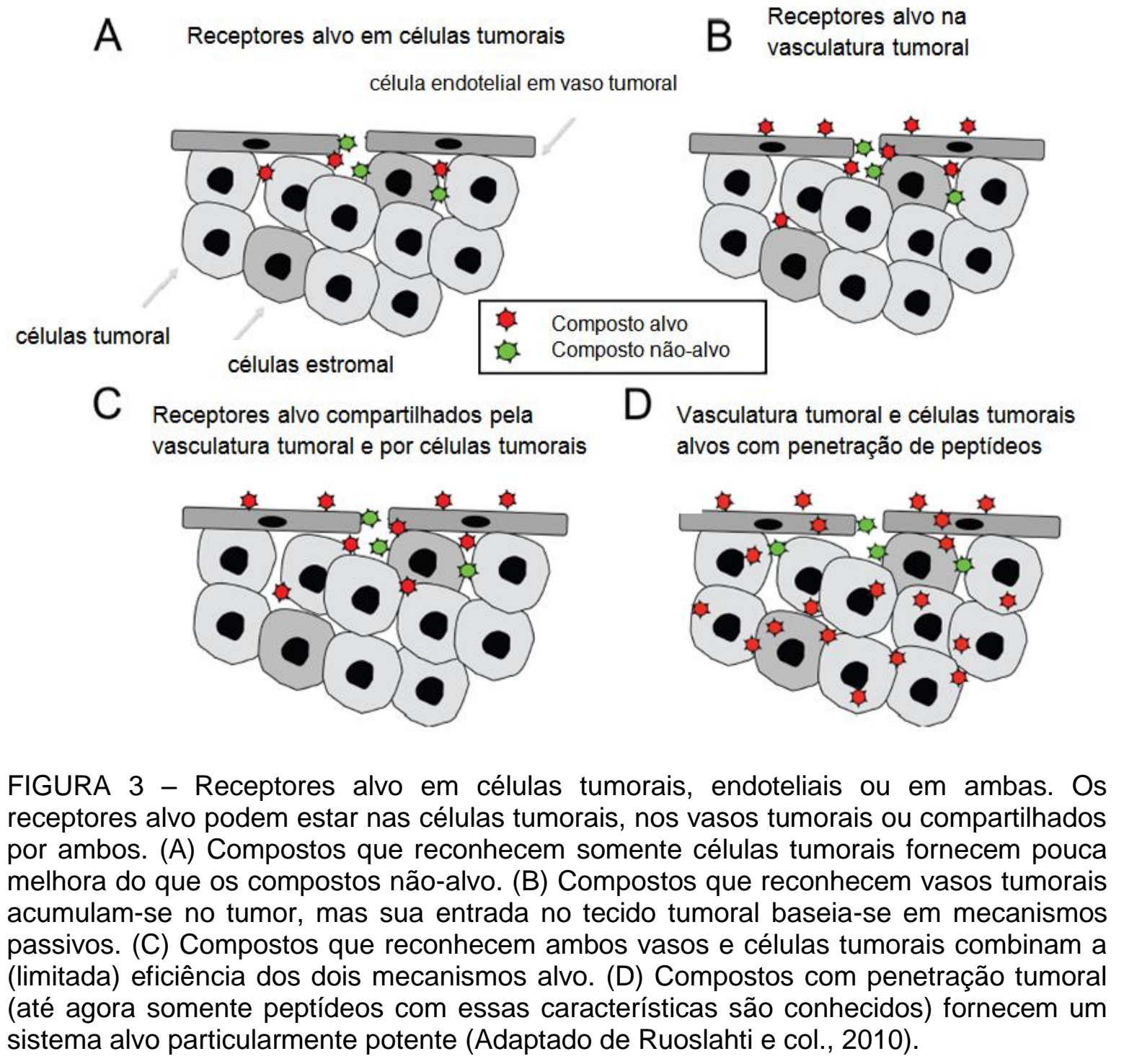

\subsection{Radioisótopo ${ }^{99 m}$ Tc para imagem diagnóstica}

O radionuclídeo ligado à molécula dá a característica diagnóstica ou terapêutica ao radiofármaco. Uma propriedade importante de um radiofármaco 
para câncer é acumular preferencialmente nas áreas tumorais, a fim de alcançar o resultado desejado, com mínimo dano aos tecidos sadios (Iman, 2005).

Os radioisótopos usados em medicina nuclear com propósito diagnóstico são essencialmente os emissores de radiação gama e pósitrons. Para uso diagnóstico, os radioisótopos emitem radiação eletromagnética que penetra o tecido e é detectado externamente, promovendo a aquisição de imagens. Raios gama ou raios $X$ distribuem suas energias uniformemente através do tecido, podendo atravessar tecidos bastante espessos (Weiner e Thakur, 1995). O progresso em técnicas de diagnóstico em Medicina Nuclear, desde a primeira aplicação do tecnécio-99 meta estável (99mTc) em 1960, é verdadeiramente notável (Banerjee e col., 2001).

O elemento químico tecnécio não é encontrado na crosta terrestre em abundância, pois o mesmo não é gerado continuamente pela reação ou decomposição de outros elementos presentes no planeta. Pequenas amostras de tecnécio foram encontradas em rochas, provavelmente devido aos raios cósmicos que bombardearam a Terra (Weeks, 1993). O tecnécio, cujo número atômico é 43, foi descoberto em 1925 pelos cientistas Noddack, Tacke e Berg, os quais o chamaram, inicialmente, de massarium. Eles se basearam nos espectros e emissão de raios $X$ obtidos com concentrados de vários minerais, como por exemplo, a columbita (Weeks, 1933).

O nome "tecnécio" foi originado do grego tecfinetos que significa "artificial" e empregado, primeiramente, por Paneth em 1947, justamente por ser o primeiro elemento radioativo produzido pelo homem. O tecnécio é um metal de transição situado no Grupo 7 da Tabela Periódica. Apresenta propriedades tanto ácidas como básicas. Seu ponto de fusão é de $2.200^{\circ} \mathrm{C}$ e seu ponto de ebulição $4.877^{\circ} \mathrm{C}$ (Banerjee e col., 2001, 2005).

Em 1938 Emilio Segrè e Glenn T. Seaborg isolaram pela primeira vez o isótopo metaestável tecnécio-99m, depois de bombardear molibdênio natural por núcleos de deutério em um cíclotron (Segrè e Wu, 1940).

O ótimo desempenho em Medicina Nuclear pode ser atribuído as suas propriedades nucleares e químicas, as quais consistem na emissão de fóton gama com energia monocromática de $140 \mathrm{keV}$ de energia (89\% de abundância), 
ideal para aquisição de imagens cintilográficas. Seu tempo de meia-vida é de aproximadamente $6 \mathrm{~h}$, o que significa que $93,7 \%$ de sua atividade decai em 24 horas, sendo suficientemente longo para realizar a síntese do radiofármaco e suficientemente pequeno para minimizar a dose de radiação ao paciente (Banerjee e col., 2005). O uso do tecnécio também foi muito facilitado com o desenvolvimento de geradores molibdênio-99/tecnécio-99m e a formulação de kits liofilizados, tornando o seu uso uma realidade em radiofarmácia hospitalar (Banerjee e col., 2001, Faintuch e col., 2005).

O ${ }^{99 m}$ Tc somente se tornou disponível para utilização rotineira em 1958, com o desenvolvimento do gerador ${ }^{99} \mathrm{Mo}-{ }^{99 \mathrm{mTC}}$ no Brookhaven National Laboratory - EUA. O desenvolvimento do gerador de molibdênio-99/tecnécio-99m $\left({ }^{99} \mathrm{Mo} /{ }^{99 m} \mathrm{Tc}\right)$ permitiu que o uso do radionuclídeo ${ }^{99 \mathrm{~m} T c}$ se tornasse economicamente viável em seu uso rotineiro (Jurisson e Lydon, 1999).

Os geradores permitem obter um radionuclídeo de $\mathrm{t}_{1 / 2}$ curto a partir de um radionuclídeo de $t_{1 / 2}$ longo. As propriedades químicas dos dois radionuclídeos têm que ser distintas para que sejam facilmente separados (Saha, 1998). A coluna cromatográfica do gerador é baseado em um sistema de alumina com o isótopo ${ }^{99}$ Mo como produto de fissão (Banerjee e col., 2001; Boyd, 1982). O ${ }^{99 m T C}$ é produzido pelo radionuclídeo "pai" ( ${ }^{99} \mathrm{Mo}$ ) com tempo de meia vida de 2,75 dias e é eluído a baixas concentrações, da ordem de 10 pmol/L (Alberto e col., 1999).

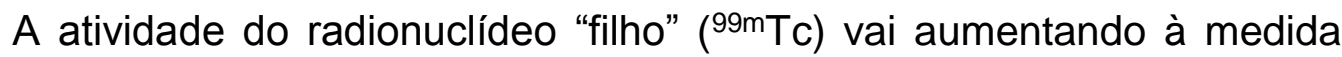
que o radionuclídeo "pai" $\left({ }^{99} \mathrm{Mo}\right)$ vai decaindo. $\mathrm{O}{ }^{99} \mathrm{Mo}$, na forma química de $\mathrm{MoO}_{4}{ }^{2-}$, encontra-se adsorvido numa coluna de alumina e por eluição com soro fisiológico é apenas eluído o ${ }^{99 \mathrm{~m}} \mathrm{TcO}^{4-}$, recolhido sob vácuo, enquanto o molibdato fica retido na coluna (FIG. 4) (Oliveira e col., 2006). 


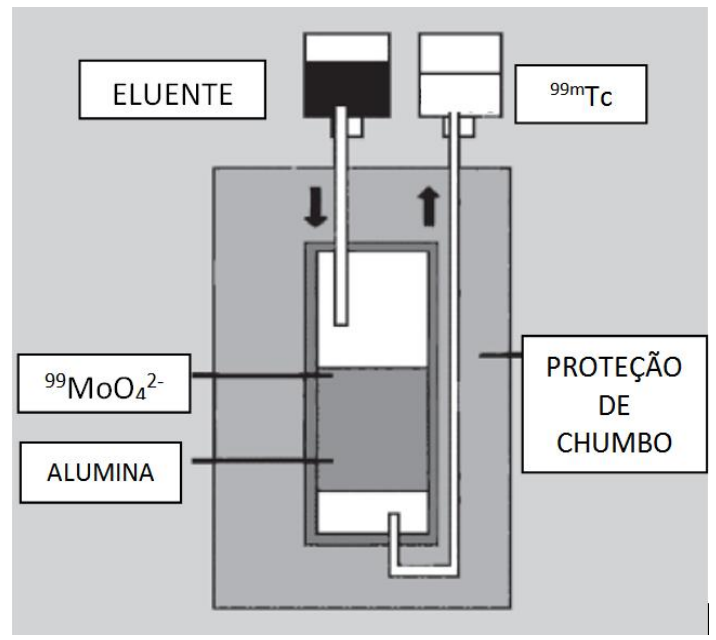

FIGURA 4 - Gerador de ${ }^{99} \mathrm{Mo} /{ }^{99 m} \mathrm{Tc}$ (Oliveira e col., 2006)

A radiomarcação relativamente fácil dos seus componentes e a falta de necessidade de purificação, faz desses tipos de traçadores adequados para produção em massa em forma de kits que podem ser distribuidos e usados em hospitais e clínicas onde haja um gerador presente (Ebenhan e col., 2014a). Na medivu nuclear brasileira, são realizados aproximadamente 2,5 milhões por ano de procedimentos médicos com radiofármacos produzidos pelo Instituto de Pesquisas Energéticas e Nucleares (Romero, 2006).

Os radiofármacos contendo tecnécio-99m tornaram-se importantes ferramentas para o diagnóstico de várias doenças. Dentre elas, pode-se destacar a localização de lesões cerebrais, estudos da tireóide, glândulas salivares e cintilografia gástrica (Marques, Okamoto e Buchpiguel, 2001). A introdução de novos métodos de marcação baseados em 99mTc cresceu continuamente nos últimos anos, evidenciando uma especificidade maior e resolução melhor para pequenas estruturas biológicas (Duatti, 2009).

\subsubsection{Marcação de biomoléculas com ${ }^{99 m}$ Tc}

Várias técnicas de marcação de biomoléculas com tecnécio foram desenvolvidas na última década. A estratégia de marcação deve ser selecionada 
apropriadamente e otimizada visando uma alta estabilidade do produto radiomarcado, propriedade hidrofílica e baixa ligação às proteínas plasmáticas. $\mathrm{O}$ 99mTc pode se apresentar em nove diferentes estados de oxidação $(-\mathrm{I} \mathrm{a}+\mathrm{VII})$. A estabilidade desses estados de oxidação depende do tipo de ligantes e do meio químico. $\mathrm{Na}$ forma de pertecnetato de sódio $\left(\mathrm{Na}^{99 \mathrm{~m}} \mathrm{TcO}_{4}\right)$, o isótopo ${ }^{99 \mathrm{~m}} \mathrm{Tc}$ possui o número de oxidação +VII, que é o mais estável em solução aquosa, porém nesta forma química o tecnécio não consegue se ligar às moléculas para formação de compostos de coordenação. Sendo assim, o uso de agentes redutores e técnicas de complexação para estabilizar o radioisótopo se fazem necessários (Banerjee e col., 2005; Jurison e Lydon, 1999).

As reações de complexação podem ser realizadas com vários tipos de agentes quelantes, cujos números de coordenação podem variar de 4 a 9 . Entre os diversos tipos de agentes quelantes vale a pena mencionar os que contém os núcleos $\left({ }^{99 \mathrm{~m} T c O}\right)^{3+}$ e $\left({ }^{99 m} \mathrm{TcO}_{2}\right)^{+}$.

\subsection{Agente quelante bifuncional}

Um ligante bifuncional possui dois propósitos: a ligação ao radionuclídeo de maneira segura sem dissociação in vivo e a formação de um apêndice estrutural para ligação à biomolécula mantendo a máxima integridade biomolecular. Portanto, a extremidade que se liga ao marcador precisa possuir elevada estabilidade cinética sob condições biológicas, enquanto a outra terminação do quelato bifuncional permite a ligação covalente à molécula biológica (Banerjee e col., 2005, Price e Orvig, 2014) .

Sua estereoquímica é importante quando da síntese de radiofármacos

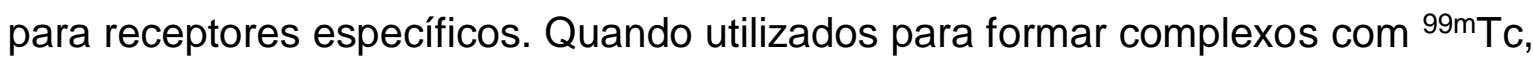
apresentam estabilidade termodinâmica e um número bastante reduzido de formação de isômeros (Kowalsky e Falen, 2004).

Um dos primeiros agentes quelantes utilizado foi 0 ácido dietilenotriamino pentaacético (DTPA), porém essencialmente para os radioisótopos ${ }^{111} \mathrm{In},{ }^{90} \mathrm{Y}$ e ${ }^{99} \mathrm{Tc}$ (Kowalsky e Falen, 2004). Outro agente, o 6- 
hidrazinonicotinamida (HYNIC), tem sido empregada nas marcações de biomoléculas com ${ }^{99 \mathrm{~m} T c / 188} \mathrm{Re}$ apresentando resultados promissores por causa de sua alta eficiência de marcação especialmente com análogos da somatostatina (Plachcinska e col., 2004) e oligonucleotídeos antisenso (Zhang e col., 2000).

A FIG. 5 mostra uma ilustração esquemática do radiotraçador alvoespecífico, que são geralmente complexos de um radiometal com um conjugado da biomolécula com o quelante. O radiotraçador alvo específico contendo metal pode ser dividido em quatro partes: biomolécula, espaçador, agente quelante bifuncional e radionuclídeo. A biomolécula serve como um carreador para transporte alvo-específico ao tecido desejado com muitos receptores alvo. $\mathrm{O}$ ligante radiomarcado liga-se a esses receptores com alta afinidade $\mathrm{e}$ especificidade, resultando em captação seletiva do radiotraçador. A escolha do radionuclídeo depende da utilidade clínica do radiotraçador (Zhou e col., 2011a).

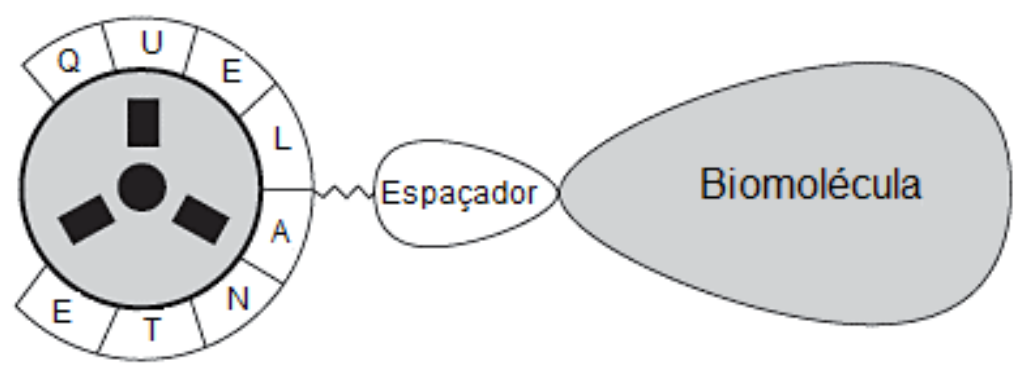

FIGURA 5 - Representação esquemática do desenho de um radiofármaco (Liu, Robinson e Edward, 2003)

Embora a escolha do quelante seja crucial para o comportamento biológico do radiofármaco, grande importância também deve ser dada à biomolécula carreadora ligada a ele. Uma variedade de quelantes tem sido usada como quelante bifuncional na marcação de proteínas, peptídeos e outras moléclas biologicamente ativas pelo 99mTc (Garcia-Garayoa e col., 2006, Maina e col., 2007, Oliveira e col., 2012). 


\subsubsection{Agente 6-hidrazinonicotinamida (HYNIC)}

O HYNIC (FIG. 6) é um agente quelante bifuncional que tem sido bastante estudado e frequentemente usado para sintetizar bioconjugados para radiomarcação com tecnécio-99m (Erfani e col., 2014; Guo e col., 2014; Meszaros e col., 2011). Historicamente, desde que Abrams e col. (1990) relataram

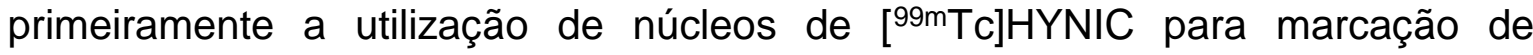
imunoglubulinas ( $\mathrm{lgG})$, as investigações utilizando este núcleo foram realizadas, primordialmente, para radiomarcação de proteínas (Hnatowich e col., 1993), pequenas biomoléculas, incluindo peptídeos quimiotáticos (van der Laken e col., 1997), análogos da somatostatina (Kopecky e col., 2004) e oligonucleotídeos antisenso (Hnatowich e col., 1995), interleucina-8 (Rennen e col., 2002) e muitos outros (Decristoforo e Mather, 1999; Erfani e col., 2014; Guo, Hinkle e Lee, 1999; Guo e col., 2014).

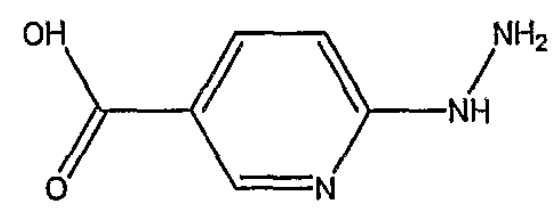

FIGURA 6 - Molécula de HYNIC

O HYNIC é o melhor candidato devido à obtenção de uma marcação com alta atividade especifica, por ajudar no aumento da estabilidade, acelerar a excreção com acumulação menor no corpo, além de permitir o uso de vários coligantes, que ajudam no controle da hidrofilicidade e farmacocinética do peptídeo radiomarcado (Gandomkar e col., 2009; Babich e Fischman, 1995; Decristoforo e col., 2006, Decristoforo e col., 2007, Janssen e col., 2002, Su e col., 2003).

Como o HYNIC ocupa somente um ou dois sítios de coordenação, um coligante é necessário para completar a geometria piramidal quadrada ou octaédrica do complexo (Liu e col., 2002). Dentre os vários ligantes, a tricina e o 
EDDA (ácido etilenodiamino diacético) alcançam a melhor eficiência de marcação (Faintuch e col., 2005).

\subsection{Espaçadores}

A farmacocinética dos complexos radiomarcados com 99mTc pode ser favorecida com o uso de espaçadores entre o radioisótopo e o agente quelante bifuncional. Já foi demonstrado anteriormente o favorecimento biológico da adição de uma molécula de polietilenoglicol como espaçador (Denardo e col., 2003).

A peguilação consiste na inserção na molécula de polímeros inertes denominados polietilenoglicóis (PEGs), hidrossolúveis e não tóxicos, produzidas pelas ligações repetidas de subunidades de óxido de etileno. A ligação covalente entre um peptídeo com polímero polietilenoglicol (PEG), resulta na inibição da degradação por enzimas proteolíticas e aumenta o tamanho da molécula, reduzindo a taxa de filtração renal e favorecendo a captação tumoral através também de estruturas ramificadas (Denardo e col., 2003). O espaçador PEG4 (FIG. 7) é usado para aumentar a distância entre dois peptídeos, e é responsável por melhorar a afinidade de ligação à integrina $\alpha_{v} \beta_{3}$ (Wang e col., 2009).

As modificações da rota farmacocinética podem ser realizadas através da inserção de espaçadores, com a finalidade de afastar o sítio de ligação do radioisótopo ao síto de ligação da biomolécula (Liu e Edwards, 1999). Às vezes, um espaçador metabolizável é usado para aumentar a depuração sanguínea e reduzir a atividade e fundo, aumentando as razões alvo/fundo. O espaçador pode ser uma simples cadeia de hidrocarbono ou um longo politetilenoglicol (PEG), que é usado frequentemente (Smith-Jones e col., 1997).

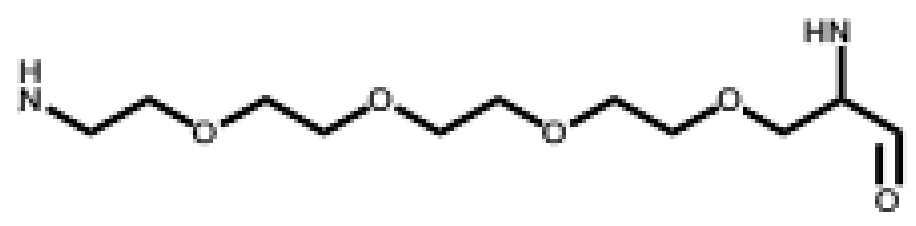

FIGURA 7 - Molécula de polietilenoglicol com quatro subunidades de óxido de etileno 


\subsection{Considerações Finais}

A necessidade do desenvolvimento de novos métodos diagnósticos para glioma e o fato deste câncer apresentar como característica a angiogênese, estimula novos estudos experimentais. Sequências curtas de peptídeos que tem afinidade por receptores da neovasculatura tumoral e de células tumorais, permitem a obtenção de imagens moleculares de maneira não-invasiva do tumor e sua perfusão, levando a uma abordagem terapêutica mais eficaz.

Em neuro-oncologia, decisões sobre a continuação ou a descontinuação de um tratamento em pacientes geralmente dependem de uma imagem adequada. Similarmente, a identificação de novas drogas ativas frequentemente dependem da avaliação da taxa de resposta objetiva ou da determinação da sobrevida livre de progressão, que é estabelecida pelas mudanças no tumor vistas na imagem. O pressuposto básico para imagens de tumores, é que mudanças encontradas nas imagens representam a atividade biológica do tumor. No entanto, estratégias de imagens convencionais não são específicas e não são uma medida direta do tamanho ou atividade do tumor (van den Bent e col., 2009).

Imagens de ressonância magnética somente refletem a atividade biológica do tumor indiretamente, pela detecção da quebra da barreira hematoencefálica. As técnicas de imagens são importantes para um diagnóstico acurado e para o tratamento dos pacientes com glioma (Dhermain e col., 2010).

Um método de imagem não invasivo e passível de aplicação precoce, para um tumor de alta mortalidade, deve contribuir para seu reconhecimento diagnóstico antes da metastatização, conduzindo a decisões terapêuticas mais adequadas para a cura da enfermidade. 


\section{OBJETIVOS}

O objetivo geral deste trabalho é o desenvolvimento de novo radiofármaco para diagnóstico por imagem de glioma, baseado em peptídeos angiogênicos marcados com o radioisótopo tecnécio-99m.

Os objetivos específicos são o desenvolvimento da marcação de dois conjugados peptídicos a saber HYNIC-PEG4-c(GX1) e HYNIC-E-[c(RGDfk)$c(G \times 1)]$ com tecnécio-99m, e avaliação biológica em modelos tumorais experimentais, na condição de estudos pré-clínicos para possíveis novas drogas. 


\section{MATERIAIS E MÉTODOS}

\subsection{Materiais}

\subsubsection{Equipamentos}

- Agitador de tubos, modelo AP56 - Phoenix, Brasil;

- Aparelho de Ressonância Magnética Biospin 7.0 Tesla $30 \mathrm{~cm}$ com bobina de radiofrequência de 2,2 cm e Bruker Paravision software - Bruker, EUA

- Aquecedor Thermomixer comfort R $\left(0-100^{\circ} \mathrm{C}\right)$ - Eppendor ${ }^{\circledR}$, EUA;

- Balança analítica, modelo M-220 - Denver Instruments, EUA;

- Bomba de Água TP500 - Gaymar Solid State, EUA.

- Bomba de vácuo, modelo 825 T - Fisaton, Brasil;

- Calibrador de doses, modelo CRC-15R - Capintec Inc., EUA;

- Capela com sistema de exaustão - BRASLAB Equipamentos para Laboratório Ltda, Brasil;

- Centrífuga, modelo HIMAC-CF 7D2 - HITACHI, EUA;

- Contador automático tipo poço com cristal Nal(TI), modelo D5002, cobra II, auto-gamma, A. Packard, Camberra, EUA;

- Cromatógrafo Líquido de Alta Eficiência (CLAE) - 1260 Infinity HPLC system, Agilent Technologies Inc., Santa Clara, CA, USA com Agilent interface 35900E e detector de radiação Raytest Gabi;

- Detector de radiação tipo poço, modelo Nuclear Spectrometer LB2040, Berthold, Alemanha;

- Estufa, modelo Orion 515 - Farrem, Brasil;

- Freezer vertical com temperatura de $-70^{\circ} \mathrm{C}$ - Eletrolab, Brasil;

- Gama-câmara equipada com os seguintes módulos:

- Detector Gama - Mediso, Hungria.

- Colimador - Mediso, Hungria.

- Software Console TH22 v.7.02 - Mediso, Hungria.

- Software InterviewXP${ }^{\circledR}$ V1.05.014 - Mediso, Hungria.

- Medidor de pH, modelo DM-31 - Digimed, Brasil;

- Microscópio de força atômica com potencial zeta, Zetasizer 300HSA Malvern Instrumentos, Reino Unido; 
- Microscópio eletrônico de transmissão com espectroscopia de energia dispersiva de raios-X - EDAX; Philips, Alemanha;

- Purificador de água Ellix acoplado a sistema de purificação MilliQ, EUA;

- Refrigerador Biflex 450 L Frostfree, Biplex 450 - Cônsul, Brasil;

\subsubsection{Reagentes e solventes}

- Acetonitrila, Ácido clorídrico, Ácido trifluoracético, Éter dietílico, Fosfato de sódio monobásico, Fosfato disódico anidro, Metiletilcetona, Octanol Merck, Alemanha;

- Ácido ascórbico, Ácido etieleno-N',N'-diaminodiacético (EDDA), Glicina, Hidróxido de Sódio, Isuflorano, Tricina, Uretana - Sigma Aldrich, EUA;

- Anestésicos: Cloridato de Xilazina (Anasedan injetável) - Vetbrands, Brasil; Solução injetável de Cetamina 10\% - Syntec, Brasil; Sulfato de Morfina Cristália, Brasil;

- Cloreto estanoso dihidratado - Merck, Alemanha;

- Conjugados Peptídicos: HYNIC-PEG4-C(GX1) (FIG. 8) e HYNIC-E[c(RGDfk)-c(GX1)] (FIG. 9) - CPC Scientific Inc. (EUA); 


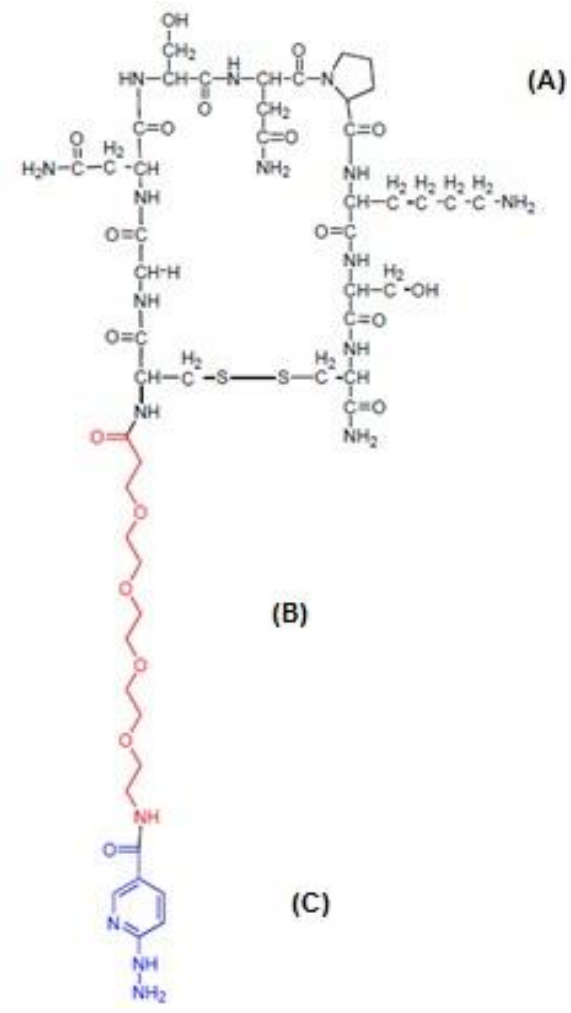

(A)

FIGURA 8 - Estrutura molecular do conjugado peptídico HYNIC-PEG 4 -c(GX1); (A) GX1 cíclico; (B) PEG4; (C) HYNIC; Peso Molecular: 1290,2

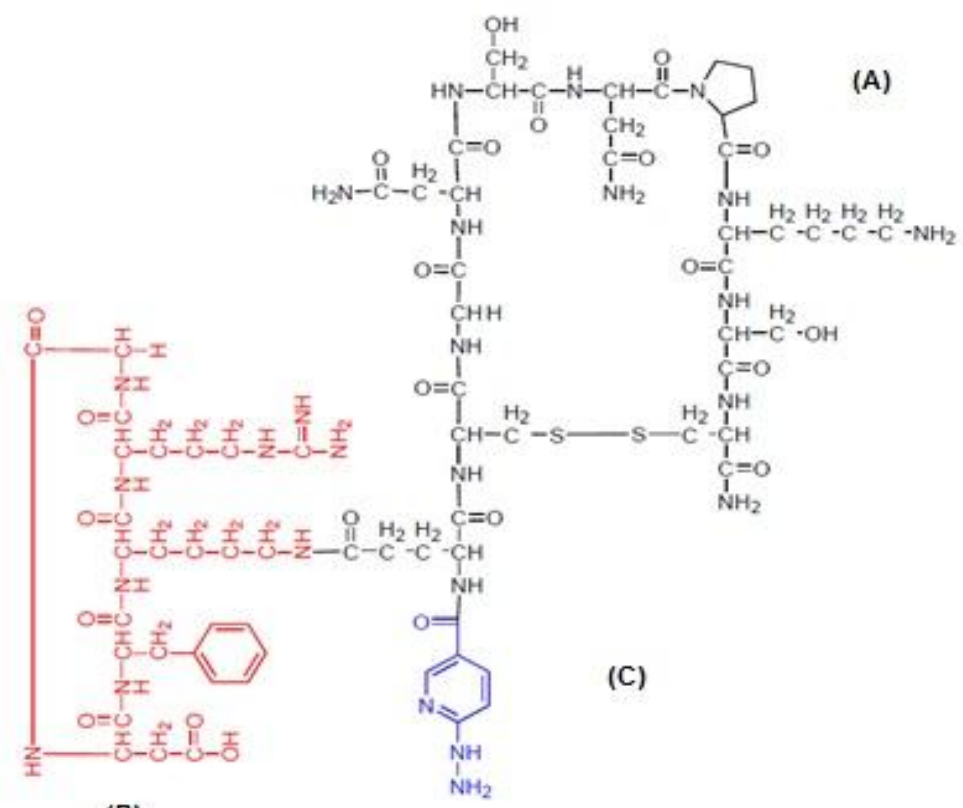

(B)

FIGURA 9 - Estrutura molecular do conjugado peptídico HYNIC-E-[c(RGDfk)-c(GX1)]; (A) GX1 cíclico; (B) RGDfk cíclico; (C) HYNIC; Peso Molecular: 1755,9 
- Cetoprofeno (Profenid) - $100 \mathrm{mg} / 2 \mathrm{~mL}$ - Sanofi Aventis, Brasil;

- Gás nitrogênio, grau de pureza 99,99\% - White Martins, Brasil;

- Heparina (Liquemine®), solução 5000 U.I./mL - Roche, Brasil;

- Magnetonanopartículas de ferro - UCLA, EUA.

- Meio de cultura DMEM/F12 (modificação de Meio Basal de Eagle com mistura nutriente F12) + 1\% FCS - Cultilab®, Brasil.

- Meio de cultura RPMI (Instituto Roswell Park Memorial) + 1\% FCS Cultilab ${ }^{\circledR}$, Brasil;

- Radioisótopo tecnécio-99m, obtido do gerador molibdênio-99/tecnécio-99m produzido no Centro de Radiofarmácia (CR) do Instituto de Pesquisas Energéticas e Nucleares (IPEN/CNEN-SP), Brasil;

- Solução fisiológica estéril (cloreto de sódio) 0,9\% - Equiplex, Brasil;

\subsubsection{Outros}

- Fitas cromatográficas ITLC-SG (Instant Thin Layer Chromatography - Silica Gel), $5 \times 20 \mathrm{~cm}$ - Pall Corporation, EUA;

- Pipetas automáticas de 10, 100 e 1000 $\mu \mathrm{L}$ - Eppendor ${ }^{\circledR}$, EUA;

- Placas de 6 e de 12 poços, estéreis- Corning Incorporated ${ }^{\circledR}$, EUA;

- Tubos reacionais de 1,5 mL, transparentes, mono-poliméricos- Axygen Scientific ${ }^{\circledR}($ MCT-150-C) - EUA;

- Membranas filtrantes 0,22 $\mu \mathrm{m}$ - Millipore ${ }^{\circledR}$, EUA;

- Fitas de pH, Neutralit pH 5-10 - Merck, Alemanha;

- Aparelho estereotáxico para camundongos e ratos (Insight, EUA);

- Vidrarias em geral e instrumentos cirúrgicos.

- Células da linhagem tumoral de glioblastoma humano U87MG - American Type Culture Collection - ATCC, EUA;

- Células da linhagem tumoral de glioblastoma humano U87MG com mutação na enzima IDH1 do tipo selvagem (IDH1 ${ }^{\mathrm{WT}}$ ) e com uma mutação conhecida na arginina do resíduo 132 (IDH1 $\left.{ }^{\text {R132}}\right)$ - UCLA, EUA.

- Células de linhagem tumoral de glioblastoma humano T98G - American Type Culture Collection - ATCC, EUA; 
- Células endoteliais humanas de cordão umbilical HUVEC - American Type Culture Collection - ATCC, EUA;

\subsubsection{Animais}

- Camundongos da linhagem Balb/c, Peso corpóreo 20-25g- Biotério IPEN/CNEN-SP, Brasil;

- Camundongos da linhagem SCID, Peso corpóreo 15-20g - Biotério IPEN/CNEN-SP, Brasil;

- Camundongos da linhagem NOD-SCID, Peso corpóreo 15-20g - Biotério do Departamento de Ciências da Saúde da Comunidade da Universidade da California, Los Angeles (UCLA), EUA;

- Ratos nude da linhagem NIH-Whn, Peso corpóreo 200-300g - Biotério da Faculdade de Ciências Farmacêuticas e Instituto de Química - USP, Brasil.

Todos os procedimentos realizados no Brasil obtiveram aprovação do Comitê de Ética do IPEN/CNEN-SP (Parecer no 88/11). Os procedimentos realizados nos EUA, foram aprovados pelo Comitê de Ética da Universidade de Los Angeles, Califórnia.

\subsection{Métodos}

\subsubsection{Marcação dos Conjugados Peptídicos GX1 e RGD-GX1 com Tecnécio-} $99 \mathrm{~m}$

O radioisótopo tecnécio-99m foi eluído de um gerador molibdênio99/tecnécio-99m ( $\left.{ }^{99} \mathrm{Mo} / 99 \mathrm{mTC}\right)$, em solução de cloreto de sódio $0,9 \%$ na forma de pertecnetato de sódio $\left(\mathrm{Na}^{99 \mathrm{~m}} \mathrm{TcO}_{4}\right)$.

Os sais dos conjugados peptídicos foram diluídos em água estéril na concentração de 774,9 $\mu \mathrm{M}$ (GX1) e 569,5 $\mu \mathrm{M}$ (RGD-GX1). 
A radiomarcação dos conjugados foi realizada seguindo-se o protocolo de Wang, Liu e Hnatowich (2006) e já utilizado anteriormente pelo nosso grupo (FAINTUCH e col., 2005, FAINTUCH e col., 2008, TEODORO e col., 2011).

Em um frasco de reação foram pesados $20 \mathrm{mg}$ de tricina e $5 \mathrm{mg}$ de ácido etieleno-N',N'-diaminodiacético (EDDA) e dissolvidos em $500 \mu \mathrm{L}$ de uma solução tampão fosfato $0,1 \mathrm{~N}(\mathrm{pH}=7,4)$, previamente nitrogenada. $\mathrm{Em}$ seguida, adicionou-se $10 \mu \mathrm{L}$ da solução-mãe do conjugado HYNIC-PEG4-c(GX1) ou HYNIC-E-[c(RGDfk)-c(GX1)], 8,9 mM de uma solução de cloreto estanoso $\left(\mathrm{SnCl}_{2} .2 \mathrm{H}_{2} \mathrm{O}\right)$ em ácido clorídrico $(\mathrm{HCl})(0,1 \mathrm{~N})$, previamente nitrogenada e $500 \mu \mathrm{L}$ de pertecnetato de sódio $\left({ }^{99 \mathrm{~m}_{\mathrm{CO}}}{ }^{-}\right)$com atividade variando entre 74 a $1850 \mathrm{MBq}$. A mistura foi agitada e aquecida durante 20 minutos à temperatura de $100{ }^{\circ} \mathrm{C}$. Após resfriamento, o volume foi completado para $1,5 \mathrm{~mL}$ com solução de cloreto de sódio ( $\mathrm{NaCl}$ ) 0,9\%, previamente nitrogenada.

\subsubsection{Avaliação radioquímica dos conjugados radiomarcados}

A avaliação radioquímica foi realizada por Cromatografia de Camada Delgada ascendente em fitas de sílica gel (ITLC-SG) usando dois sistemas de solventes: metiletilcetona e acetonitrila $50 \%$. O cálculo radioquímico foi determinado em porcentagem da atividade de cada espécie radioquímica em relação a atividade total da fita, sempre de acordo com o fator de retenção $\left(R_{f}\right)$ correspondente.

A avaliação radioquímica também foi realizada por Cromatografia Líquida de Alta Eficiência (CLAE) usando uma coluna $\mathrm{C} 18$ de fase reversa com fluxo de $1 \mathrm{~mL} / \mathrm{min}$. O sistema de solventes no CLAE consistiu em água contendo 0,1\% de ácido trifluoracético - TFA (solvente A) e acetonitrila contendo 0,1\% de ácido trifluoracético - TFA (solvente B). O sistema de gradientes começou com uma composição de solventes de $95 \%$ de $A$ e $5 \%$ de $B$ e seguiu um gradiente linear de $30 \%$ de $A$ e $70 \%$ de $B$ de 0 a 25 minutos e $5 \%$ de $A$ e $95 \%$ de $B$ dos 25 aos 30 minutos. Também foi analisado o nível de impurezas no UV, no comprimento de $280 \mathrm{~nm}$ dos compostos peptídicos antes e depois da radiomarcação. 


\subsubsection{Análise da estabilidade dos produtos radiomarcados em soro humano}

Para obtenção do soro humano, foi coletado $10 \mathrm{~mL}$ de sangue sem coagulante de doador sadio. Após centrifugação por 10 minutos, para separação do coágulo, foi coletado $1 \mathrm{~mL}$ de soro e incubado com $100 \mu \mathrm{L}$ do produto radiomarcado a $37^{\circ} \mathrm{C}$ por 1,2 e $4 \mathrm{~h}$. Decorrido o tempo, foi coletada uma alíquota da mistura e adicionada uma solução de cloreto de sódio 0,9\% (1:1). As amostras foram analisadas em CLAE, utilizando o mesmo sistema de solventes descrito anteriormente no item 3.2.2.

\subsubsection{Determinação da lipofilicidade dos produtos radiomarcados}

A determinação da lipofilicidade dos radiomarcados foi realizada por meio do teste de coeficiente de partição $(\mathrm{P})$, utilizando n-octanol e água como solventes (Okarvi, 2004).

Uma alíquota de $100 \mu \mathrm{L}$ do complexo radiomarcado foi adicionada a uma mistura de $6 \mathrm{~mL}$ de n-octanol e água (1:1). A mistura foi homogeneizada e, com a finalidade de se separar as duas fases (aquosa e orgânica), centrifugado à $5000 x g$ durante 3 min à temperatura ambiente. Após a centrifugação e repouso, foram coletadas amostras de $100 \mu \mathrm{L}$ de cada fase em triplicata e colocadas em tubos para a determinação da atividade. O coeficiente de partição $(P)$ foi calculado de acordo com a equação abaixo e expresso em $\log P$.

$$
\log P=\frac{c p m(\text { octanol })}{c p m(\text { água })}
$$

onde: $\mathrm{cpm}=$ contagem por minuto . 


\subsubsection{Determinação da ligação às proteínas plasmáticas}

Os estudos in vitro de ligação às proteínas plasmáticas para os complexos radiomarcados foram realizados pelo método de precipitação (VanlićRazumenic, Petrovic and Gorkic, 1984). Amostras de aproximadamente 0,5 mL de sangue foram coletadas de camundongos sadios da linhagem Balb/c (anestesiados), 5, 60 e 120 minutos após a administração da droga. As alíquotas foram transferidas para tubos de fundo cônico, previamente heparinizados, e o experimento realizado em triplicata. As amostras de sangue foram centrifugadas por 15 minutos $(1,877 \mathrm{xg})$ a temperatura ambiente, permitindo assim a coleta do plasma. À $200 \mu \mathrm{L}$ do plasma adicionou-se $1 \mathrm{~mL}$ de ácido tricloroacético (TCA $10 \%)$. Os tubos foram centrifugados por 15 minutos $(2,815 \mathrm{xg})$ a temperatura de $4^{\circ} \mathrm{C}$. O sobrenadante foi descartado e o procedimento repetido por mais duas vezes. Após a última centrifugação, o precipitado foi reservado e a radioatividade mensurada no contador tipo poço NAI (TI) com o padrão (com total), que corresponde ao plasma intacto $(200 \mu \mathrm{L})$. A porcentagem de ligação às proteínas plasmáticas de cada conjugado radiomarcado foi calculada de acordo com a equação abaixo.

$$
\% \text { Ligação às proteínas plasmáticas }=\frac{c p m_{\text {precipitado }}}{c p m_{\text {total }}} \times 100
$$

onde: $\mathrm{cpm}_{\text {total }}=\mathrm{cpm}_{\text {plasma intacto }}$

\subsubsection{Biodistribuição em camundongos sadios}

Foram utilizados camundongos da linhagem Balb/c em grupos de 6 animais por tempo, para cada produto, totalizando 84 animais. A água e a alimentação estiveram disponíveis durante todo o período de experimentação.

Foram injetados $50 \mu \mathrm{L}$ de uma solução (5,16 $\mu \mathrm{M}$ 99mTc-HYNIC-PEG4$c(G X 1)$ e 3,79 $\mu M$ 99mTc-HYNIC-E-[c(RGDfk)-c(GX1)]) da droga na veia caudal dos camundongos sadios com atividade de 37-74 MBq. Os estudos foram 
conduzidos após o sacrifício dos animais aos $5 \mathrm{~min}, 30 \mathrm{~min}, 1 \mathrm{~h}, 2 \mathrm{~h}, 4 \mathrm{~h}, 6 \mathrm{~h}, 24 \mathrm{~h}$ após administração das drogas.

Tecidos e órgãos (sangue, coração, pulmão, rins, baço, estômago, pâncreas, fígado, intestino grosso e delgado, músculo, osso e cérebro), de todos os camundongos foram retirados, pesados e colocados em tubos para que a sua atividade radioativa fosse medida em contador do tipo poço de $\mathrm{Nal}(\mathrm{TI})$. A cauda foi retirada para correção da atividade administrada.

O padrão foi preparado com o mesmo volume de droga administrada nos camundongos, e colocado para a contagem da atividade no mesmo momento em que a atividade dos órgãos foi mensurada. As porcentagens de dose injetada por órgão (\%Dl/órgão) e por grama (\%Dl/g), de todos os órgãos avaliados, foram calculadas considerando o padrão como $100 \%$ da dose administrada aos camundongos, e os experimentos conduzidos considerando um número amostral de seis animais por tempo estudado.

A porcentagem de dose injetada no sangue total foi calculada para uma volemia de $7 \%$ do peso corpóreo do animal multiplicado pela \%DI/mL de cada tempo estudado. A porcentagem de dose injetada (\%DI) do músculo e do osso total foi calculada assumindo, respectivamente, um volume de $40 \%$ e $10 \%$ do peso corpóreo respectivamente.

\subsubsection{Cultivo celular}

Células endoteliais humanas de cordão umbilical (HUVEC) foram cultivadas em meio de cultura RPMI suplementado com soro fetal bovino (SFB) a $10 \%$, e com $100 \mathrm{U} / \mathrm{mL}$ de penicilina e $50 \mathrm{mg} / \mathrm{mL}$ de estreptomicina.

Células de glioblastoma humano U87MG e T98G, para estudos in vitro e inoculação em animais, foram cultivadas em meio de cultura DME/F12, todos suplementados com soro fetal bovino (SFB) a 10\%, e com $100 \mathrm{U} / \mathrm{mL}$ de penicilina e $50 \mathrm{mg} / \mathrm{mL}$ de estreptomicina.

Células de glioblastoma humano U87MG, U87MG-IDH1WT e U87MG$\mathrm{IDH} 1^{\mathrm{R} 132}$, para estudos de inoculação intracranial em animais e aquisição de 
imagem por ressonância magnética, foram cultivadas da mesma maneira, apenas com acréscimo de $2 \mathrm{mM}$ glutamina e $100 \mathrm{U} / \mathrm{mL}$ de penicilina e estreptomicina.

O cultivo foi realizado em garrafas próprias para o cultivo celular sob atmosfera de $5 \% \mathrm{CO}_{2}$ a $37^{\circ} \mathrm{C}$. Após atingirem a confluência, as células tumorigênicas foram então tripsinizadas, centrifugadas (5 min a 100xg) e ressuspendidas em tampão fosfato-salina (PBS, $\mathrm{pH}=7,4$ ).

Para a realização dos ensaios in vitro com as células HUVEC, as células foram ressuspensas em meio de cultura contendo $1 \%$ de SFB e então distribuídas em placas de doze poços a uma concentração final de $5 \times 10^{5}$ células/poço e o volume final para as placas de doze poços foi de $1 \mathrm{~mL}$. Para a realização dos ensaios in vitro com as células tumorais, as células após serem ressuspensas, foram distribuídas em placas de seis poços a uma concentração final de $1 \times 10^{6}$ células/poço. $O$ volume final para as placas de seis poços foi de 1,5 $\mathrm{mL}$. Após 24 horas de incubação, as placas foram disponibilizadas para os ensaios.

\subsubsection{Ensaios in vitro de ligação às células}

Os ensaios de ligação às células das moléculas ${ }^{99 m}{ }^{\mathrm{Tc}}$-HYNIC-PEG4$c(G X 1)$ e ${ }^{99 m} T c-H Y N I C-E-[c(R G D f k)-c(G X 1)]$ foram realizados utilizando-se o protocolo de Oliveira e col. (2012). Foi realizada uma lavagem com meio de cultura gelado.

Para a determinação de ligação total do radiotraçador às células endoteliais adicionou-se aos poços $900 \mu \mathrm{L}$ de meio de cultura e $100 \mu \mathrm{L}$ do produto radiomarcado marcado $(1,35 \mathrm{nM})$. Para a determinação da ligação não específica, $800 \mu \mathrm{L}$ de meio de cultura, $100 \mu \mathrm{L}$ de produto não-marcado $(15 \mu \mathrm{M}) \mathrm{e}$ $100 \mu \mathrm{L}$ de do radiotraçador foram adicionados aos poços.

Para a determinação de ligação total do radiotraçador às células tumorais adicionou-se aos poços $1400 \mu \mathrm{L}$ de meio de cultura e $100 \mu \mathrm{L}$ do produto radiomarcado marcado (1,35 nM). Para a determinação da ligação não específica, 
$1300 \mu \mathrm{L}$ de meio de cultura, $100 \mu \mathrm{L}$ de produto não-marcado $(15 \mu \mathrm{M})$ e $100 \mu \mathrm{L}$ de do radiotraçador foram adicionados aos poços.

As placas foram então incubadas por 5, 30, 60, 90 e 120 minutos a $37^{\circ} \mathrm{C}$. O sobrenadante foi coletado em tubos para contagem radioativa e as células lavadas duas vezes com solução de tampão fosfato salina (PBS) gelado. A atividade associada à superfície celular foi removida por uma lavagem ácida de 5 minutos com solução tampão glicina (50 mM glicina e $1 \mathrm{M} \mathrm{NaCl}, \mathrm{pH}=2,8)$ à temperatura ambiente, e coletado para a contagem da atividade. Finalmente, a quantidade do radiotraçador internalizado foi obtido pela lise das células com $\mathrm{NaOH}(1 \mathrm{~N})$, e a atividade também mensurada em contador do tipo poço de $\operatorname{Nal}(\mathrm{TI})$.

A ligação total específica foi determinada a partir da subtração da ligação total pela ligação total não específica.

\subsubsection{Inoculação das células tumorais nos animais}

\subsubsection{Inoculação subcutânea em camundongos imunodeprimidos}

As células de glioblastoma $\left(5 \times 10^{6}\right.$ células $\left./ 0,1 \mathrm{~mL}\right)$ da linhagem U87MG e T98G foram injetadas subcutaneamente no dorso superior direito dos camundongos SCID (severe combined immunodeficiency) em grupos de 5 animais. O acompanhamento do crescimento tumoral foi realizado a cada três dias e os estudos realizados quando os tumores sólidos estivessem visíveis, palpáveis e atingissem um tamanho de aproximadamente $1 \mathrm{~cm}$ de diâmetro. $\mathrm{O}$ tempo estimado de desenvolvimento do tumor nos animais ficou compreendido entre 4 semanas para as células U87MG e de 10 semanas para as células T98G. 


\subsubsection{Inoculação intracranial em camundongos imunodeprimidos}

Esse procedimento foi aprovado pelo Comitê de Ética da Universidade da Califórnia, Los Angeles (UCLA), e realizado no biotério do Departamento de Ciências da Saúde da Comunidade da mesma universidade. Um total de 12 camundongos NOD/SCID (non-obese diabetic - severe combined immunodeficiency) foram usados nesse estudo. Neste estudo além das células de glioblastoma U87MG foram utilizadas células U87MG com mutação na enzima IDH1 do tipo selvagem (IDH1 ${ }^{\mathrm{WT}}$ ) e com uma mutação conhecida na arginina do resíduo 132 (IDH1 ${ }^{\text {R132}) . ~}$

Os animais foram anestesiados com gás isofluorano $(5 \%)$ e acomodados em uma superfície aquecida. Após o corte dos pelos na região da cabeça, a pele da incisão foi desinfetada com uma solução de iodo e foi administrado subcutaneamente uma solução analgésica de Carprofeno $(5 \mathrm{mg} / \mathrm{kg})$, e a área da cabeça e do pescoço foram cobertas com um pano estéril. Os olhos foram protegidos com pomada oftalmológica. Foi feita uma incisão de $2 \mathrm{~cm}$ e 0 periósteo foi raspado para longe da região de interesse. $O$ tecido do periósteo foi removido com um cotonete estéril e solução salina. $O$ aparato estereotáxico foi usado para calcular as coordenadas $(2 \mathrm{~mm}$ lateral, $0,5 \mathrm{~mm}$ anterior e 3,3 para baixo a partir do nível bregma-lâmbda) para furar um buraco para permitir a injeção dentro do striatum. Uma broca de dentista foi usada para abrir o buraco da injeção. Uma seringa Hamilton de $10 \mu \mathrm{L}$ equipada com uma agulha de calibre 26 , que estava fixada ao quadro estereotáxico, foi carregada com as células apropriadas. Um total de $2,5 \mu \mathrm{L}$ da linhagem celular (U87MG, U87MG-IDH1 ${ }^{\mathrm{WT}}$ e U87MG-IDH1 ${ }^{\text {R132, }}$, aproximadamente 100.000 células/ $\mu \mathrm{L}$ ) foi injetado estereotaxicamente nas coordenadas acima na velocidade de $1 \mu \mathrm{L} /$ minuto. A agulha foi deixada no lugar por 4 minutos e então foi removida devagar. Em seguida, o plano ósseo foi recomposto com cera óssea e a pele fechada usando suturas de nylon. Os animais foram removidos do aparato estereotáxico e deixados em recuperação. Os animais foram retornados para as gaiolas estéreis depois de total recuperação. As suturas foram removidas de 7 a 10 dias após a cirurgia. Os animais foram colocados em gaiolas autoclavadas com água 
esterilizada e maravalhas e ração irradiadas, com umidade de 30-70\% e ciclos de luz de $12 \mathrm{~h}$.

\subsubsection{Inoculação intracranial em ratos imunodeprimidos}

Esse procedimento foi realizado no biotério do IPEN com colaboração do Instituto de Pesquisa do Hospital Sírio Libanês. Um total de 10 ratos nude foram usados nesse estudo, sendo que 1 animal não foi inoculado para atuar como controle. As células tumorais U87MG foram utilizadas, pois apresentaram melhores resultados que a T98G nos estudos anteriores.

Os animais foram anestesiados com uma mistura composta de Cetamina (57\%), Xilazina (21,5\%) e Morfina (21,5\%). A inoculação foi conduzida como já descrita no item 3.2.9.2 com pequenas modificações.

Foi administrado subcutaneamente uma solução analgésica de Lidocaína $2 \%$ após a incisão. As coordenadas utilizadas foram $3 \mathrm{~mm}$ lateral e 4,5 de profundidade a partir do nível bregma-lâmbda. Foi injetado um total de $5 \mu \mathrm{L}$ da linhagem celular U87MG (aproximadamente 80.000 células/ $\mu \mathrm{L}$ ).

Em dois animais foi feito um segundo furo, seguindo as mesmas coordenadas, do lado direito, no qual foi inoculado $5 \mu \mathrm{L}$ de meio de cultura DMEM, que será usado como controle.

Analgésico pós-cirúrgico (20 mg/kg de cetoprofeno) foi administrado diariamente por 3 dias.

\subsubsection{Biodistribuição em camundongos portadores de tumor}

Os estudos de biodistribuição em animais com inoculação de células tumorais no dorso, foram conduzidos conforme descrito no item 3.2.6. Este estudo foi conduzido no tempo de $1 \mathrm{~h}$ p.i. para ambos os traçadores e no tempo de $2 \mathrm{~h}$ p.i. para o traçador RGD-GX1. 
Estudos de bloqueio tumoral foram realizados com a finalidade de avaliar a especificidade dos radiomarcados. Para esta avaliação, os camundongos receberam concomitantemente a mesma dose dos conjugados radiomarcados e uma dose de $0,05 \mathrm{~mL}$ dos respectivos conjugados peptídicos frios.

\subsubsection{Conjugação dos peptídeos com as nanopartículas magnéticas}

Os conjugados peptídicos HYNIC-PEG4-c(GX1) e HYNIC-E-[c(RGDfk)$c(G \times 1)]$ foram conjugados covalentemente, via glicerina, às nanopartículas magnéticas (NPM) compostas de partículas de óxido de ferro e dextran, e preparadas para injeção intravenosa na veia caudal dos animais. As partículas foram caracterizadas no Instituto Jane e Terry Semel de Neurociência e Comportamento Humano, na escola de Medicina David Geffen, na UCLA, Califórnia, EUA usando microscopia eletrônica de transmissão com espectroscopia de energia dispersiva de raios X (EDAX; Philips, Alemanha), microscopia de força atômica, assim como potencial zeta (Zetasizer 300HSA, Inglaterra).

\subsubsection{Aquisição de imagens}

\subsubsection{Gama-câmara}

Os animais com tumores subcutâneos foram anestesiados com $40 \mu \mathrm{L}$ de uretana 16,7\%. Imagens planares em gama-câmara foram obtidas após 1 e 2 horas da administração dos radiotraçadores para animais bloqueados e nãobloqueados. 


\subsubsection{Ressonância Magnética}

A aquisição das imagens de ressonância magnética foram realizadas em um equipamento 7 Tesla Bruker Biospec (EUA) de $30 \mathrm{~cm}$ no Centro de Mapeamento Cerebral Ahmanson-Lovelace na UCLA, com uma bobina de radiofrequência personalizada de $2,2 \mathrm{~cm}$. As imagens foram feitas nos camundongos de 14 a 21 dias após a injeção das células de glioblastoma por cirurgia intracranial. Antes das imagens, os animais foram anestesiados com isoflurano (4\% indução e manutenção com 1,5\%). Durante as imagens, a respiração foi monitorada e os níveis de isoflurano foram ajustados se a respiração fosse $<20$ ou $>60$ por minuto. Os camundongos foram mantidos aquecidos com água a $37^{\circ} \mathrm{C}$ circulante através de uma bomba de água. Foram adquiridas imagens preliminares antes da injeção de 80 à $100 \mu \mathrm{L}$ do contraste conjugado aos peptídeos e após, nos tempos de 15min, 30min, 1h, 1h30 e $2 \mathrm{~h}$.

Para quantificar no tempo de relaxação transversal T2 dos tumores, foi usada a sequência MSME (multislice multi-echo) com os parâmetros: tempo de repetição (TR)/tempo de eco $(T E)=2000 / 7,26-101,64 \mathrm{~ms}, 14$ ecos, resolução no plano $78 \mu \mathrm{m}^{2}$, fatias com $1 \mathrm{~mm}$ de espessura. Para as imagens anatômicas foi usada a sequência RARE (Rapid Acquisition with Relaxation Enhancement). As imagens de substração, que consistem na substração da imagem prévia à injeção da imagem de determinado tempo após a injeção, e a quantificação em T2 com média e desvio padrão dos tumores foram processadas usando o software ImageJ com o recurso da calculadora para Análises de Imagens Ressonância Magnética.

Os animais foram eutanasiados após a conclusão das imagens por deslocamento cervical.

\subsubsection{SPECT/CT}

As imagens foram feitas nos ratos 16 dias após a injeção das células de glioblastoma por cirurgia intracranial. Os animais foram anestesiados com uma mistura de $3 \%$ de isofluorano em oxigênio. O radiotraçador RGD-GX1, que obteve 
os melhores resultados nos ensaios anteirores, foi injetado na veia peniana $(100 \mu \mathrm{L})$ e após 1 hora, imagens foram adquiridas no aparelho microSPECT/PET/CT (Gamma Medica-Ideas, Sherbrooke, Canadá) do Centro de Medicina Nuclear do Hospital das Clínicas por 30 minutos, para animais bloqueados e não-bloqueados. Ambas as imagens foram exportadas no padrão DICOM e observadas no software Pmod.

\subsubsection{Teste do Campo Aberto}

Estes estudos foram realizados com os animais inoculados por cirugia intracranial e após a aquisição de imagem em SPECT/CT.

O teste da arena foi utilizado para avaliar diversos parâmetros de comportamento motor. Foi utilizada uma caixa retangular de material plástico resistente com dimensões $40 \mathrm{~cm} \times 40 \mathrm{~cm} \times 60 \mathrm{~cm}$, onde os animais $(n=6)$ foram observados por um período de 5 minutos. Foram utilizados parâmetros tradicionais de atividade motora e categorias tidas como novas para medidas comportamentais dos animais (Anseloni e Brandão, 1997, Gilad e Shiller, 1989).

A avaliação motora avaliou a distância percorrida total (distância total que o animal percorreu durante o teste), a distância percorrida no centro (distância que o animal percorreu no centro da arena durante o teste), a distância percorrida na periferia (distância que o animal percorreu na periferia da arena durante o teste) e o levantamento (postura bípede em que o animal apoia as patas posteriores no assoalho da arena, permanecendo ereto ou completamente arqueado).

A avaliação comportamental avaliou o Levantamento (Rearing), que é a subida total ou parcial pelos membros com ou sem apoio das paredes do campo aberto; Esticamento, caracterizado pela postura exploratória do animal ao se esticar e, em seguida, retornar à posição inicial, sem se movimentar para frente; Autolimpeza, sequência de autolimpeza característica da espécie, iniciando pelo focinho, indo às orelhas e terminando na limpeza de todo o corpo; Congelamento, paralisação completa do animal, exceto pelo movimento realizado para a 
respiração; e Farejamento, que consiste em uma postura exploratória em que o animal fareja o ambiente.

\subsubsection{Perfusão e Análise histológica}

Para a perfusão, os animais foram profundamente anestesiados com Tiopental na proporção $40 \mathrm{mg} / \mathrm{kg}$ de peso corpóreo e perfundidos por via transcardíaca com $150 \mathrm{~mL}$ de uma solução salina 0,9\%, seguidos de $500 \mathrm{~mL}$ de uma solução fixadora de paraformaldeído a $4 \%$ diluído em tampão fosfato de sódio $0,1 \mathrm{M}(\mathrm{pH} 7,4)$. Os encéfalos foram removidos e transferidos para uma solução contendo sacarose $20 \%$ em paraformaldeído a $4 \%$ diluído em tampão fosfato de sódio $0,1 \mathrm{M}$.

Foram realizados cortes com espessura de $40 \mu \mathrm{m}$, os quais foram fixados em lâminas de vidro. Os cortes foram avaliados quanto à posição da injeção estereotáxica por coloração de Nissl.

\subsubsection{Análise estatística}

A análise estatística foi realizada usando o teste $t$ de student para dados não-pareados, para determinar diferenças significativas entre os grupos nos estudos acima. Os resultados foram apresentados em média \pm DP e as diferenças no nível de confiança de 95\% ( $p<0,05)$ foram consideradas significantes. 


\section{RESULTADOS}

\subsection{Síntese dos conjugados peptídicos}

O conjugado peptídico HYNIC-PEG4-GX1 (PM = 1290,4) foi obtido comercialmente com pureza de $96 \%$ e o conjugado peptídico HYNIC-E[c(RGDfk)-c(GX1)] (PM = 1755,9) com pureza de 91,1\%.

\subsection{Radiomarcação e avaliação radioquímica dos conjugados radiomarcados}

A pureza radioquímica obtida por cromatografia de camada delgada demonstrou que o produto radiomarcado e a impureza ${ }^{99 \mathrm{~m}} \mathrm{TcO}_{2}$ ficam no início da fita $\left(\mathrm{R}_{\mathrm{f}}=0\right)$ quando metiletilcetona foi utilizado como solvente. Com acetonitrila $50 \%$, o produto se desloca $\left(\mathrm{R}_{\mathrm{f}}=1\right)$ juntamente com a impureza de ${ }^{99 \mathrm{~m}} \mathrm{Tc}$ livre na forma de pertecnetato de sódio $\left(\mathrm{Na}^{99 \mathrm{~m}} \mathrm{TcO}_{4}\right)$.

Os valores da pureza radioquímica obtidos para o ${ }^{99 m} \mathrm{mc}-\mathrm{HYNIC}_{-} \mathrm{PEG}_{4-}$ $c(G X 1)$ foi de $98,83 \pm 0,87 \%$ e para o ${ }^{99 m T c-H Y N I C-E-[c(R G D f k)-c(G X 1)] ~ f o i ~ d e ~}$ $96,06 \pm 1,83 \%(n=5)$. Os resultados obtidos por CLAE com tempo de retenção ( $t_{R}$ ) de 7,757 min e 8,120 min para os peptídeos frios e 8,552 min e 9,055 min, para os radiomarcados, respectivamente, confirmaram os valores encontrados através da cromatografia de camada delgada, resultando em uma única espécie radioquímica principal para cada conjugado radiomarcado (FIG. 10 e FIG. 11) Aos

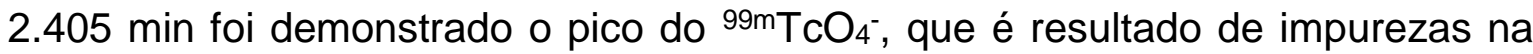
radiomarcação, porém os peptídeos radiomarcados apresentaram nenhuma ou mínima presença deste composto. 

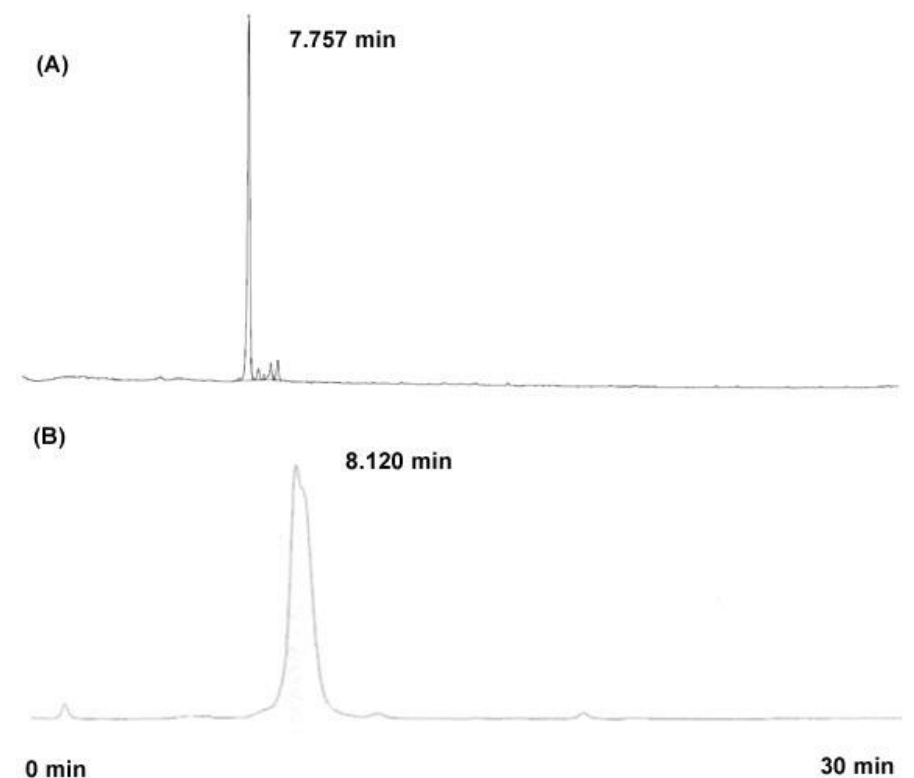

FIGURA 10 - Cromatograma dos conjugados peptídicos (A) HYNIC-PEG ${ }_{4}-\mathrm{C}(\mathrm{GX} 1)$ e (B) HYNIC-E-[c(RGDfk)-c(GX1)]

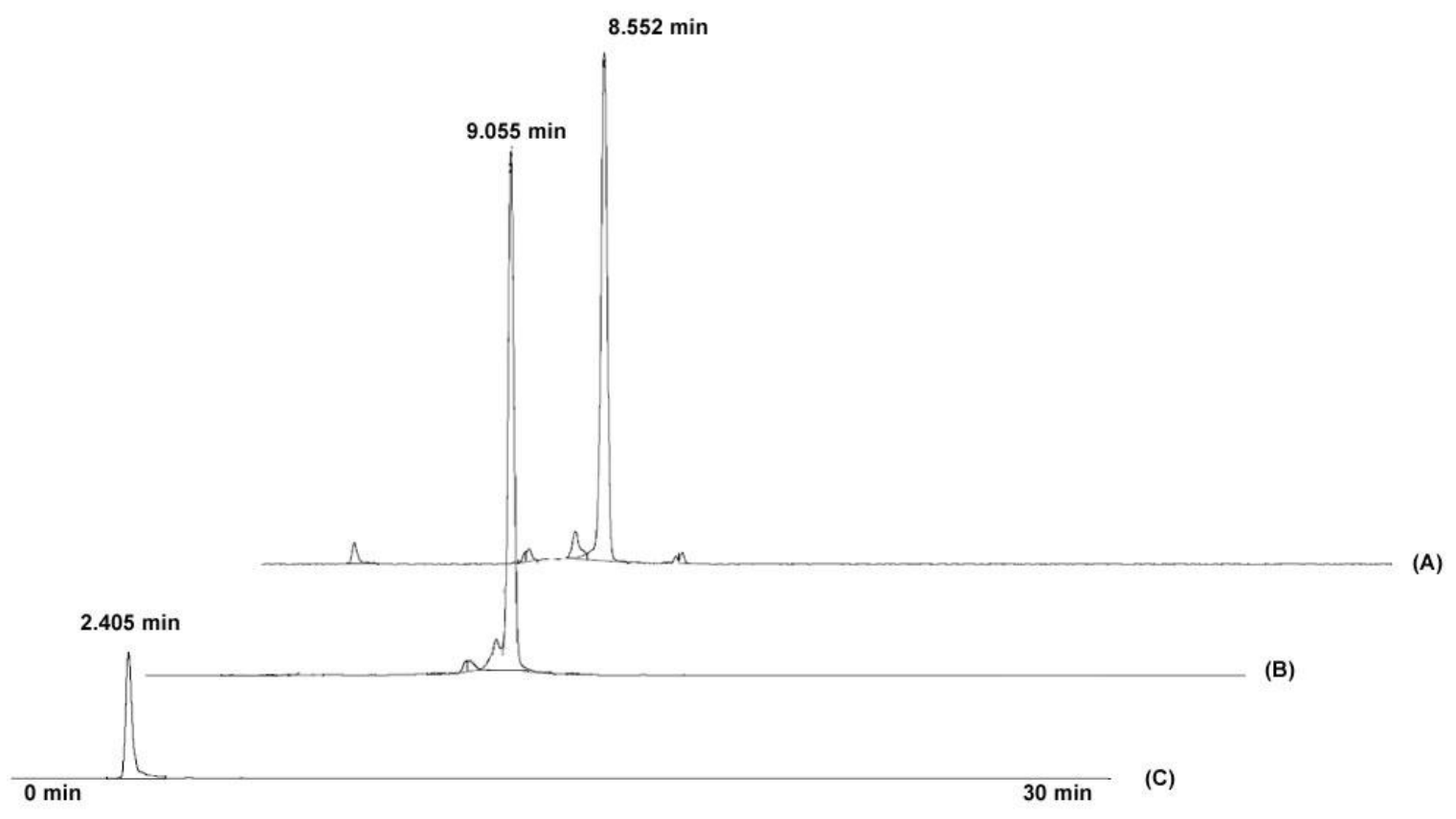

FIGURA 11- Radiocromatograma do (A) ${ }^{99 m} \mathrm{TC}-H Y N I C-P E G 4-C(G X 1)$; (B) ${ }^{99 m}$ TC-HYNIC-E[c(RGDfk)-c(GX1)] e (C) ${ }^{99 \mathrm{~m}^{-} \mathrm{TO}_{4}^{-}}$ 
Os cromatogramas dos conjugados radiomarcados mostram os picos dos conjugados peptídicos próximo ao tempo de retenção encontrado no perfil

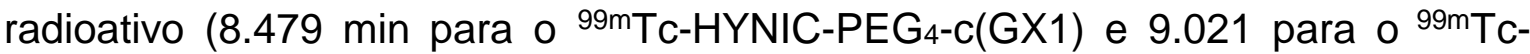
HYNIC-E-[c(RGDfk)-c(GX1)]), além de outros picos provenientes das outras substâncias utilizadas durante a radiomarcação, como tampão fosfato, cloreto estanoso, tricina e EDDA (FIG. 12).

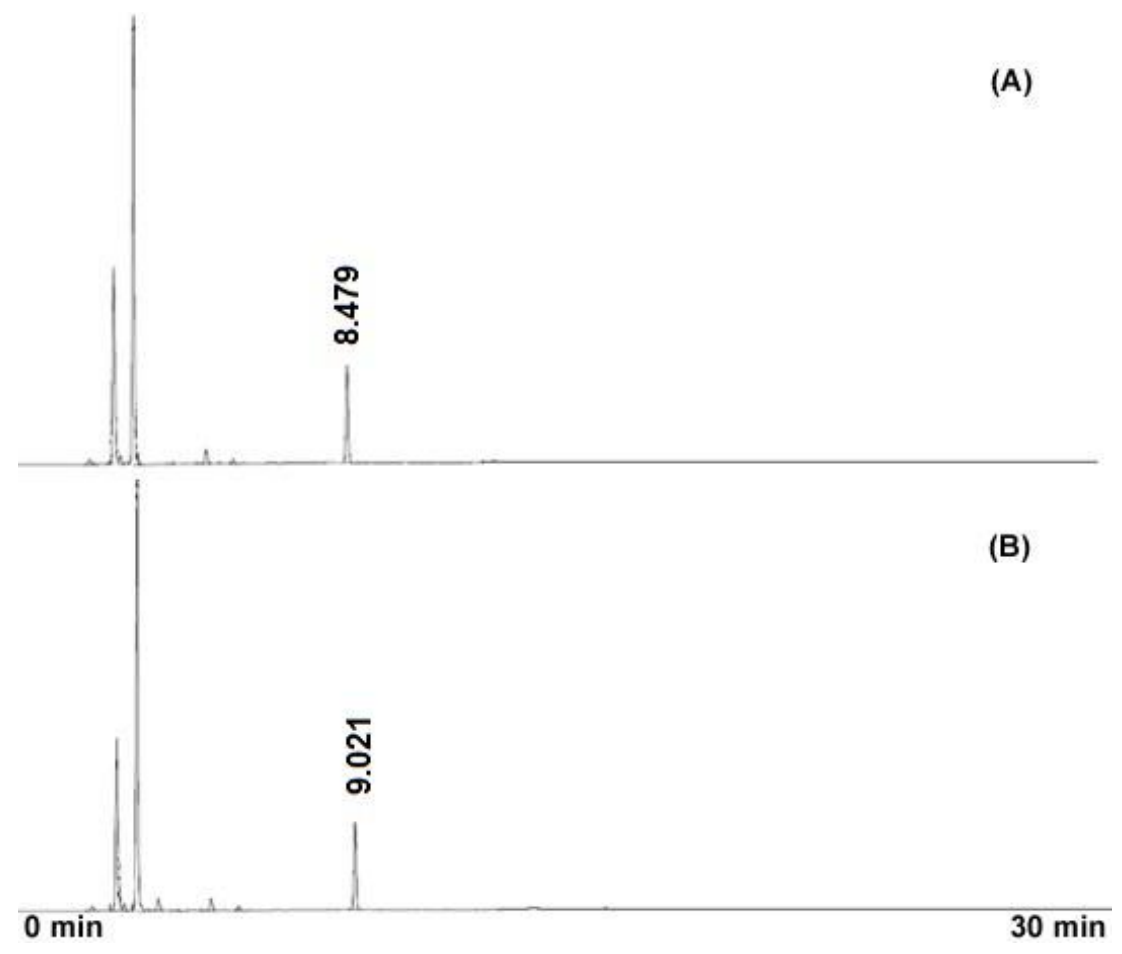

FIGURA 12 - Cromatograma dos conjugados peptídicos radiomarcados (A) ${ }^{99 \mathrm{~m} T C-}$ HYNIC-PEG ${ }_{4}-\mathrm{C}(\mathrm{GX} 1)$; (B) ${ }^{99 \mathrm{~m} T C-H Y N I C-E-[c(R G D f k)-c(G X 1)]}$ 


\subsection{Análise da estabilidade dos produtos radiomarcados em soro humano}

As análises de estabilidade em soro humano mostrou uma grande estabilidade para ambos os produtos (FIG. 13 e FIG. 14). Em todos os tempos analisados, não houve aumento no nível de impurezas, indicando a manutenção da molécula sem degradação.
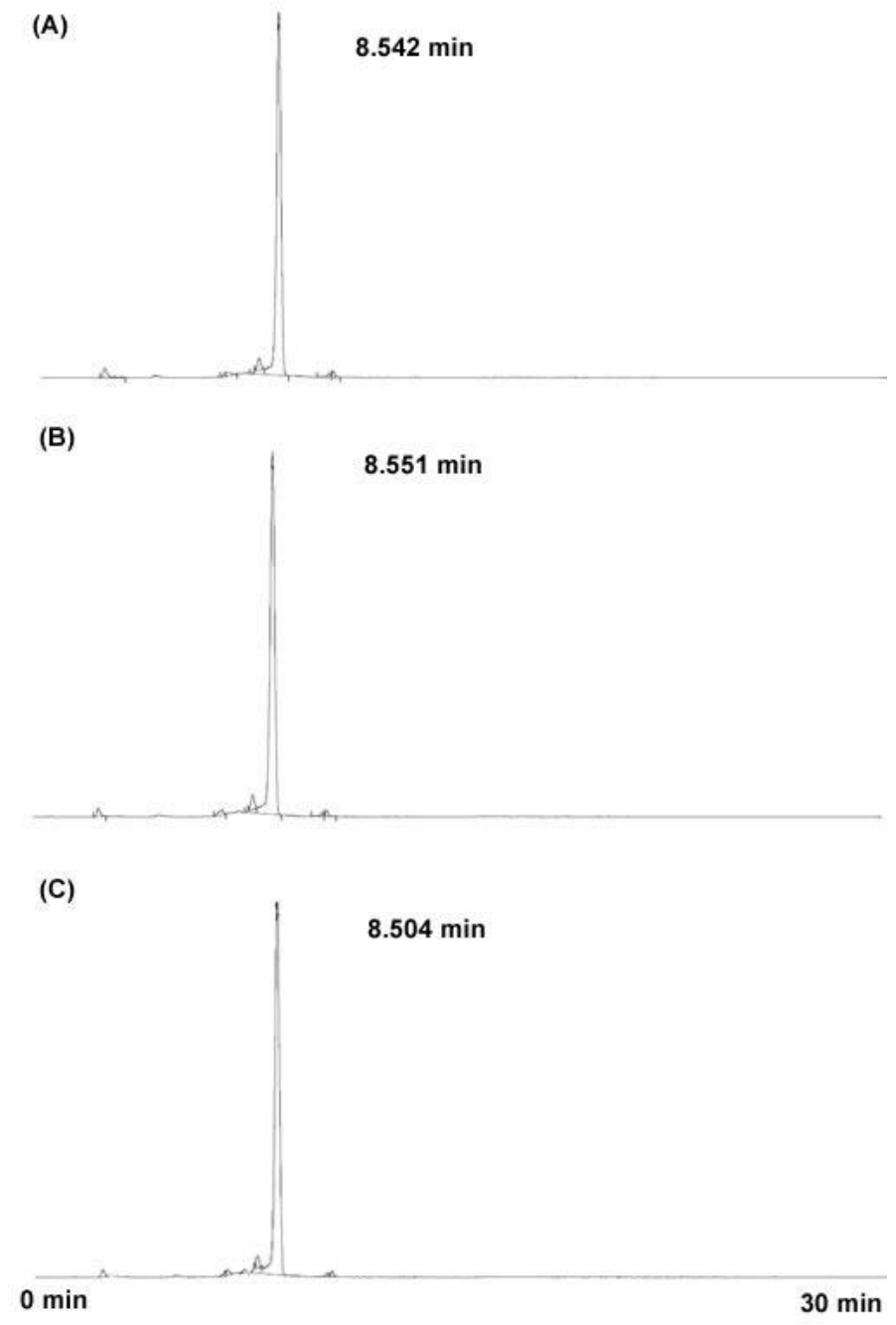

FIGURA 13 - Estabilidade em soro do ${ }^{99 m}$ Tc-HYNIC-PEG 4 -c(GX1) em (A)1h; (B) 2h e (C) $4 \mathrm{~h}$ 

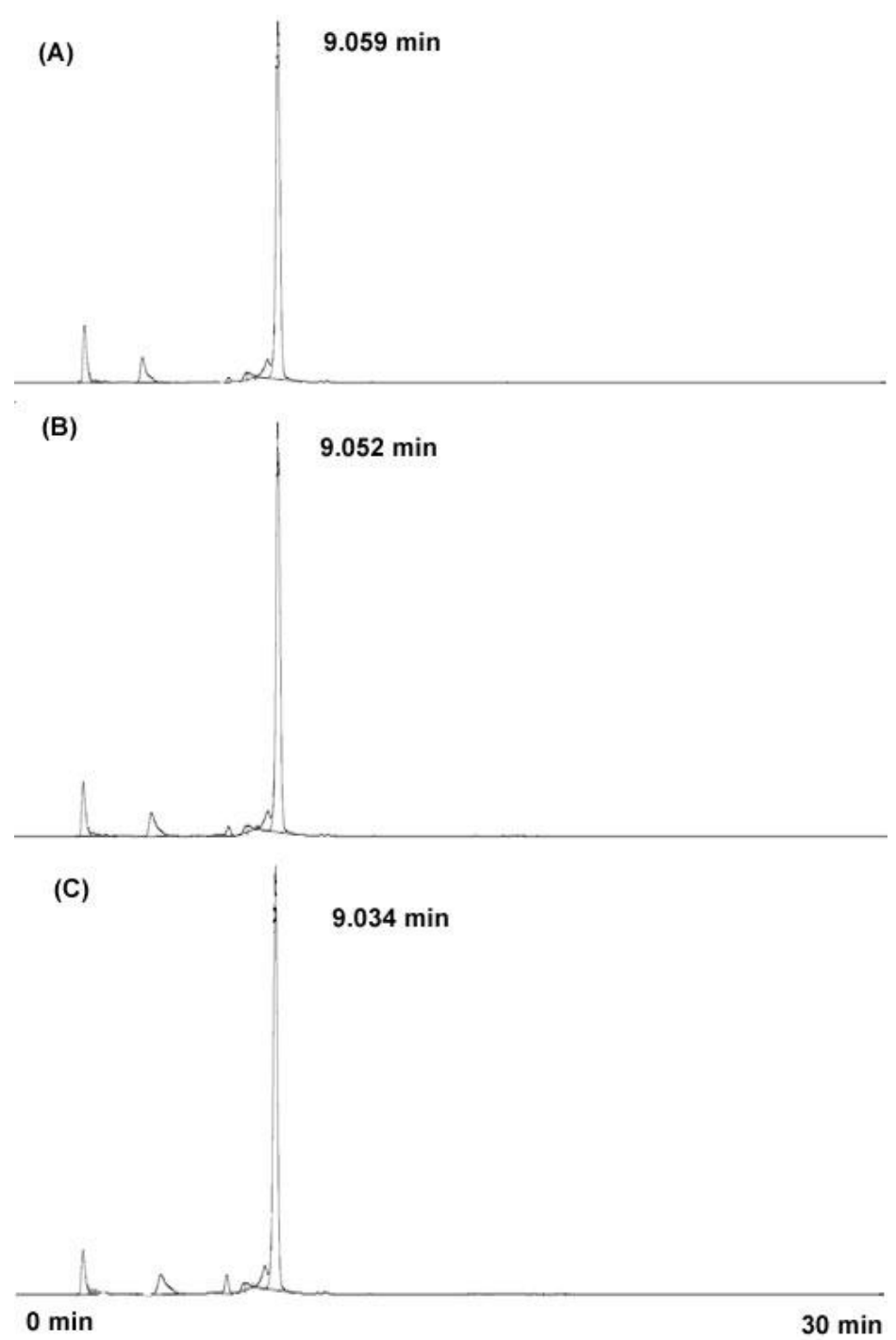

FIGURA 14 - Estabilidade em soro do ${ }^{99 m}$ Tc- HYNIC-E-[c(RGDfk)-c(GX1)] em (A)1h; (B) $2 \mathrm{~h}$ e $(\mathrm{C}) 4 \mathrm{~h}$

\subsection{Determinação da lipofilicidade dos produtos radiomarcados}

Os valores do coeficiente de partição dos radiotraçadores foram $\log P=-$ $2,51 \pm 0,04$ para o traçador $\mathrm{GX} 1$ e $\log P=-2,25 \pm 0,07$ para o traçador RGD-GX1, $n=3$, mostrando que houve diferença significativa entre eles $(p<0,05)$. Ambos encontram-se na faixa de hidrofilicidade, mas o radiotraçador $99 \mathrm{~m}$ Tc-HYNIC$\mathrm{PEG}_{4}-\mathrm{c}(\mathrm{GX1}$ ) é mais hidrofílico que o 99mTc-HYNIC-E-[c(RGDfk)-c(GX1)]. 


\subsection{Determinação da ligação às proteínas plasmáticas}

A ligação às proteínas plasmáticas revelou uma ligação crescente com o tempo para ambos os radiotraçadores, atingindo os valores às $2 \mathrm{~h}$ de 99,24 \pm 0,23\% para o ${ }^{99 m}$ Tc-HYNIC-PEG 4 -c(GX1) e 54,87 $\pm 5,49 \%$ para o ${ }^{99 m}$ Tc-HYNIC-E[c(RGDfk)-c(GX1)] (TAB. 1). Apesar dos altos valores, essa porcentagem representa somente $0,07 \pm 0,03 \%$ e $0,14 \pm 0,00 \%$, respectivamente, da dose injetada por $\mathrm{mL}$, demonstrando que a ligação às proteínas plasmáticas foi mínima (FIG. 15 e FIG. 16).

TABELA 1 -Ligação às proteínas plasmáticas do 99mTc-HYNIC-PEG4-C(GX1) e 99mTc-HYNIC-E-[c(RGDfk)-c(GX1)] em camundongos Balb/c sadios $(n=3)$

\begin{tabular}{ccccc}
\hline & & $\mathbf{5}$ $\mathbf{m i n}$ & $\mathbf{1 h}$ & $\mathbf{2 h}$ \\
\hline $\begin{array}{c}\text { \% de ligação às } \\
\text { proteínas }\end{array}$ & $G \times 1$ & $12,74 \pm 6,92$ & $17,62 \pm 2,15^{*}$ & $99,24 \pm 0,23^{*}$ \\
\hline
\end{tabular}

${ }^{*} p<0,05$ entre GX1 e RGD-GX1 no mesmo tempo e análise

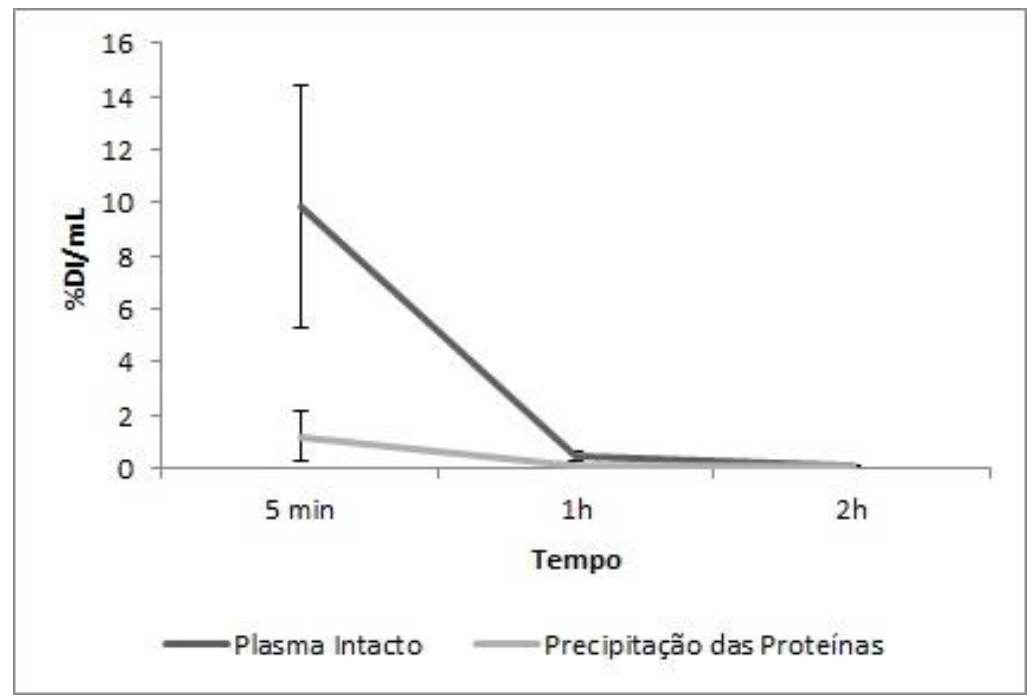

FIGURA 15 - Perfil de ligação do ${ }^{99 m}$ Tc-HYNIC-PEG 4 -C(GX1) ao plasma intacto e às proteínas plasmáticas em camundongos Balb/c sadios 


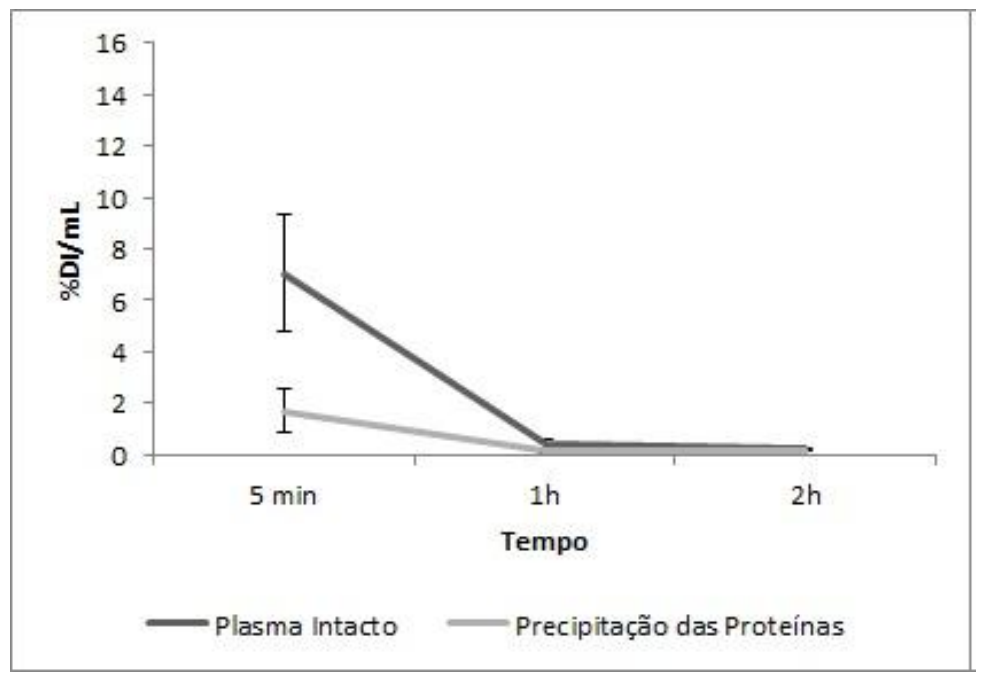

FIGURA 16 - Perfil de ligação do ${ }^{99 m}$ Tc-HYNIC-E-[c(RGDfk)-c(GX1)] ao plasma intacto e às proteínas plasmáticas em camundongos $B a l b / c$ sadios

\subsection{Biodistribuição em camundongos sadios}

Os resultados do estudo de biodistribuição para ambos radiotraçadores em animais Balb/c sadios estão demonstrados em porcentagem de dose injetada por grama $(\% \mathrm{DI} / \mathrm{g})$. Os radioconjugados mostraram perfis similares, para a maioria dos órgãos.

Foi observada uma notável captação sanguínea no primeiro tempo de avaliação (5 min) para ambos os radiotraçadores, diminuindo 73\% após os $30 \mathrm{~min}$ e 93\% em 1h após a injeção para o 99mTc-HYNIC-PEG4-c(GX1) e 47\% aos 30 min e $93 \%$ às $2 \mathrm{~h}$ para o ${ }^{99 m}$ Tc-HYNIC-E-[c(RGDfk)-c(GX1)] (FIG. 17). 


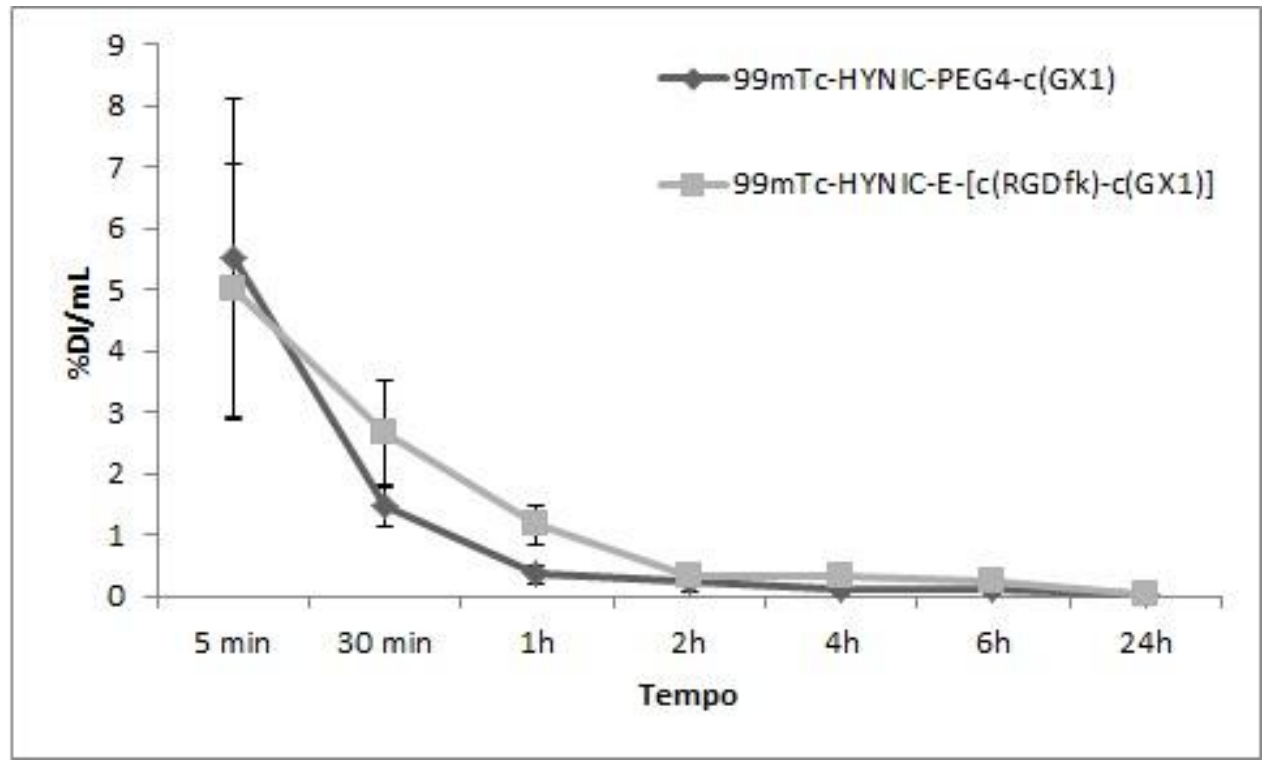

FIGURA 17 - Depuração sanguínea em camundongos Balb/c sadios ( $\mathrm{n}=6)$

As captações nos órgãos de excreção estão demonstradas na FIG. 18 e FIG. 19. A maior captação para ambos radiotraçadores ocorreu nos rins, aos 30 min para o ${ }^{99 m}$ Tc-HYNIC-PEG $4-c(G X 1)$ e a $1 \mathrm{~h}$ para o ${ }^{99 m}$ Tc-HYNIC-E-[c(RGDfk)-

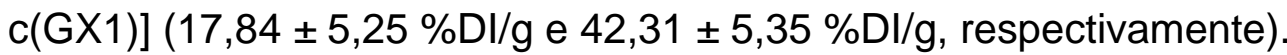

Captações mais acentuadas no fígado $(2,74 \pm 0,88 \% \mathrm{Dl} / \mathrm{g})$, intestino delgado $(2,73 \pm 0,81 \% \mathrm{DI} / \mathrm{g})$ e intestino grosso $(2,63 \pm 1,03 \% \mathrm{DI} / \mathrm{g})$ foram obtidas aos 5 min p.i. para o ${ }^{99 m}$ Tc-HYNIC-PEG $4-c(G X 1)$, diminuindo gradativamente até $2 h$ p.i. 


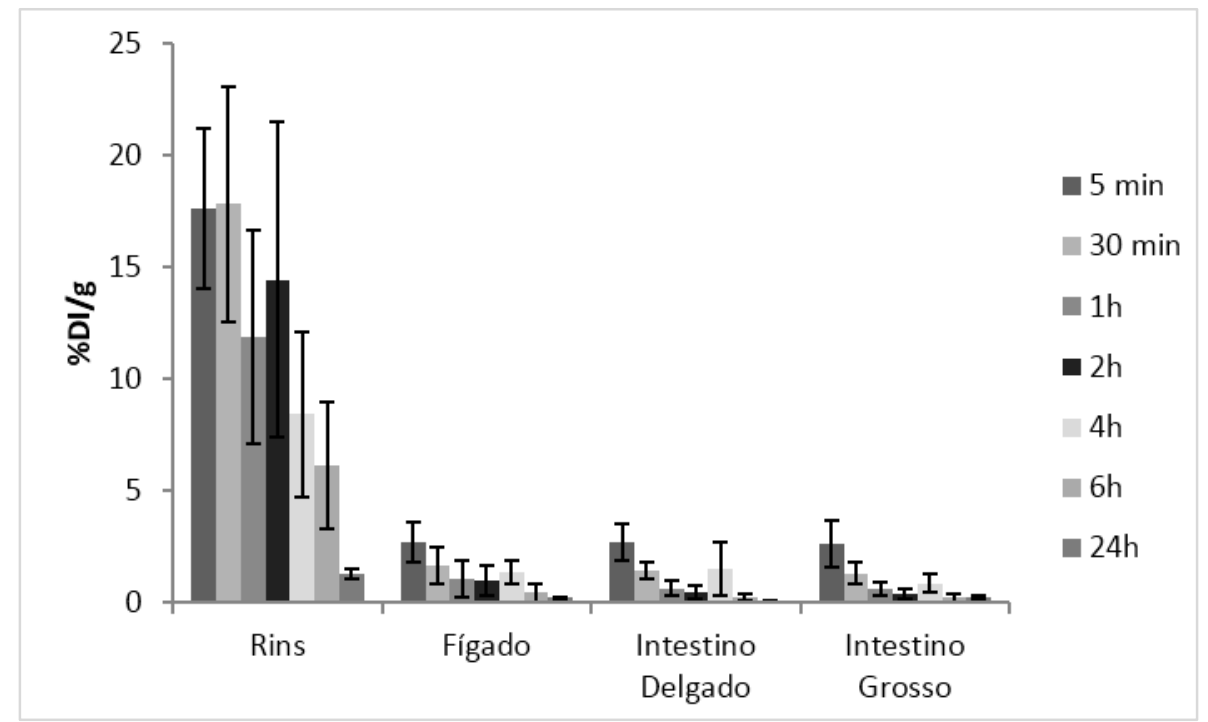

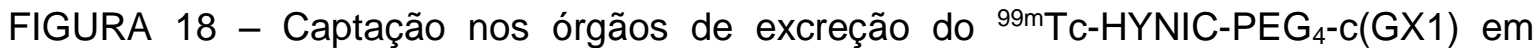
camundongos Balb/c sadios $(n=6)$. A radioatividade nos intestinos foi avaliada após remoção do conteúdo luminal

Para o 99mTc-HYNIC-E-[c(RGDfk)-c(GX1)], também houve alta captação no fígado $(2,73 \pm 0,20 \% \mathrm{Dl} / \mathrm{g})$, intestino delgado $(6,21 \pm 1,27 \% \mathrm{DI} / \mathrm{g})$ e intestino grosso $(6,34 \pm 2,02 \% \mathrm{DI} / \mathrm{g})$ aos $5 \mathrm{~min}$ p.i., seguidos de uma diminuição constante com o passar do tempo para os mesmos órgãos, devido à depuração que está ocorrendo.

Os perfis de biodistribuição nos rins, fígado e intestinos estão de acordo com o coeficiente de partição hidrofílico e indicam a via urinária como a via principal de excreção. Além disso, uma porcentagem significante de radioatividade permanece no trato hepatobiliar, indicando a importância dessa via na eliminação total dos complexos radioativos. 


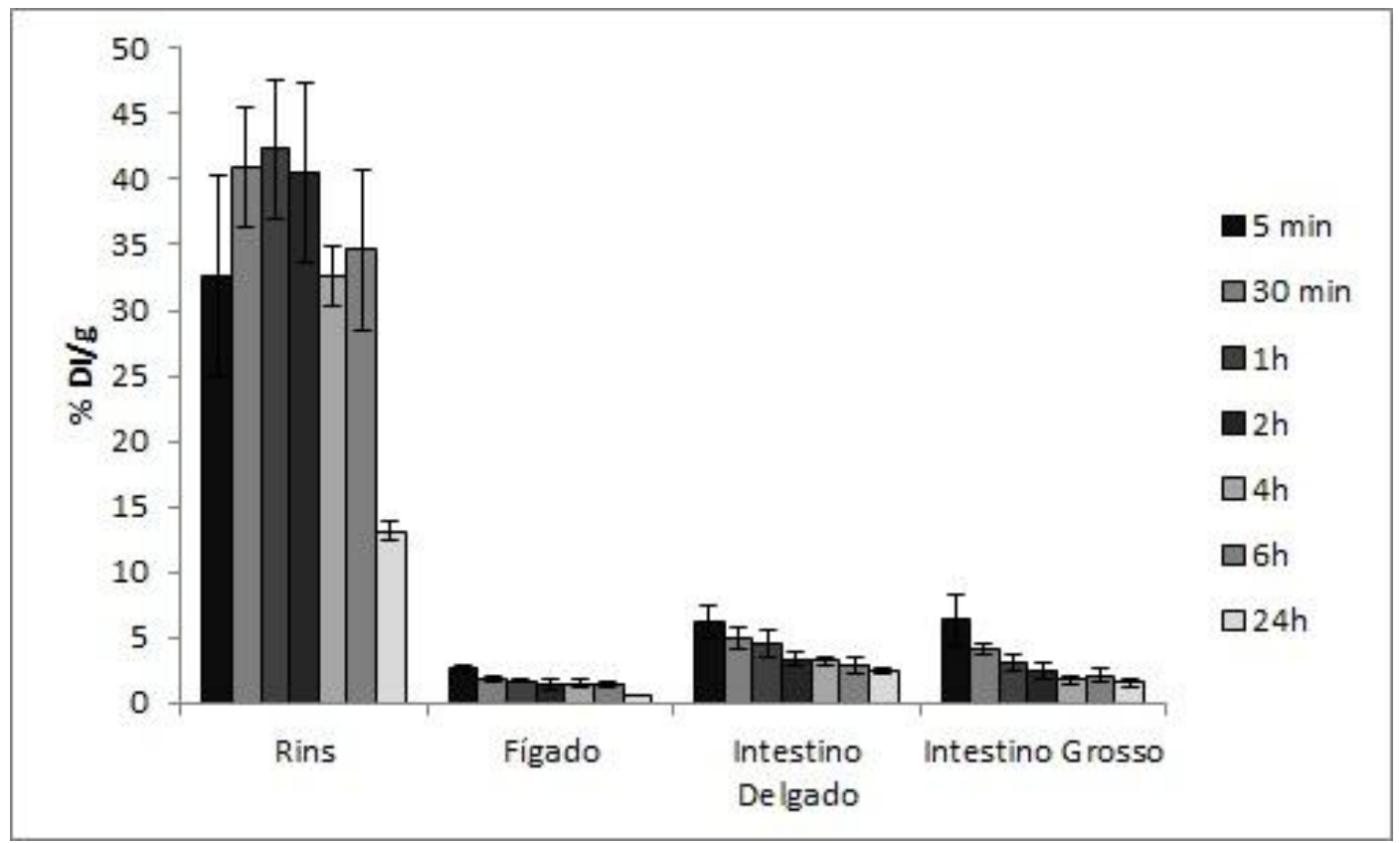

FIGURA 19 - Captação nos órgãos de excreção do ${ }^{99 m}$ TC-HYNIC-E-[c(RGDfk)-c(GX1)] em camundongos $B a l b / c$ sadios $(n=6)$. A radioatividade nos intestinos foi avaliada após remoção do conteúdo luminal

Nos demais órgãos as maiores captações para ambos radiotraçadores foram observadas nos pulmões, baço e estômago aos 5 min p.i. Foi observada também que o traçador RGD-GX1 em relação ao GX1 tem uma depuração nos órgãos mais lenta e também maior captação, como é demonstrado na TAB. 2. 
TABELA 2 - Biodistribuição do 99mTc-HYNIC-PEG4-c(GX1) e 99mTc-HYNIC-E[c(RGDfk)-c(GX1)] em camundongos Balb/c sadios (\%DI/g \pm DP) $(n=6)$

\begin{tabular}{|c|c|c|c|c|c|c|c|c|}
\hline $\begin{array}{l}\text { Órgão/ } \\
\text { tempo }\end{array}$ & & $5 \mathrm{~min}$ & $30 \mathrm{~min}$ & $1 \mathrm{~h}$ & $2 \mathrm{~h}$ & $4 h$ & $6 h$ & $24 \mathrm{~h}$ \\
\hline \multirow{2}{*}{ Coração } & $G X 1$ & 2,74 & $1,31 \pm$ & $0,55 \pm 0,34$ & $0,35 \pm 0,29$ & $0,08 \pm 0,04$ & $0,06 \pm 0,03$ & 0,02 \\
\hline & $R G D-G X 1$ & $2,68 \pm 0,64$ & $1,44 \pm 0,28$ & $0,85 \pm 0,18$ & $0,46 \pm 0,07$ & $0,40 \pm 0,02$ & $0,45 \pm 0,08$ & $0,27 \pm 0,03$ \\
\hline \multirow{2}{*}{ Pulmão } & $G \times 1$ & $6,13 \pm 1,40$ & $2,97 \pm 0,64$ & $1,14 \pm 0,59$ & $0,78 \pm 0,54$ & $0,18 \pm 0,11$ & $0,16 \pm 0,09$ & $0,04 \pm 0,01$ \\
\hline & $R G D-G X 1$ & $5,79 \pm 1,73$ & $3,53 \pm 0,72$ & $2,57 \pm 0,25$ & $1,16 \pm 0,19$ & $0,97 \pm 0,09$ & $1,00 \pm 0,13$ & $0,73 \pm 0,32$ \\
\hline \multirow{2}{*}{ Baço } & $G X 1$ & $3,01 \pm 1,15$ & $1,33 \pm 0,30$ & $0,75 \pm 0,39$ & $0,39 \pm 0,19$ & $0,19 \pm 0,06$ & $0,20 \pm 0,10$ & $0,04 \pm 0,01$ \\
\hline & $R G D-G X 1$ & $4,31 \pm 1,15$ & $0,73 \pm 0,38$ & $2,39 \pm 0,65$ & $2,54 \pm 0,29$ & $1,97 \pm 0,42$ & $2,58 \pm 0,71$ & $2,20 \pm 0,22$ \\
\hline \multirow{2}{*}{ Estômago } & $G X 1$ & $2,30 \pm 0,39$ & $1,77 \pm 0,69$ & $0,55 \pm 0,35$ & $1,38 \pm 0,86$ & $1,26 \pm 0,06$ & $0,59 \pm 0,40$ & $0,15 \pm 0,02$ \\
\hline & $R G D-G X 1$ & $2,25 \pm 0,26$ & $2,05 \pm 0,64$ & $1,43 \pm 0,34$ & $2,09 \pm 0,26$ & $2,20 \pm 0,24$ & $2,26 \pm 0,63$ & $1,11 \pm 0,09$ \\
\hline \multirow{2}{*}{ Pâncreas } & $G X 1$ & $2,28 \pm 0,62$ & $1,16 \pm 0,49$ & $0,77 \pm 0,37$ & $0,32 \pm 0,24$ & $0,10 \pm 0,06$ & $0,08 \pm 0,05$ & $0,03 \pm 0,03$ \\
\hline & $R G D-G X 1$ & $2,76 \pm 0,64$ & $1,30 \pm 0,28$ & $0,98 \pm 0,13$ & $0,50 \pm 0,13$ & $0,41 \pm 0,04$ & $0,43 \pm 0,05$ & $0,24 \pm 0,02$ \\
\hline \multirow{2}{*}{ Músculo } & $G X 1$ & $1,36 \pm 0,37$ & $0,73 \pm 0,35$ & $0,26 \pm 0,17$ & $0,18 \pm 0,16$ & $0,08 \pm 0,05$ & $0,05 \pm 0,02$ & $0,01 \pm 0,00$ \\
\hline & $R G D-G X 1$ & $1,17 \pm 1,10$ & $0,85 \pm 0,12$ & $0,61 \pm 0,16$ & $0,28 \pm 0,02$ & $0,24 \pm 0,01$ & $0,26 \pm 0,07$ & $0,18 \pm 0,03$ \\
\hline \multirow{2}{*}{ Oss } & $G X 1$ & $2,24 \pm 0,69$ & $1,52 \pm 0,83$ & $0,61 \pm 0,42$ & $0,36 \pm 0,18$ & $0,27 \pm 0,19$ & $0,24 \pm 0,16$ & $0,03 \pm 0,01$ \\
\hline & $R G D-G X 1$ & $2,51 \pm 0,31$ & $2,43 \pm 0,74$ & $1,61 \pm 0,35$ & $0,90 \pm 0,15$ & $0,72 \pm 0,06$ & $0,98 \pm 0,15$ & $0,68 \pm 0,16$ \\
\hline \multirow{2}{*}{ Cérebro } & $G \times 1$ & $0,30 \pm 0,12$ & $0,14 \pm 0,08$ & $0,06 \pm 0,04$ & $0,05 \pm 0,04$ & $0,02 \pm 0,02$ & $0,02 \pm 0,02$ & $0,00 \pm 0,00$ \\
\hline & $R G D-G X 1$ & $0,30 \pm 0,06$ & $0,15 \pm 0,03$ & $0,11 \pm 0,02$ & $0,06 \pm 0,02$ & $0,07 \pm 0,05$ & $0,06 \pm 0,01$ & $0,03 \pm 0,01$ \\
\hline
\end{tabular}

A porcentagem da dose total injetada dos radiomarcados no sangue, músculo e osso pode ser observada na TAB. 3. Aos 5 min p.i., há um grande acúmulo de atividade no sangue, músculo e osso para ambos radiomarcados. $A$ partir das $2 \mathrm{~h}$ p.i. há uma grande redução desses valores, causados pela depuração e eliminação da radioatividade pelas vias de excreção. Ambos radiomarcados apresentarem padrões similares na redução do acúmulo da radioatividade no sangue, sendo que o 99mTc-HYNIC-PEG $4-c(G X 1)$, apresentou uma depuração mais rápida, quando comparado ao 99mTc-HYNIC-E-[c(RGDfk)$c(G \times 1)]$. 
TABELA 3 - Porcentagem da dose total injetada dos radiomarcados ${ }^{99 m} \mathrm{Tc}$ HYNIC-PEG 4 -c(GX1) e 99mTc-HYNIC-E-[c(RGDfk)-c(GX1)] em camundongos Balb/c sadios em diferentes tempos (\%DI)

\begin{tabular}{|c|c|c|c|c|c|c|c|c|}
\hline $\begin{array}{l}\text { Órgão/ } \\
\text { Tempo }\end{array}$ & & $5 \mathrm{~min}$ & $30 \mathrm{~min}$ & $1 \mathrm{~h}$ & $2 \mathrm{~h}$ & $4 h$ & $6 h$ & $24 \mathrm{~h}$ \\
\hline \multirow{2}{*}{ Sangue } & $G \times 1$ & $13,00 \pm 1,25$ & $2,62 \pm 0,60$ & $0,64 \pm 0,26$ & $0,39 \pm 0,23$ & $0,22 \pm 0,14$ & $0,25 \pm 0,06$ & $0,05 \pm 0,01$ \\
\hline & $R G D-G X 1$ & $9,46 \pm 4,20$ & $5,06 \pm 2,02$ & $2,28 \pm 0,65$ & $0,62 \pm 0,21$ & $0,63 \pm 0,20$ & $0,43 \pm 0,14$ & $0,09 \pm 0,02$ \\
\hline \multirow{2}{*}{ Músculo } & $G \times 1$ & $13,44 \pm 3,91$ & $5,17 \pm 1,07$ & $1,47 \pm 0,72$ & $0,77 \pm 0,23$ & $0,40 \pm 0,13$ & $0,37 \pm 0,17$ & $0,09 \pm 0,04$ \\
\hline & $R G D-G X 1$ & $13,21 \pm 2,90$ & $9,04 \pm 1,50$ & $6,06 \pm 1,08$ & $2,86 \pm 0,33$ & $2,54 \pm 0,31$ & $2,55 \pm 0,65$ & $1,76 \pm 0,31$ \\
\hline \multirow{2}{*}{ Osso } & $G \times 1$ & $5,53 \pm 1,32$ & $3,01 \pm 1,32$ & $0,74 \pm 0,37$ & $0,65 \pm 0,24$ & $0,46 \pm 0,13$ & $0,35 \pm 0,20$ & $0,08 \pm 0,02$ \\
\hline & $R G D-G X 1$ & $6,74 \pm 1,06$ & $6,45 \pm 1,92$ & $4,38 \pm 0,88$ & $2,31 \pm 0,35$ & $1,92 \pm 0,24$ & $2,39 \pm 0,32$ & $1,67 \pm 0,44$ \\
\hline
\end{tabular}

\subsection{Ensaios in vitro de ligação às células}

\subsubsection{Células endoteliais humanas de cordão umbilical (HUVEC)}

Os resultados dos estudos de ligação in vitro podem ser observados na FIG. 20 e 21. A ligação total do ${ }^{99 m}$ Tc-HYNIC-PEG $4-c(G X 1)$ às células HUVEC alcançaram o maior valor após 60 min de incubação $(0,41 \pm 0,04 \%)$ mantendo-se em torno de $0,25 \%$ nos outros tempos. A ligação específica seguiu a tendência da ligação total, mas com valores menores, alcançando o máximo de 0,14 \pm 0,07\% em 60 min, o que representa 34\% da ligação total. A internalização total foi maior no primeiro tempo de análise ( $5 \mathrm{~min}$ ) $0,14 \pm 0,01 \%$, ou seja, $51 \%$ da ligação total, diminuindo após esse período e aumentando novamente no último tempo de análise de $120 \mathrm{~min}$.

Para o 99mTc-HYNIC-E-[c(RGDfk)-c(GX1)], a ligação total em células HUVEC teve um pico aos 120 min de incubação $(0,35 \pm 0,07 \%)$, sendo que manteve valores semelhantes nos tempos anteriores. A ligação específica aumentou com o tempo e chegou a 0,16 \pm 0,01\% aos 120 min de incubação. Nesse caso, $45 \%$ da ligação total foi específica. A internalização total seguiu a 
tendência da ligação total e teve seu maior valor aos $120 \min (0,19 \pm 0,05 \%)$, representando $54 \%$ da ligação total.

A ligação total e específica dos dois produtos atingiram níveis muito semelhantes, porém manteve-se 0 padrão encontrado nos estudos de biodistribuição em animais sadios, de maior captação do ${ }^{99 m}$ TC- HYNIC-PEG 4 $c(G X 1)$ no tempo de 60 min e do ${ }^{99 m}$ Tc-HYNIC--E-[c(RGDfk)-c(GX1)] aos $120 \mathrm{~min}$.

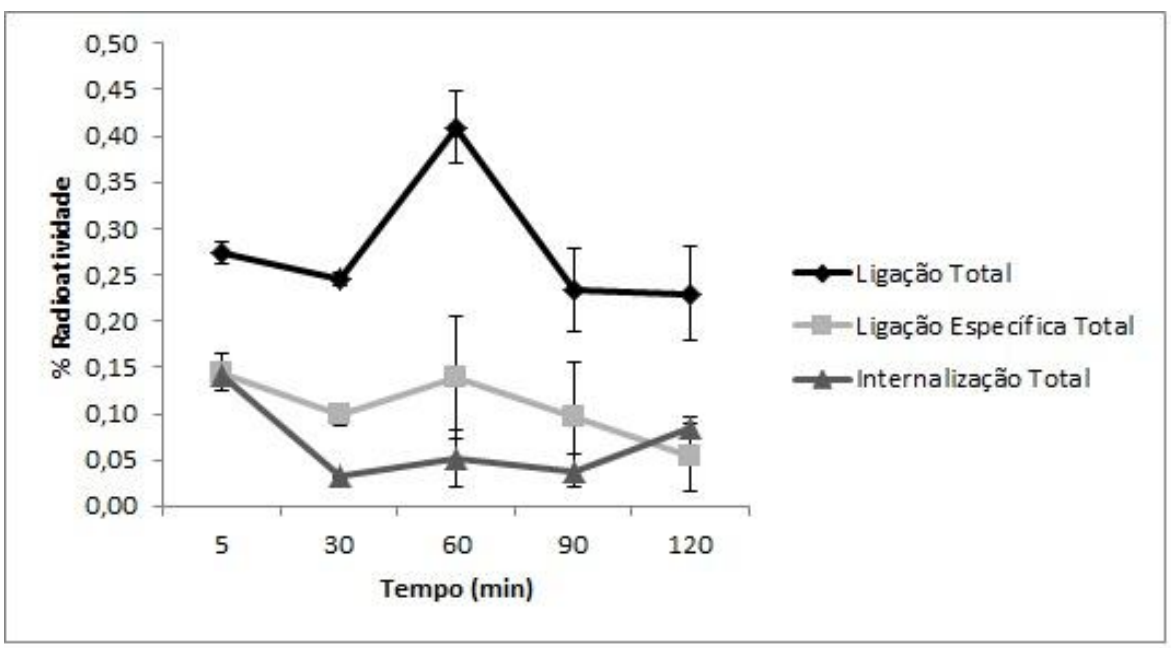

FIGURA 20 - Ligação total, ligação específica e internalização às células HUVEC com o 99mTc-HYNIC-PEG 4 -c(GX1)

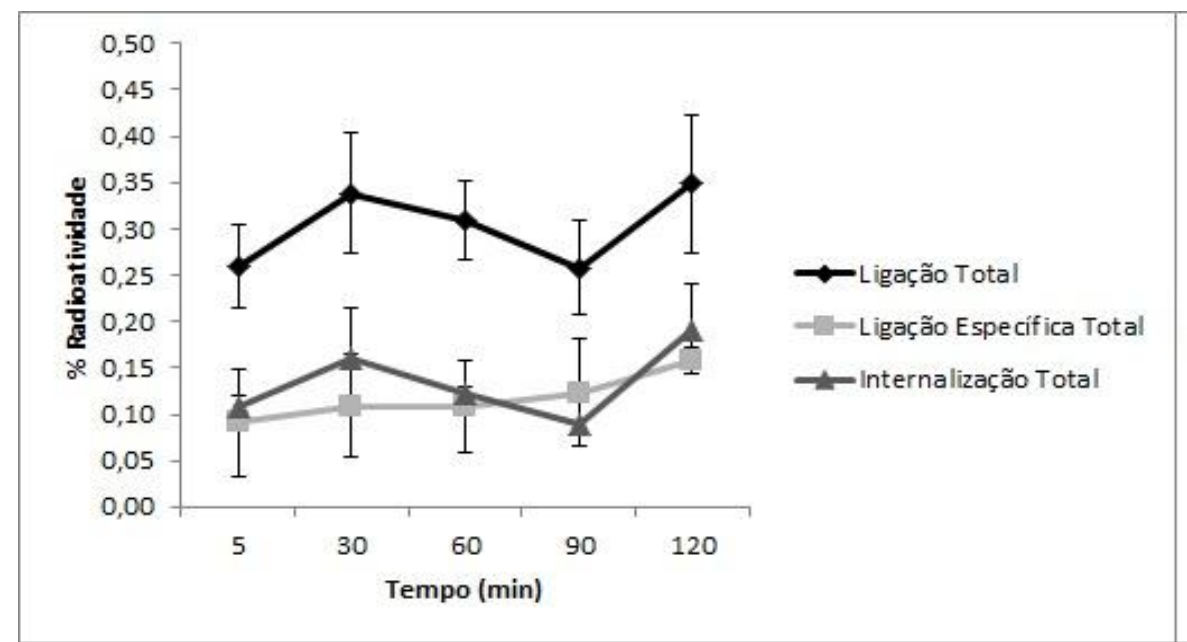

FIGURA 21 - Ligação total, ligação específica e internalização às células HUVEC com o 99mTc-HYNIC-E-[c(RGDfk)-c(GX1)] 


\subsubsection{Células tumorais de glioblastoma humano U87MG e T98G}

Os resultados dos estudos de ligação dos radiotraçadores in vitro às células de glioblastoma humano U87MG podem ser observados na FIG. 22 e FIG. 23.

A ligação total do 99mTc-HYNIC-PEG4-c(GX1) às células U87MG demonstraram um perfil de crescimento até 1 hora de incubação, decrescendo após este tempo. O maior valor obtido no tempo de 1 h de incubação foi de 0,69 \pm 0,06\%. A ligação específica seguiu a tendência da ligação total, mas com valores menores, alcançando 0,14 \pm 0,06\% em $60 \mathrm{~min}$, o que representa $20,28 \%$ da ligação total. A internalização total também foi maior na análise de 60 min $(0,05 \pm$ $0,01 \%$ ) , representando somente $7,24 \%$ da ligação total.

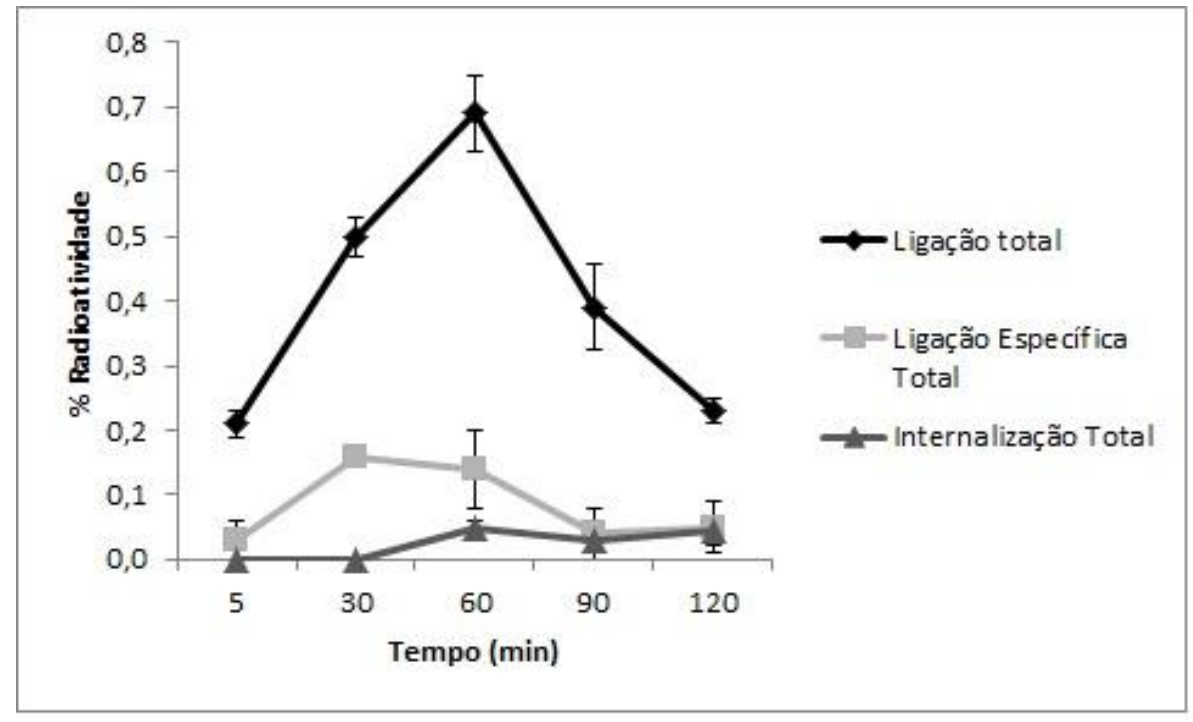

FIGURA 22 - Ligação total, ligação específica e internalização do ${ }^{99 m}$ Tc-HYNIC-PEG ${ }_{4-}^{-}$ c(GX1) às células U87MG

O perfil de ligação do 99mTc-HYNIC-E-[c(RGDfk)-c(GX1)] às células U87MG diferiu do 99mTc-HYNIC-PEG4-c(GX1), pois mostrou-se dependente do tempo de incubação, com o maior valor de ligação total após 120 min de incubação (1,14 \pm 0,35\%), A ligação específica também aumentou com o tempo de incubação e chegou a $0,86 \pm 0,32 \%$ no último tempo estudado. Nesse caso, 
$75,43 \%$ da ligação total foi específica. A internalização total seguiu a tendência da ligação total e teve seu maior valor aos $120 \min (0,17 \pm 0,07 \%)$, representando $14,91 \%$ da ligação total.

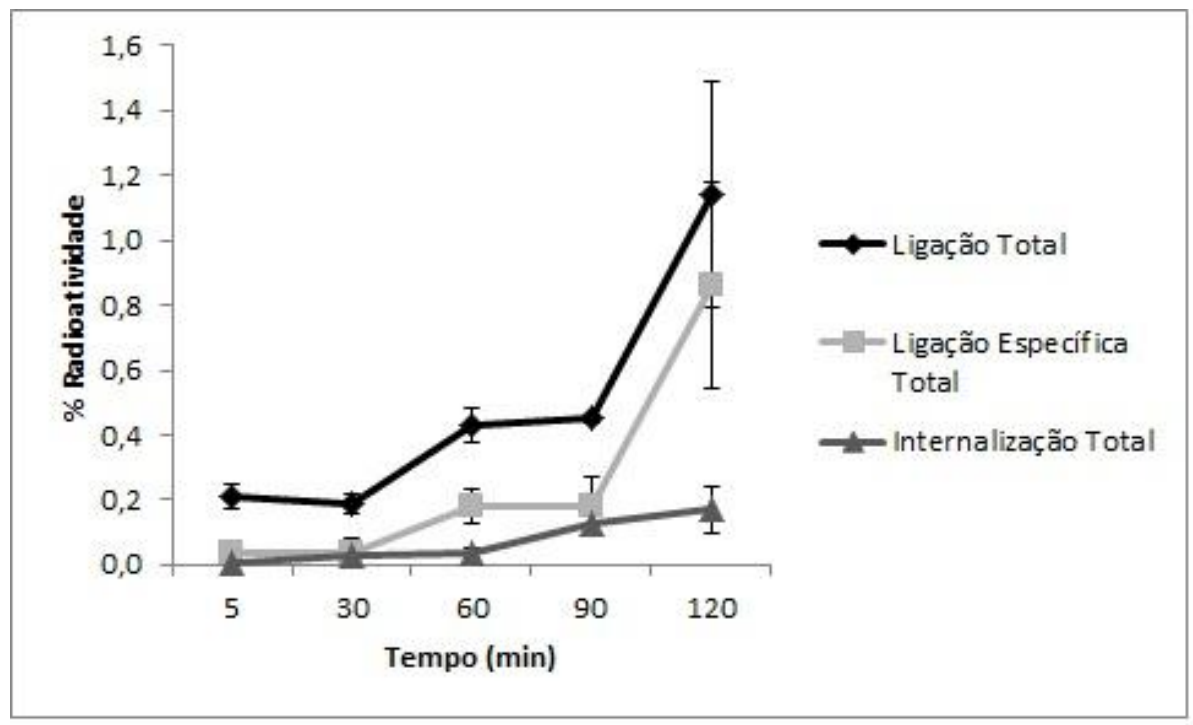

FIGURA 23 - Ligação total, ligação específica e internalização do ${ }^{99 m}$ Tc-HYNIC-E[c(RGDfk)-c(GX1)] às células U87MG

Os resultados dos estudos de ligação in vitro às células de glioblastoma humano T98G podem ser observados na FIG. 24 e FIG. 25. Assim como nas células tumorais U87MG, a ligação total do 99mTc-HYNIC-PEG4-c(GX1) às células T98G alcançaram o maior valor após 60 min de incubação $(0,54 \pm$ $0,05 \%)$ diminuindo nos outros tempos $(p<0,05)$. A ligação específica foi de 0,19 \pm 0,07\% nesse mesmo tempo, o que representou $35,18 \%$ da ligação total, diminuindo em seguida. A internalização total se manteve baixa em todos os tempos, tendo o valor de $0,02 \pm 0,01 \%$ aos $60 \mathrm{~min}$, ou seja, 3,7\% da ligação total. 


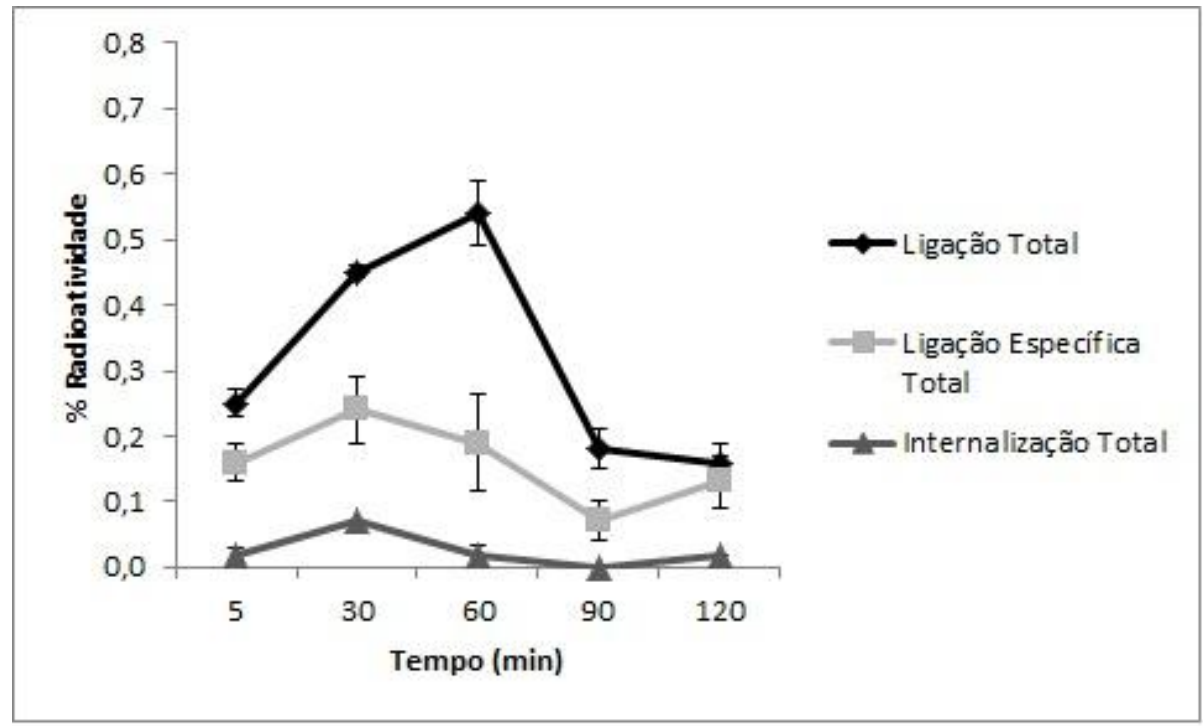

FIGURA 24 - Ligação total, ligação específica e internalização do ${ }^{99 m}$ Tc-HYNIC-PEG $4^{-}$ $c(G X 1)$ às células T98G

Para o 99mTc-HYNIC-E-[c(RGDfk)-c(GX1)], a ligação total em células T98G também seguiu o mesmo padrão do observado nas células U87MG, apresentando o maior valor aos 120 min de incubação, porém com um valor bastante inferior $(0,45 \pm 0,03 \%)(p<0,05)$. A ligação específica e a internalização também aumentaram com o tempo de incubação, e aos 120 min a ligação específica foi $0,14 \pm 0,05 \%$. Nesse caso, $31,11 \%$ da ligação total foi específica nesse tempo. Nesse mesmo tempo, a internalização total foi de 0,08 $\pm 0,02 \%$, representando $17,7 \%$ da ligação total. 


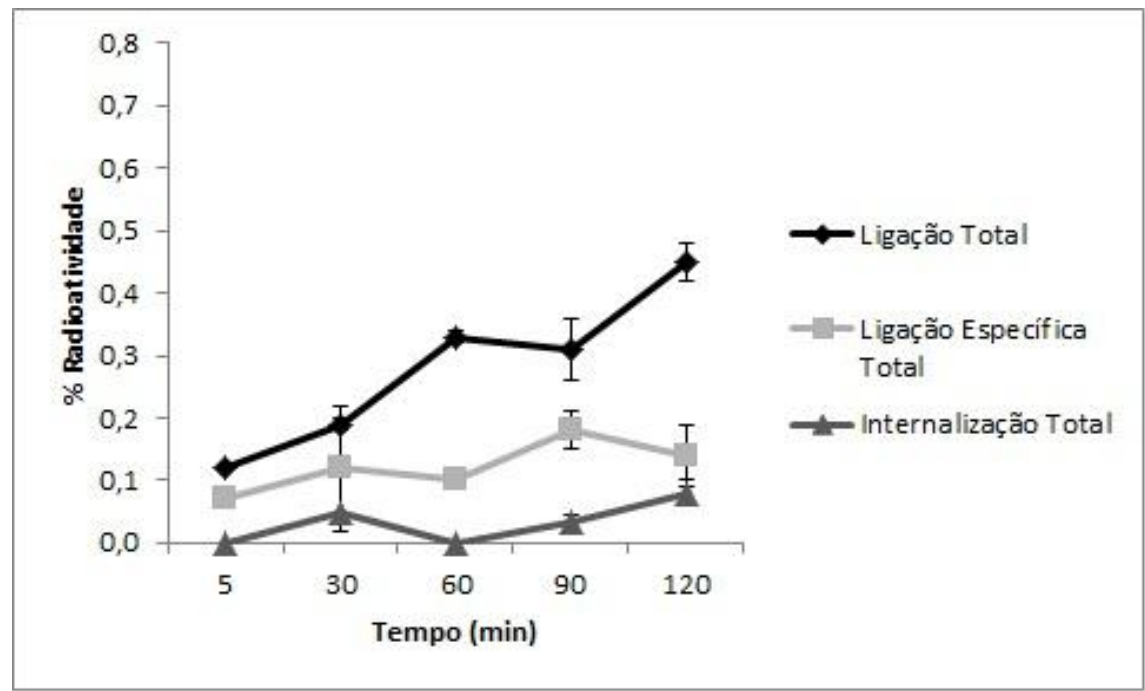

FIGURA 25 - Ligação total, ligação específica e internalização do ${ }^{99 m}$ Tc-HYNIC-E[c(RGDfk)-c(GX1)] às células T98G

\subsection{Biodistribuição em camundongos portadores de tumor}

A captação média de ambos traçadores pela maioria dos órgãos e tecidos, em camundongos portadores de células tumorais, foi baixa, com exceção para rins e intestinos, que apresentam alta captação por fazerem parte da via de excreção dos compostos, confirmando o perfil encontrado no estudo prévio de biodistribuição em animais sadios.

Os estudos sobre as propriedades farmacocinéticas e alvo para glioma U87MG do 99mTc-HYNIC-PEG 4 -c(GX1) e 99mTc-HYNIC-E-[c(RGDfk)-c(GX1)] podem ser observadas na TAB. 4.

Os resultados de biodistribuição exibiram também uma captação tumoral substancial aos $60 \mathrm{~min}$ p.i. com 99mTc-HYNIC-E-[c(RGDfk)-c(GX1)] $(2,96 \pm 0,70 \% \mathrm{DI} / \mathrm{g})$, quando comparado com a captação pelo ${ }^{99 m T c-H Y N I C-P E G} 4-$ $c(G X 1) \quad(1,52 \pm 0,34 \% D I / g), \quad(p<0,005)$. O tumor foi bloqueado com o uso de peptídeo frio em $47,29 \%$ e 47,36\%, respectivamente.

Aos 120 min p.i. a captação foi de $2,87 \pm 0,53 \%$ Dl/g para o ${ }^{99 m T c-}$ HYNIC-E-[c(RGDfk)-c(GX1)] com bloqueamento de 68,98\%, porém essa 
captação não teve diferença significativa quando comparado ao tempo de $60 \mathrm{~min}$ $(p>0,5)$.

TABELA 4 - Biodistribuição do 99mTc-HYNIC-PEG ${ }_{4}-c(G X 1)$ e do ${ }^{99 m}$ Tc-HYNIC-E[c(RGDfk)-c(GX1)] em camundongos SCID portadores de células tumorais de glioblastoma humano U87MG aos 60 e 120 min p.i. $(n=5)$

\begin{tabular}{|c|c|c|c|c|c|c|}
\hline \multirow{2}{*}{$\begin{array}{l}\text { Órgão/tecido } \\
\text { (\%DI/g } \pm \text { DP) }\end{array}$} & \multicolumn{6}{|c|}{ Células U87MG } \\
\hline & GX1 & $\begin{array}{c}\text { GX1 } \\
\text { bloqueado }\end{array}$ & RGD-GX1 & $\begin{array}{c}\text { RGD-GX1 } \\
\text { bloqueado }\end{array}$ & RGD-GX1 & $\begin{array}{l}\text { RGD-GX1 } \\
\text { bloqueado }\end{array}$ \\
\hline Tempo & $1 \mathrm{~h}$ & & & & $2 h$ & \\
\hline Sangue & $1,22 \pm 0,34$ & $1,27 \pm 1,16$ & $1,20 \pm 0,11$ & $1,09 \pm 0,18$ & $0,78 \pm 0,11$ & $0,59 \pm 0,07$ \\
\hline Coração & $1,38 \pm 0,30$ & $0,55 \pm 0,23$ & $1,10 \pm 0,27$ & $0,93 \pm 0,53$ & $1,72 \pm 0,43$ & $1,51 \pm 0,40$ \\
\hline Pulmões & $2,23 \pm 0,70$ & $1,34 \pm 0,63$ & $2,48 \pm 0,67$ & $1,86 \pm 0,87$ & $3,88 \pm 0,54$ & $3,38 \pm 0,47$ \\
\hline Rins & $22,31 \pm 8,19$ & $14,97 \pm 1,68$ & $46,87 \pm 15,45$ & $28,68 \pm 9,22$ & $16,95 \pm 4,88$ & $13,98 \pm 1,61$ \\
\hline Baço & $1,05 \pm 0,50$ & $0,46 \pm 0,35$ & $3,29 \pm 1,45$ & $1,54 \pm 0,92$ & $3,25 \pm 0,41$ & $2,79 \pm 0,40$ \\
\hline Estômago & $1,62 \pm 0,68$ & $1,17 \pm 0,26$ & $3,61 \pm 0,80$ & $1,54 \pm 0,01$ & $3,23 \pm 0,56$ & $1,34 \pm 0,12$ \\
\hline Pâncreas & $2,31 \pm 0,79$ & $0,81 \pm 0,43$ & $1,54 \pm 0,45$ & $1,07 \pm 0,62$ & $2,34 \pm 0,52$ & $2,33 \pm 0,82$ \\
\hline Fígado & $2,33 \pm 0,69$ & $2,26 \pm 1,27$ & $2,61 \pm 0,61$ & $0,94 \pm 0,11$ & $6,83 \pm 0,86$ & $6,17 \pm 1,97$ \\
\hline Int. Grosso & $2,39 \pm 0,99$ & $0,77 \pm 0,22$ & $4,27 \pm 0,39$ & $1,83 \pm 0,70$ & $4,15 \pm 1,66$ & $2,29 \pm 0,56$ \\
\hline Int. Delgado & $1,85 \pm 0,34$ & $0,95 \pm 0,56$ & $8,87 \pm 1,74$ & $1,96 \pm 0,65$ & $3,85 \pm 0,74$ & $3,50 \pm 1,00$ \\
\hline Músculo & $0,59 \pm 0,25$ & $0,40 \pm 0,15$ & $0,51 \pm 0,21$ & $0,40 \pm 0,26$ & $0,87 \pm 0,23$ & $0,84 \pm 0,73$ \\
\hline Osso & $1,55 \pm 0,25$ & $1,04 \pm 0,38$ & $1,47 \pm 0,51$ & $1,15 \pm 0,73$ & $2,11 \pm 0,17$ & $2,01 \pm 0,34$ \\
\hline Cérebro & $0,21 \pm 0,11$ & $0,11 \pm 0,04$ & $0,16 \pm 0,04$ & $0,13 \pm 0,08$ & $0,25 \pm 0,05$ & $0,24 \pm 0,08$ \\
\hline Tumor & $1,52 \pm 0,34$ & $0,72 \pm 0,34$ & $2,96 \pm 0,70$ & $1,40 \pm 0,30$ & $2,87 \pm 0,53$ & $1,98 \pm 0,18$ \\
\hline
\end{tabular}

Foram obtidas maiores razões tumor/sangue $(2,4)$ e tumor/músculo $(5,8)$ para o traçador RGD-GX1 em 1h em animais portadores de células U87MG do que para o traçador GX1 (FIG. 26). 


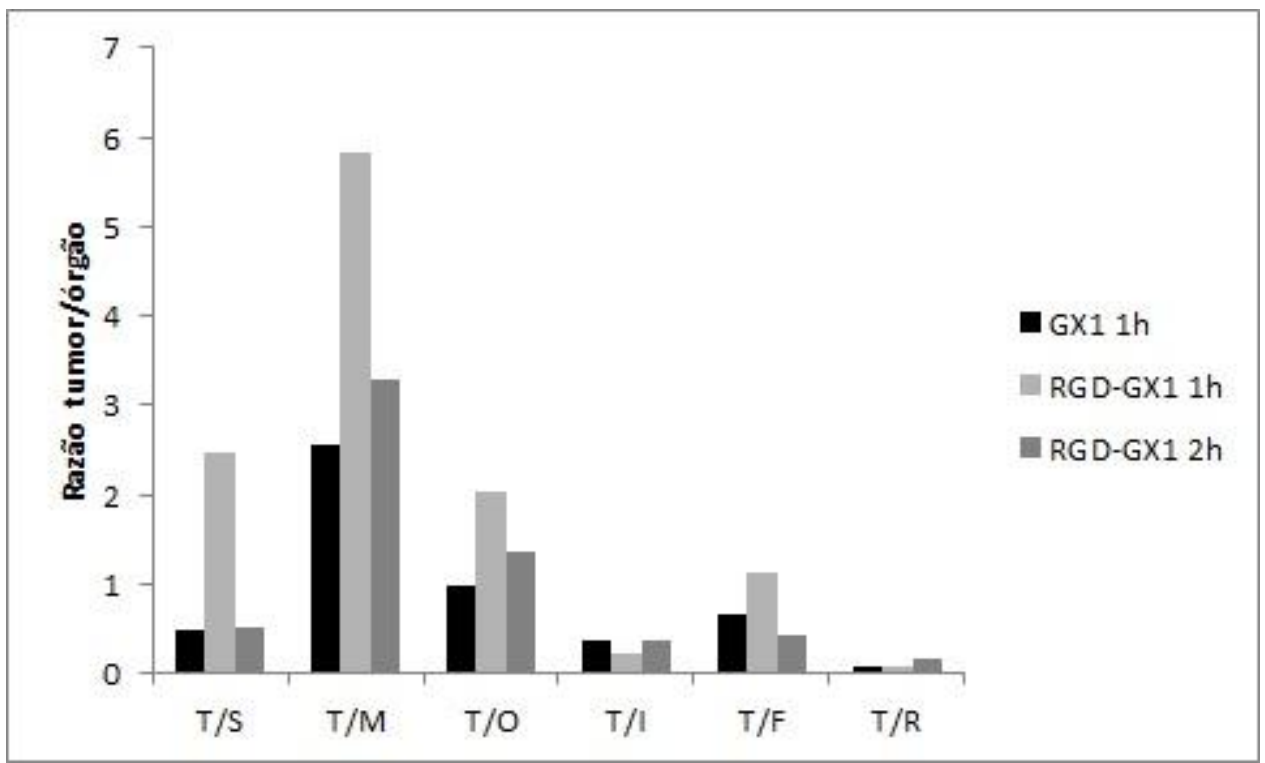

FIGURA 26 - Razões tumor/órgão e tumor/tecidos em camundongos SCID para células U87MG (T=Tumor; $\mathrm{S}=$ Sangue; $M=$ Músculo; $\mathrm{O}=$ Osso; I= Intestinos; F=Fígado; $\mathrm{R}=\mathrm{Rins}$ ) com os traçadores ${ }^{99 m}$ Tc-HYNIC-PEG $4-c(G X 1)$ em 1h e ${ }^{99 m}$ Tc-HYNIC-E-[c(RGDfk)$\mathrm{c}(\mathrm{GX} 1)]$ em 1 e $2 \mathrm{~h}$

Os estudos sobre as propriedades farmacocinéticas e alvo para glioma T98G do 99mTc-HYNIC-PEG4-c(GX1) e 99mTc-HYNIC-E-[c(RGDfk)-c(GX1)] podem ser observadas na TAB. 5.

Os resultados de biodistribuição exibiram uma notável captação tumoral para animais portadores de células do tumor T98G com 99mTc-HYNIC-E-

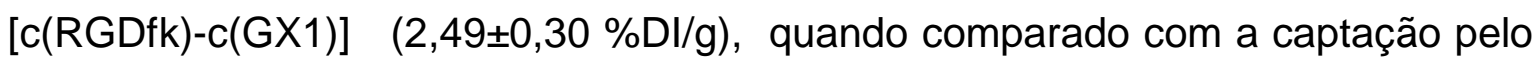
99mTc-HYNIC-PEG 4 -c(GX1) $(0,78 \pm 0,44 \%$ DI/g), ( $<<0,001)$. O tumor foi bloqueado $42,3 \%$ com o uso de $50 \mu \mathrm{g}$ de peptídeo frio para o primeiro traçador e $46,5 \%$ com o segundo (TAB. 5, FIG. 27).

$\mathrm{Na}$ análise feita aos 120 min p.i., a captação foi de 1,58 \pm 0,60\% Dl/g para o 99mTc-HYNIC-E-[c(RGDfk)-c(GX1)] com bloqueamento de 50\%, porém essa captação também não teve diferença significativa quando comparado ao tempo de 60 min analisado anteriormente $(p>0,5)$. 
TABELA 5 - Biodistribuição do ${ }^{99 m}$ Tc-HYNIC-PEG4-c(GX1) e do ${ }^{99 m T c-H Y N I C-E-~}$ [c(RGDfk)-c(GX1)] em camundongos SCID portadores de células tumorais de glioblastoma humano T98G aos 60 e 120 min p.i. $(n=5)$

\begin{tabular}{lcccccc}
\hline \multirow{2}{*}{$\begin{array}{l}\text { Órgão/tecido } \\
\text { (\%DI/g } \pm \text { DP) }\end{array}$} & $\mathbf{G X 1}$ & $\begin{array}{c}\text { GX1 } \\
\text { bloqueado }\end{array}$ & RGD-GX1 & $\begin{array}{c}\text { RGD-GX1 } \\
\text { bloqueado }\end{array}$ & RGD-GX1 & $\begin{array}{c}\text { RGD-GX1 } \\
\text { bloqueado }\end{array}$ \\
\cline { 2 - 7 } Tempo & $\mathbf{1 h}$ & & $\mathbf{2 h}$ \\
\hline Sangue & $1,83 \pm 1,06$ & $1,19 \pm 0,37$ & $1,57 \pm 0,79$ & $1,11 \pm 0,37$ & $0,58 \pm 0,32$ & $0,38 \pm 0,28$ \\
Coração & $0,57 \pm 0,25$ & $0,25 \pm 0,07$ & $1,21 \pm 0,53$ & $1,04 \pm 0,58$ & $0,43 \pm 0,14$ & $0,17 \pm 0,06$ \\
Pulmões & $1,22 \pm 0,55$ & $0,57 \pm 0,12$ & $2,51 \pm 0,56$ & $2,26 \pm 0,93$ & $1,06 \pm 0,26$ & $0,48 \pm 0,10$ \\
Rins & $14,57 \pm 5,37$ & $10,96 \pm 3,42$ & $26,50 \pm 8,74$ & $21,88 \pm 6,58$ & $21,55 \pm 4,40$ & $21,52 \pm 9,32$ \\
Baço & $0,57 \pm 0,34$ & $0,27 \pm 0,05$ & $2,26 \pm 0,21$ & $1,55 \pm 0,67$ & $1,44 \pm 0,53$ & $0,66 \pm 0,23$ \\
Estômago & $1,81 \pm 0,30$ & $2,07 \pm 0,60$ & $1,80 \pm 0,76$ & $1,90 \pm 0,89$ & $2,46 \pm 0,34$ & $1,72 \pm 0,46$ \\
Pâncreas & $0,70 \pm 0,39$ & $0,28 \pm 0,06$ & $1,21 \pm 0,57$ & $1,26 \pm 0,57$ & $0,55 \pm 0,07$ & $0,22 \pm 0,09$ \\
Fígado & $1,38 \pm 1,23$ & $0,49 \pm 0,03$ & $3,31 \pm 1,05$ & $3,66 \pm 0,20$ & $1,44 \pm 0,78$ & $0,82 \pm 0,59$ \\
Int. Grosso & $0,90 \pm 0,57$ & $0,97 \pm 0,49$ & $3,21 \pm 0,89$ & $1,78 \pm 1,28$ & $2,02 \pm 0,41$ & $0,70 \pm 0,26$ \\
Int. Delgado & $1,15 \pm 0,85$ & $1,07 \pm 0,70$ & $4,97 \pm 0,74$ & $1,57 \pm 0,35$ & $3,70 \pm 0,58$ & $1,01 \pm 0,15$ \\
Músculo & $0,28 \pm 0,08$ & $0,23 \pm 0,06$ & $0,63 \pm 0,21$ & $0,52 \pm 0,02$ & $0,33 \pm 0,24$ & $0,06 \pm 0,01$ \\
Osso & $0,81 \pm 0,44$ & $0,53 \pm 0,32$ & $1,17 \pm 0,38$ & $1,40 \pm 0,15$ & $0,57 \pm 0,11$ & $0,48 \pm 0,27$ \\
Cérebro & $0,10 \pm 0,071$ & $0,05 \pm 0,03$ & $0,15 \pm 0,04$ & $0,12 \pm 0,07$ & $0,07 \pm 0,03$ & $0,03 \pm 0,01$ \\
Tumor & $0,78 \pm 0,44$ & $0,45 \pm 0,16$ & $2,49 \pm 0,30$ & $1,33 \pm 0,29$ & $1,58 \pm 0,60$ & $0,79 \pm 0,37$ \\
\hline
\end{tabular}




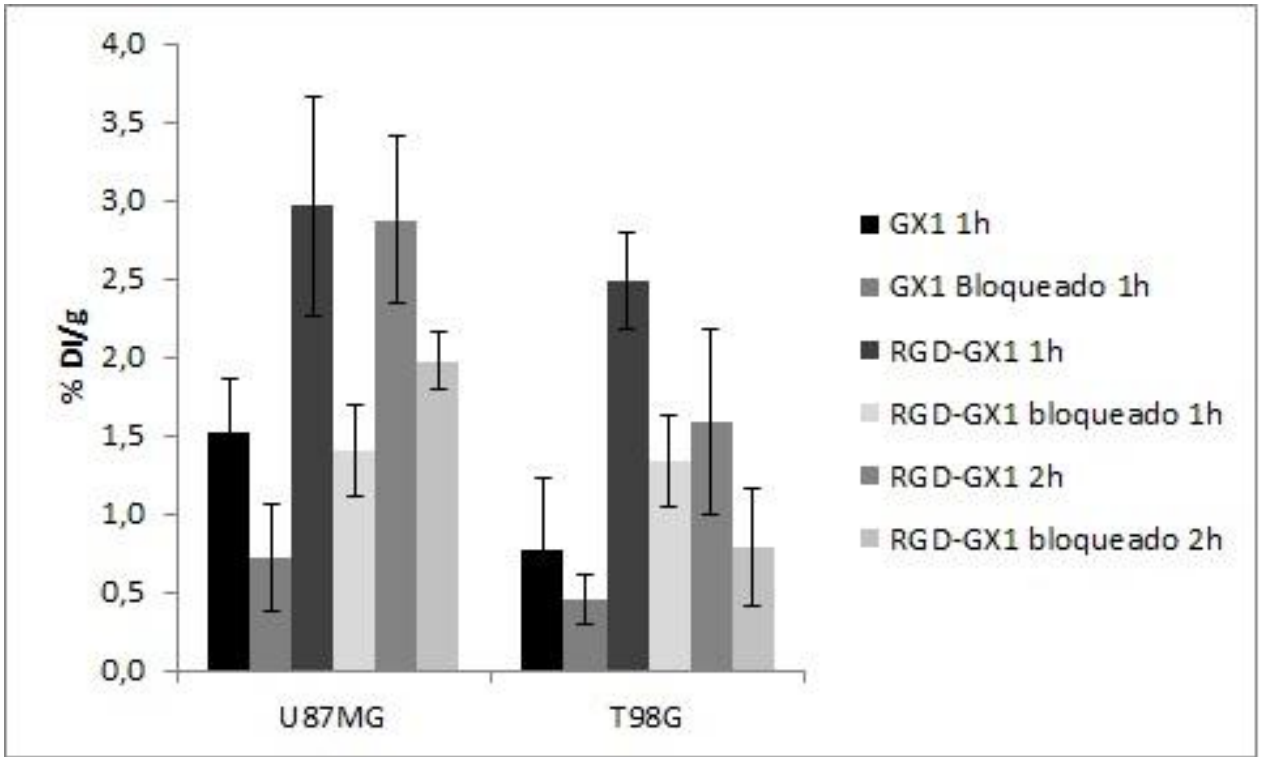

FIGURA 27 - Captação dos radiotraçadores em tumor e em tumor bloqueado após a injeção em células tumorais de glioblastoma U87MG e T98G em camundongos SCID

As razões da captação foram maiores para o ${ }^{99 m}$ Tc-HYNIC-E-[c(RGDfk)c(GX1)] em células T98G especialmente para tumor/sangue $(2,7)$ e tumor/músculo $(4,8)$ (FIG. 28).

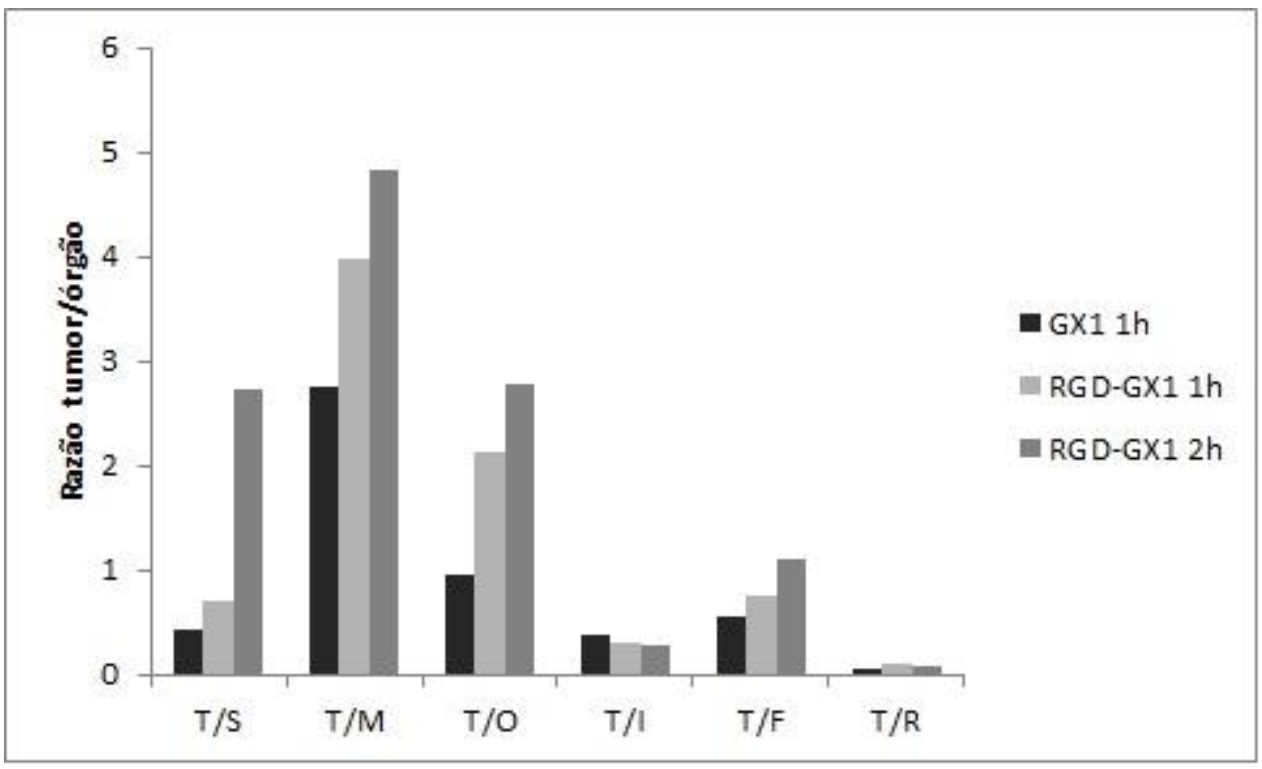

FIGURA 28 - Razões tumor/órgão e tumor/tecidos em camundongos SCID para células T98G (T=Tumor; S=Sangue; M=Músculo; O=Osso; I= Intestinos; F=Fígado; R= Rins) com os traçadores ${ }^{99 m T c-H Y N I C-P E G} 4-c(G X 1)$ em $1 \mathrm{~h}$ e 99mTc-HYNIC-E-[c(RGDfk)$c(G X 1)]$ em 1 e $2 h$ 


\subsection{Imagens Cintilográficas por gama-câmara}

Nesta etapa do estudo proposto foram realizadas as aquisições de imagens cintilográficas. A partir delas podemos avaliar o comportamento do radiofármaco em um tempo conhecido e também e visualização tumoral através dos aparelhos de imagem diagnóstica disponíveis atualmente.

Os tumores de glioma U87MG no flanco dos animais foram claramente visualizados com os dois radiotraçadores em todos os tempos estudados (FIG 29 a 31). O melhor resultado foi o obtido com o radioconjugado ${ }^{99 m T C-H Y N I C-E-~}$ [c(RGDfk)-c(GX1)] no tempo de $1 \mathrm{~h}$. Ambos radioconjugados exibiram alta captação tumoral em relação aos órgão normais, com exceção aos órgão excretórios.
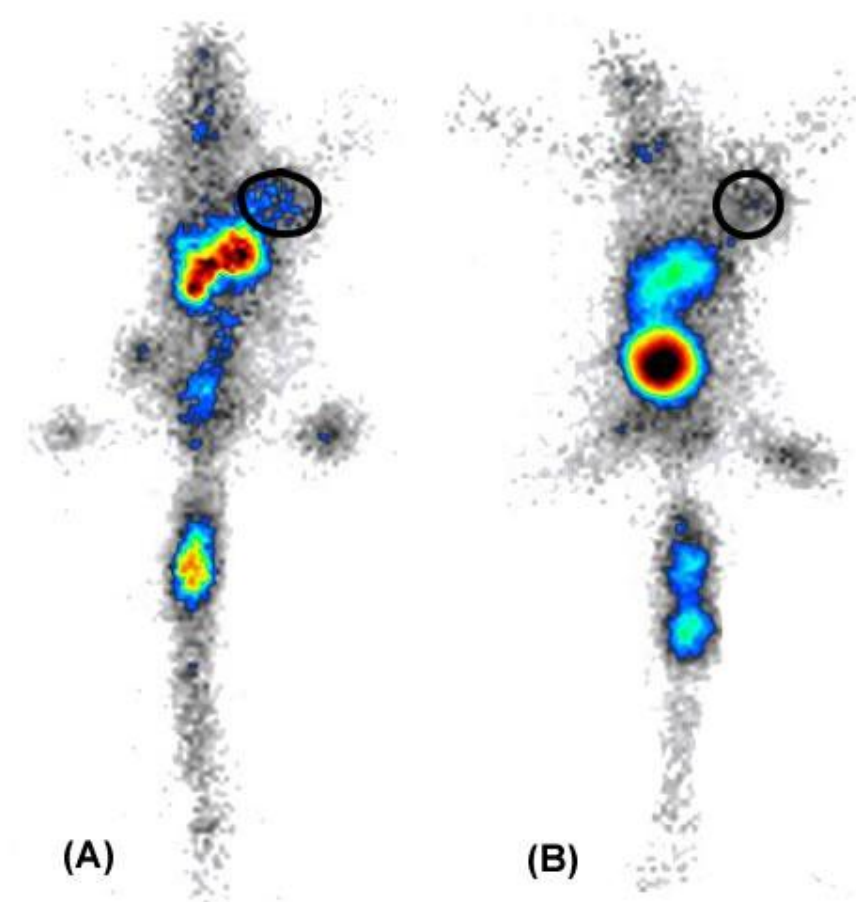

FIGURA 29 - Imagens cintilográficas obtidas após 1 h da injeção de ${ }^{99 m}$ TC-HYNIC-PEG 4 c(GX1) em camundongos SCID portadores de células tumorais de glioblastoma U87MG (A) Sem bloqueamento ROI 5,21\% (B) Com bloqueamento ROI 1,66\% 

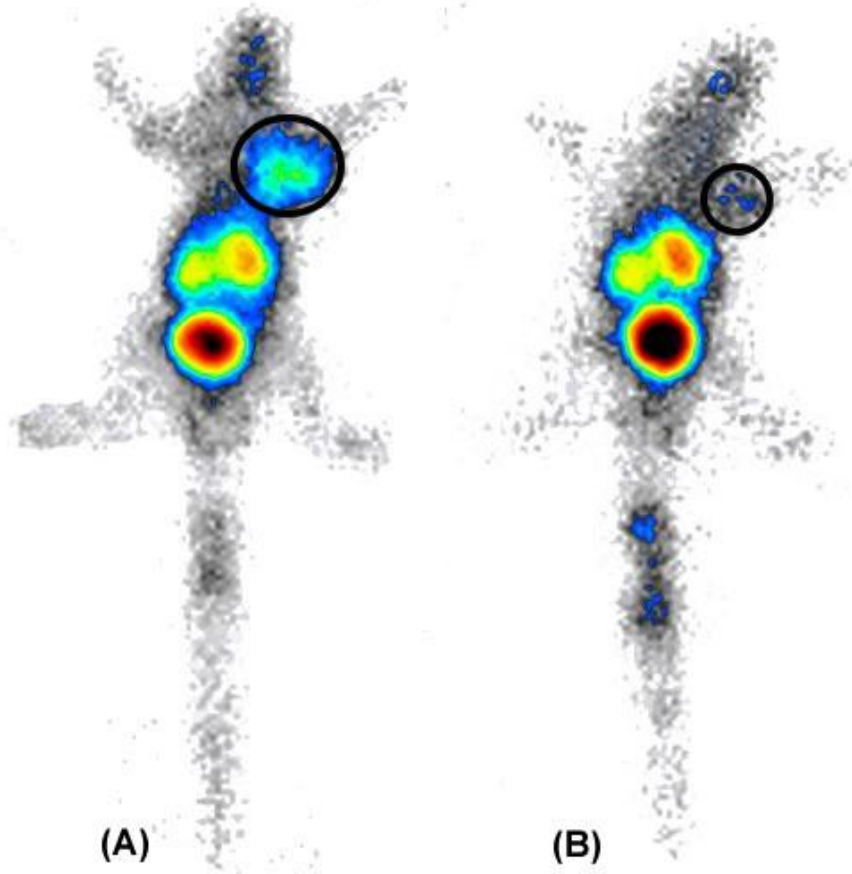

FIGURA 30 - Imagens cintilográficas obtidas após 1h da injeção de ${ }^{99 m}$ TC-HYNIC-E[c(RGDfk)-c(GX1)] em camundongos SCID portadores de células tumorais de glioblastoma U87MG (A) Sem bloqueamento ROI 8,72\% (B) Com bloqueamento ROI $0,78 \%$
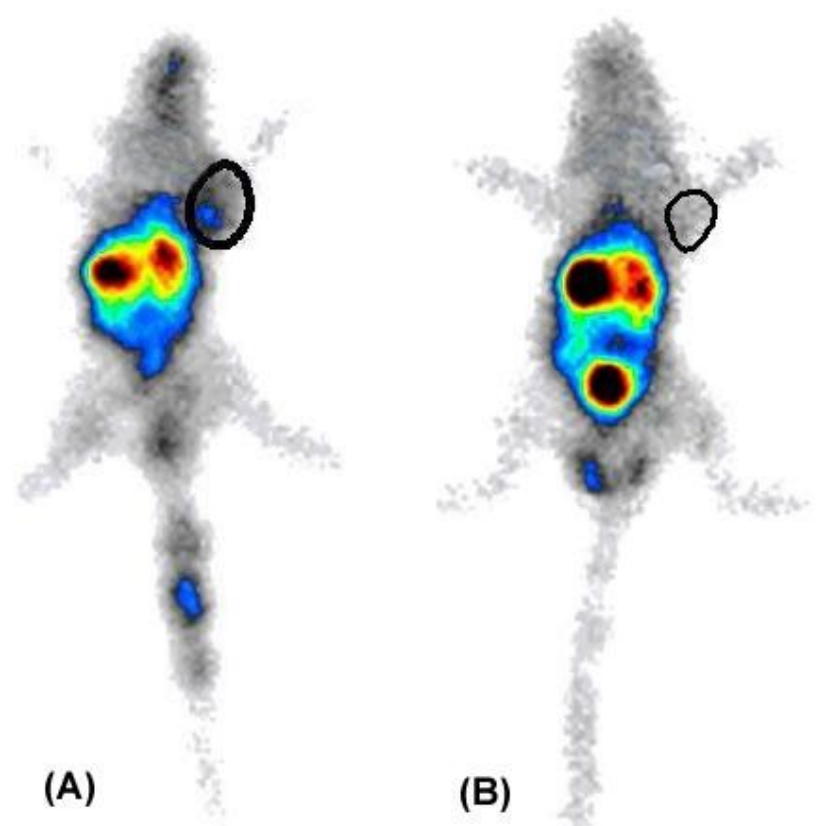

FIGURA 31 - Imagens cintilográficas obtidas após 2h da injeção de ${ }^{99 m}$ Tc-HYNIC-E[c(RGDfk)-c(GX1)] em camundongos SCID portadores de células tumorais de glioblastoma U87MG (A) Sem bloqueamento ROI 3,87\% (B) Com bloqueamento ROI $0,65 \%$ 
As imagens dos tumores de glioma T98G no flanco dos animais também foram claramente visualizados com os dois radiotraçadores em todos os tempos estudados (FIG 32 a 34). O melhor resultado foi o obtido com o radioconjugado ${ }^{99 m}$ Tc-HYNIC-E-[C(RGDfk)-c(GX1)] no tempo de $2 \mathrm{~h}$. O perfil de captação sistemática foi o mesmo encontrado em todas as análises, com alta captação nos órgãos de excreção.

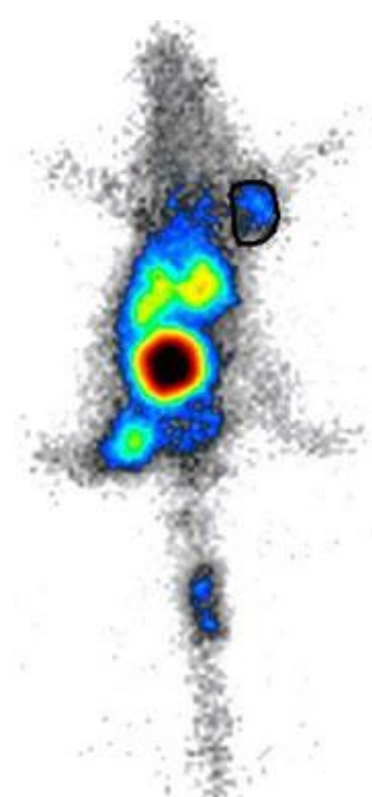

(A)

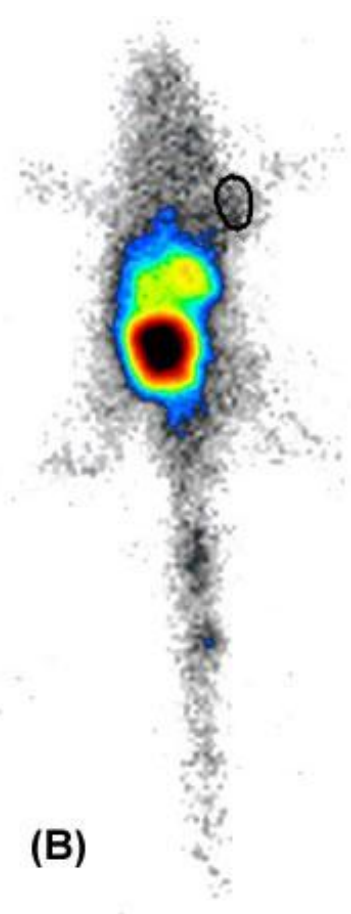

FIGURA 32 - Imagens cintilográficas obtidas após $1 \mathrm{~h}$ da injeção de ${ }^{99 m} \mathrm{TC}-\mathrm{HYNIC} \mathrm{PEG}_{4-}$ c(GX1) em camundongos SCID portadores de células tumorais de glioblastoma T98G (A) Sem bloqueamento ROI 1,21\% (B) Com bloqueamento ROI 0,34\% 


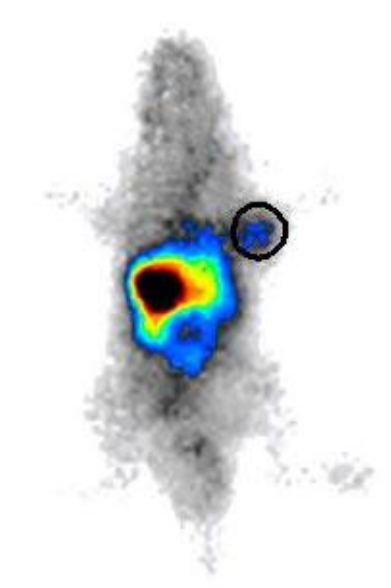

(A)

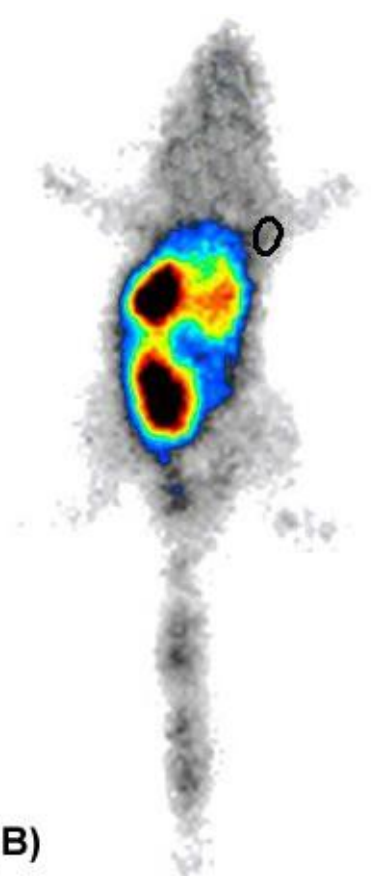

FIGURA 33 - Imagens cintilográficas obtidas após $1 \mathrm{~h}$ da injeção de ${ }^{99 m}$ TC-HYNIC-E[c(RGDfk)-c(GX1)] em camundongos SCID portadores de células tumorais de glioblastoma T98G (A) Sem bloqueamento ROI 2,63\% (B) Com bloqueamento ROI 0,33\%

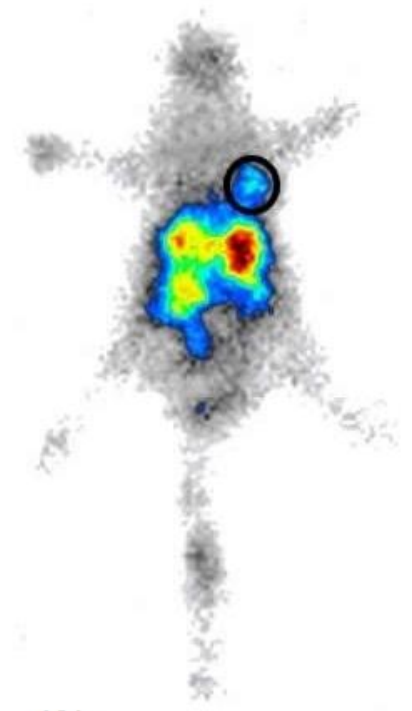

(A)

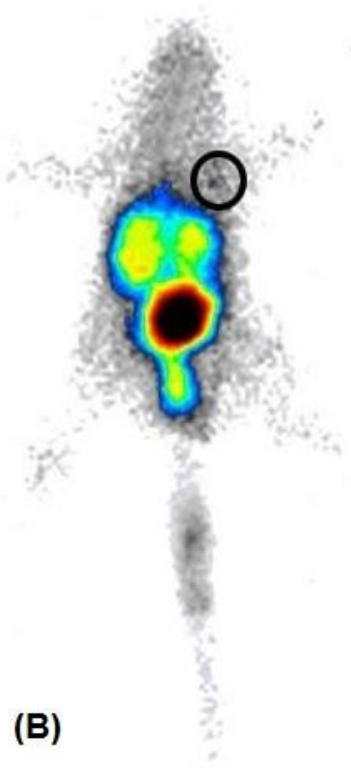

(B)

FIGURA 34 - Imagens cintilográficas obtidas após $2 \mathrm{~h}$ da injeção de ${ }^{99 m}$ TC-HYNIC-E[c(RGDfk)-c(GX1)] em camundongos $S C I D$ portadores de células tumorais de glioblastoma T98G (A) Sem bloqueamento ROI 3,18\% (B) Com bloqueamento ROI 0,38\% 


\subsection{Imagens de Ressonância Magnética}

As imagens obtidas com os animais portadores do tumor U87MG, U87MG-IDH1 ${ }^{\mathrm{WT}}$, U87MG-IDH1 ${ }^{\mathrm{R} 132}$ ponderadas no tempo de relaxação transversal T2 e injetados com os conjugados peptídicos ligados às nanopartículas magnéticas estão demonstradas abaixo. As nanopartículas magnéticas são capazes de atravessar a barreira hematoencefálica do cérebro, permitindo sua visualização pela ressonância magnética (AKHTARI e col., 2008).

Foram analisados 4 animais para cada grupo e exibido o que obteve as melhores imagens. As imagens estão apresentadas nessa ordem: (A) anatomia cerebral na sequência RARE antes da injeção do contraste; (B a F) representam a subtração entre a imagem prévia e a imagens feitas após 15 minutos, 30 minutos, 1 hora, 1 hora e 30 minutos e 2 horas, nessa ordem, da injeção do contraste. Em todas as situações é possível verificar que as figuras anatômicas mostram o tumor, confirmando sua presença, tamanho e localização (FIG. 35A, 36A, 38A, 39A, 41A e 42A).

\subsubsection{Células U87MG}

A FIG. 35 e FIG. 36 são referentes às imagens obtidas com os contrastes dos conjugados do peptídeo HYNIC-PEG4-C(GX1) e do peptídeo HYNIC-E-[c(RGDfk)-c(GX1)], respectivamente, com as nanopartículas magnéticas de óxido de ferro (NPM) nas células U87MG.

As FIG. de 35B a 35F e de 36B a 36F mostram a evolução da captação dos contrastes injetados em todos os tempos de análise. Já é possível verificar no primeiro tempo (15 minutos) uma maior captação na região tumoral quando comparado ao resto do cérebro, sendo que essa captação aumentou com o tempo, com o melhor resultado às $2 \mathrm{~h}$ para ambos os peptídeos. Desse modo é possível verificar a especificidade dos conjugados ao tumor. 

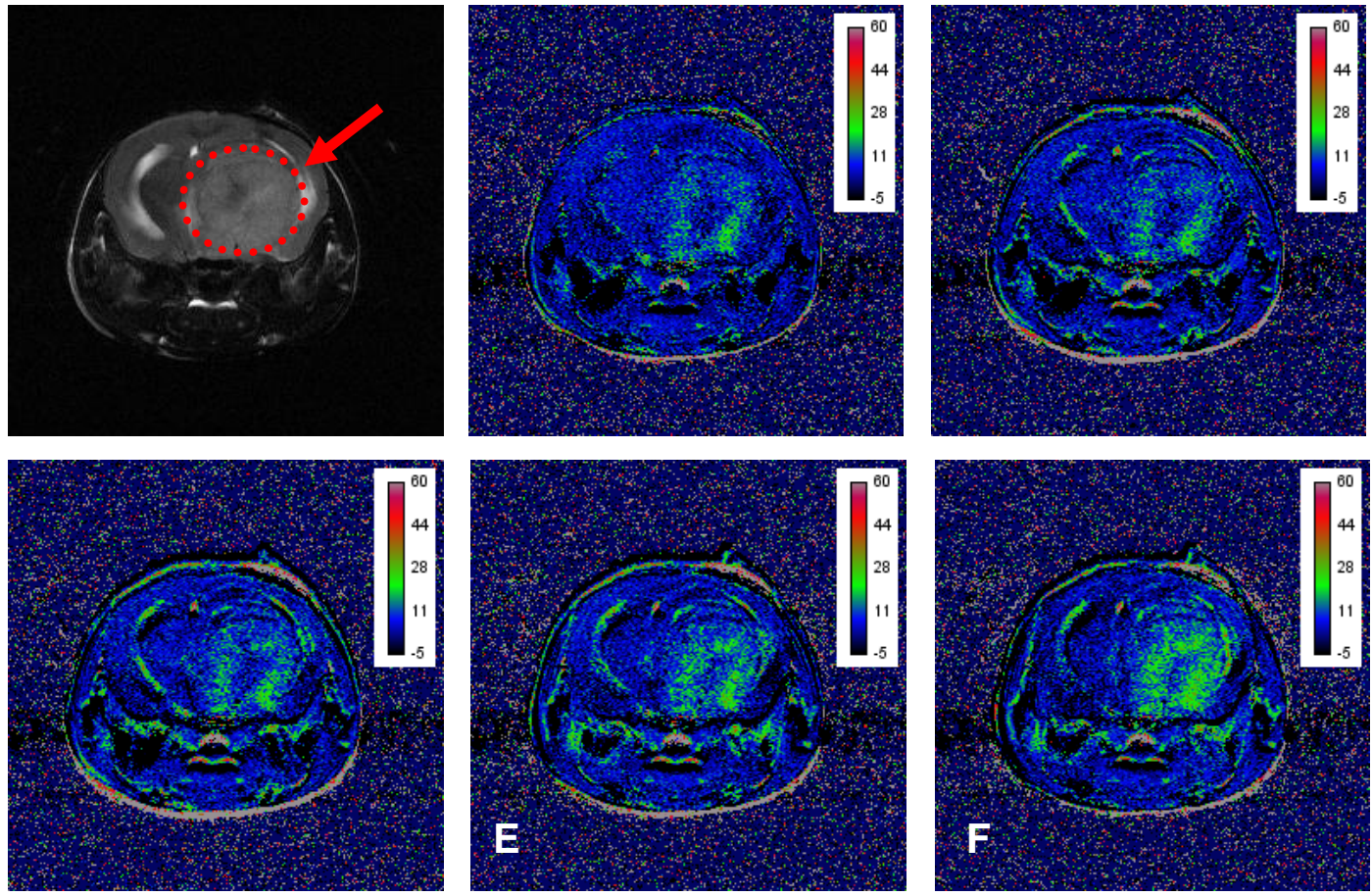

FIGURA 35 - Imagem de ressonância magnética de camundongos NOD-SCID inoculados com células de glioblastoma humano U87MG e injetados com o contraste do conjugado NPM-HYNIC-PEG 4 -C(GX1); (A) Anatomia (RARE); Mapa de subtração em T2 (B) 0-15min; (C) 0-30min; (D) 0-1h; (E) 0-1h30; (F) 0-2h pós-injeção
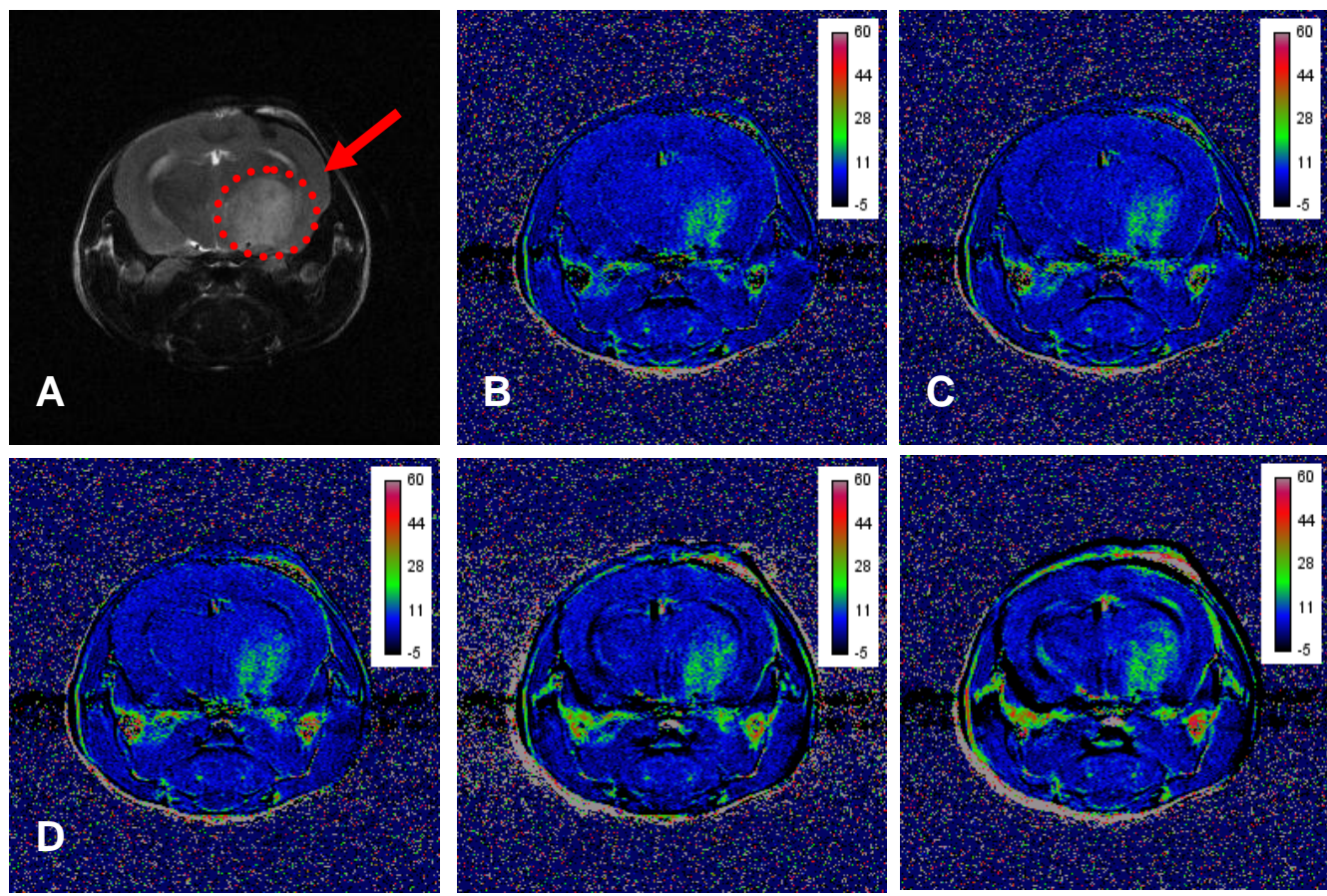

FIGURA 36 - Imagem de ressonância magnética de camundongos NOD-SCID inoculados com células de glioblastoma humano U87MG e injetados com o contraste do conjugado NPM-HYNIC-E-[c(RGDfk)-c(GX1)]; (A) Anatomia (RARE); Mapa de subtração em T2 (B) 0-15min; (C ) 0-30min; (D) 0-1h; (E) 0-1h30; (F) 0-2h pós-injeção 
A FIG. 37 demonstra a quantificação dos valores T2 das captações obtidas nos tumores de células U87MG dos mesmos animais através das imagens de ressonância magnética.

É possível verificar que houve redução do sinal, indicando captação pelo tumor, logo após a injeção de ambos os contrastes. Os perfis de captação foram bastante semelhantes. Nos dois casos a maior captação ocorreu às $2 \mathrm{~h}$, sendo que com o conjugado NPM-HYNIC-PEG4-C(GX1) a captação foi de 20,2\% e com o NPM-HYNIC-E-[c(RGDfk)-c(GX1)] de 18,6\%, porém essa diferença não foi significativa $(p>0,05)$.

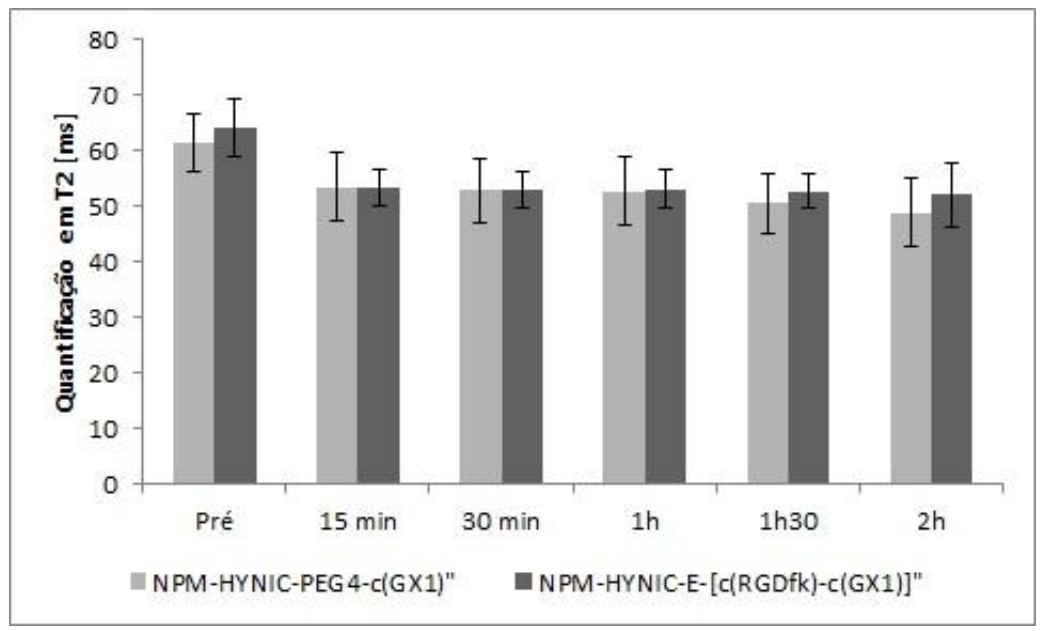

FIGURA 37 - Quantificação em T2 nos tumores dos animais portadores do tumor das células U87MG obtida através das imagens de ressonância magnética com os contrastes conjugados NPM-HYNIC-PEG 4 -c(GX1) e NPM-HYNIC-E-[c(RGDfk)-c(GX1)]

\subsubsection{Células U87MG-IDH1 ${ }^{\mathrm{WT}}$}

A FIG. 38 é referente às imagens obtidas com o contraste do conjugado do peptídeo HYNIC-PEG4-c(GX1) com as nanopartículas magnéticas de óxido de ferro (NPM) nas células U87MG-IDH1WT. As FIG. de 38B a 38F mostram a evolução da captação do contraste injetado. Nos primeiros tempos de análise (de $15 \mathrm{~min}$ à $1 \mathrm{~h}$ ) há uma pequena captação no tumor, sendo que a partir de 1 h30 é possível verificar o aumento da ligação ao tumor, atingindo o melhor resultado às $2 \mathrm{~h}$ após a injeção. 

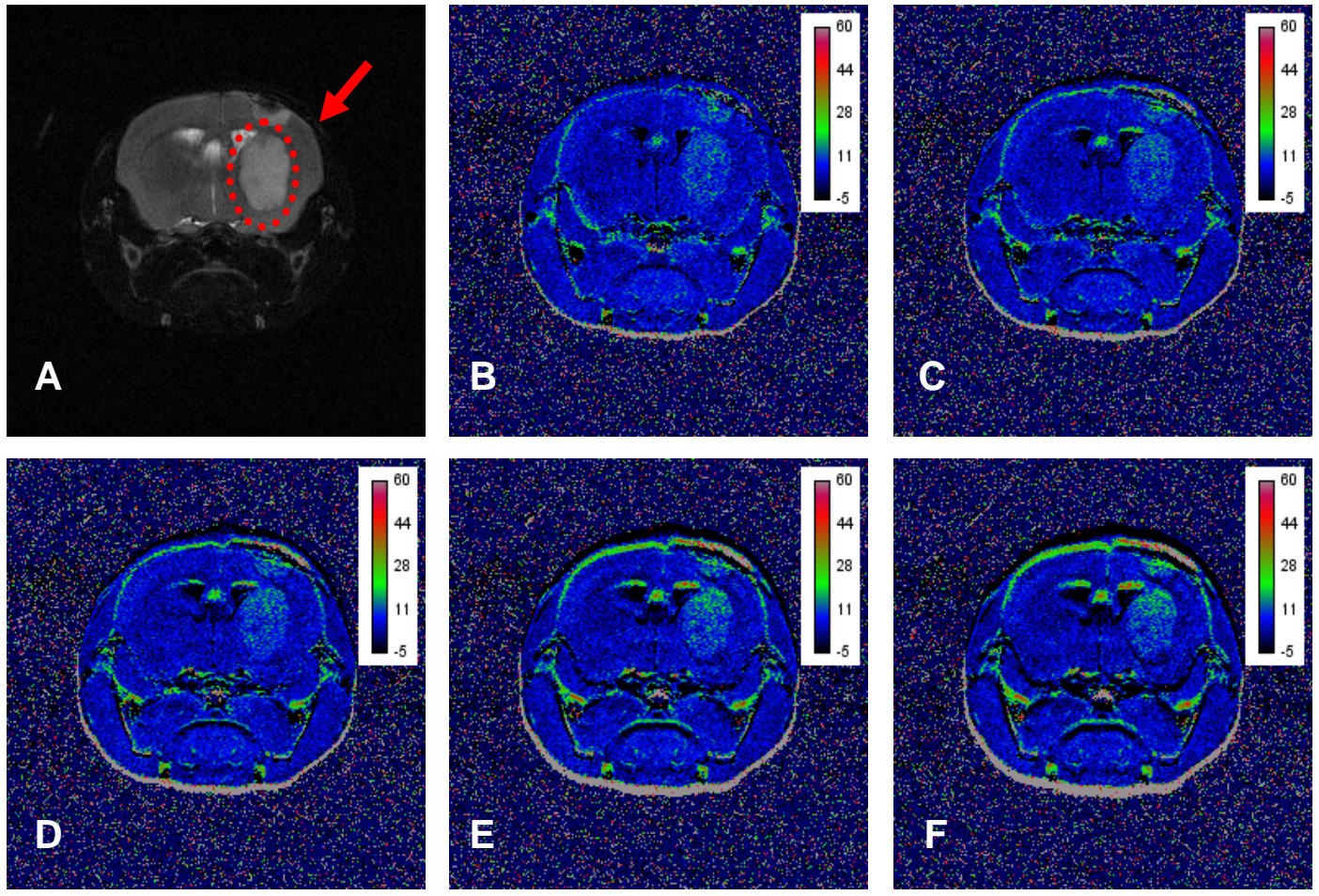

FIGURA 38 - Imagem de ressonância magnética de camundongos NOD-SCID inoculados com células de glioblastoma humano U87MG-IDH1 ${ }^{\mathrm{WT}}$ e injetados com 0 contraste do conjugado NPM-HYNIC-PEG $-\mathrm{C}(\mathrm{GX} 1)$; (A) Anatomia (RARE); Mapa de subtração em T2 (B) 0-15min; (C) 0-30min; (D) 0-1h; (E) 0-1h30; (F) 0-2h pós-injeção
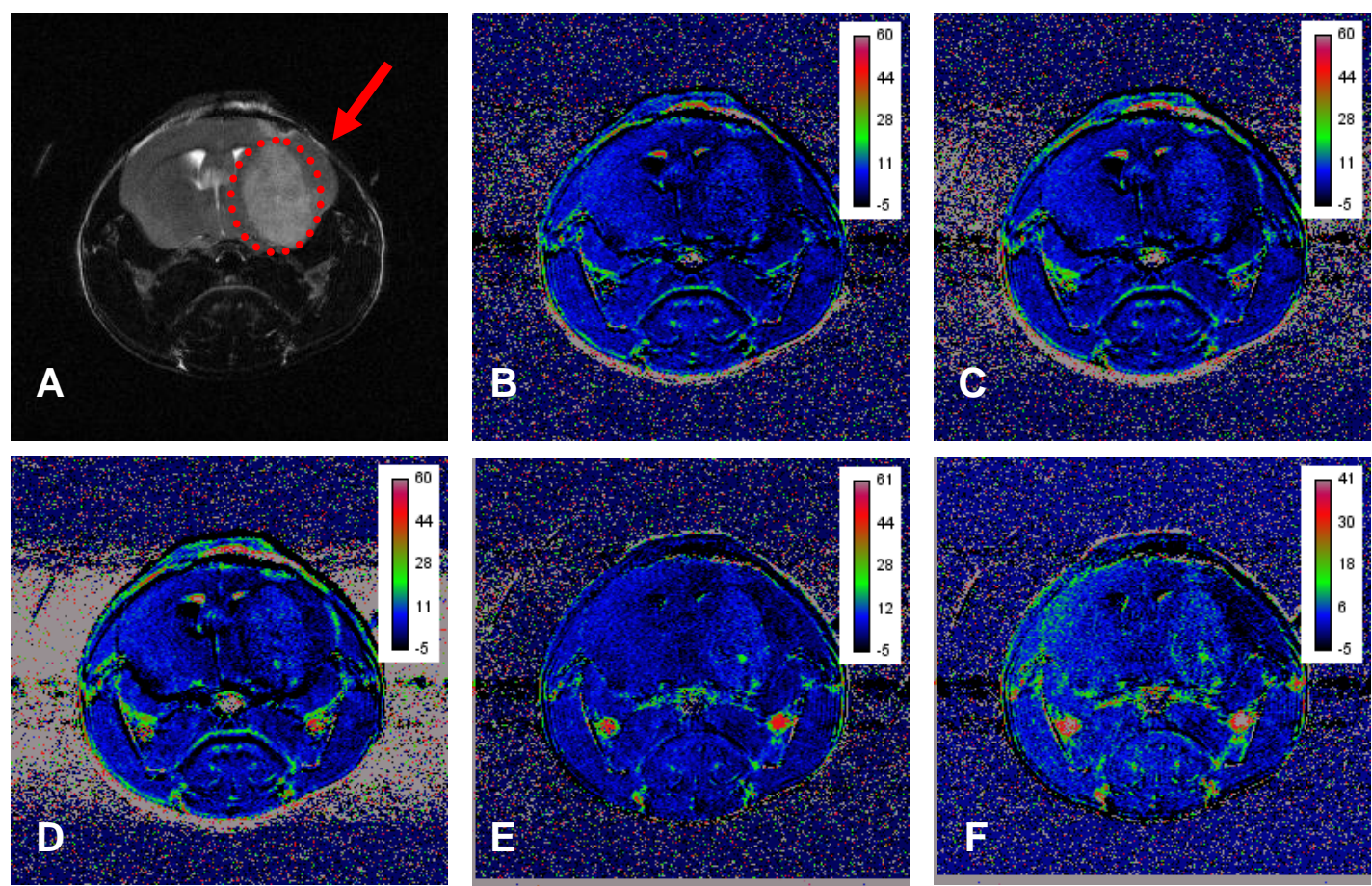

FIGURA 39 - Imagem de ressonância magnética de camundongos NOD-SCID inoculados com células de glioblastoma humano U87MG-IDH1 ${ }^{\mathrm{WT}}$ e injetados com 0 contraste do conjugado NPM-HYNIC-E-[c(RGDfk)-c(GX1)]; (A) Anatomia (RARE); Mapa de subtração em T2 (B) 0-15min; (C) 0-30min; (D) 0-1h; (E) 0-1h30; (F) 0-2h pós-injeção 
A FIG. 39 é referente às imagens obtidas com o contraste do conjugado do peptídeo HYNIC-E-[c(RGDfk)-c(GX1)] com as nanopartículas magnéticas de óxido de ferro (NPM) nas células U87MG-IDH1 ${ }^{\text {WT }}$. As FIG. de 39B a 39F mostram a evolução da captação do contraste injetado. Em todos os tempos de análise a captação foi muito pequena.

A FIG. 40 demonstra a quantificação dos valores T2 das captações obtidas nos tumores de células U87MG-IDH1 ${ }^{\mathrm{WT}}$ dos mesmos animais através das imagens de ressonância magnética.

É possível verificar que houve redução do sinal, indicando captação pelo tumor, logo após a injeção de ambos os contrastes. Com o conjugado NPMHYNIC-PEG $4-C(G X 1)$ é possível verificar a captação logo aos $15 \mathrm{~min}$ e aumentando ao longo do tempo, chegando a $14,66 \%$ de captação às $2 \mathrm{~h}$. Assim como o visualizado nas imagens, é possível verificar que a captação com o conjugado NPM-HYNIC-E-[c(RGDfk)-c(GX1)] foi muito pequena e variou pouco durante os tempos de análise, chegando somente a 3,5\% de captação no tempo de $2 h$.

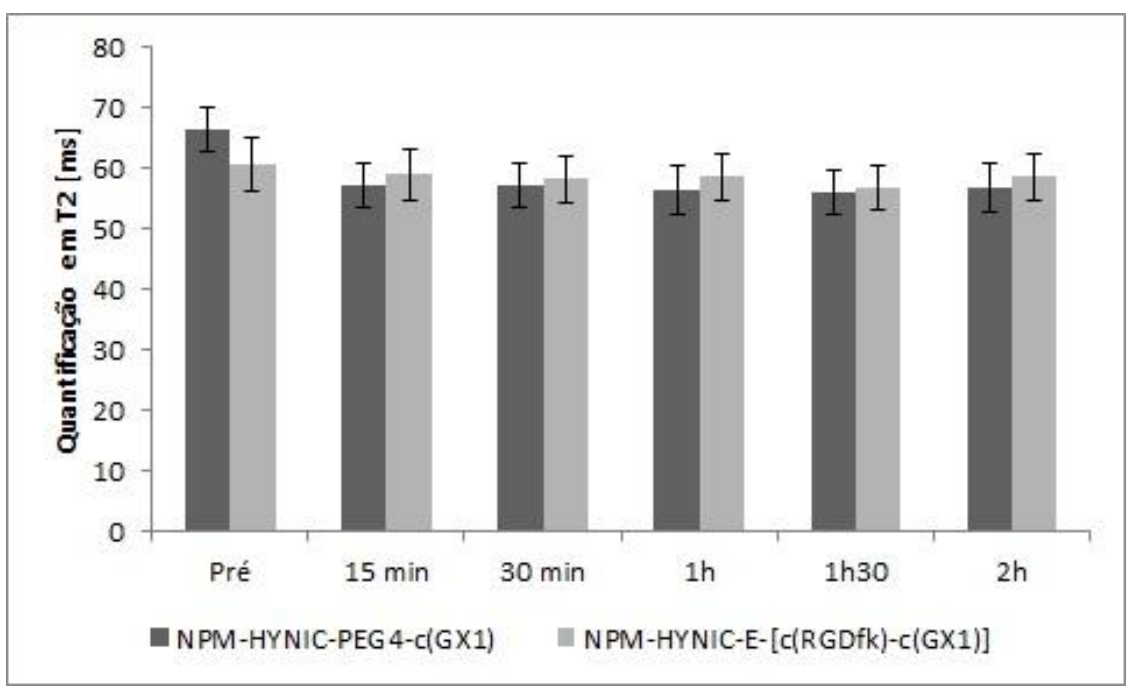

FIGURA 40 - Quantificação em T2 nos tumores dos animais portadores do tumor das células U87MG-IDH1WT obtida através das imagens de ressonância magnética com os contrastes conjugados NPM-HYNIC-PEG ${ }_{4}-\mathrm{C}(\mathrm{GX} 1)$ e NPM-HYNIC-E-[c(RGDfk)-c(GX1)] 


\subsubsection{Células U87MG-IDH1 ${ }^{\text {R132 }}$}

A FIG. 41 e FIG. 43 são referentes às imagens obtidas com os contrastes dos conjugados do peptídeo HYNIC-PEG $4-C(G X 1)$ e do peptídeo HYNIC-E-[c(RGDfk)-c(GX1)], respectivamente, com as nanopartículas magnéticas de óxido de ferro (NPM) nas células U87MG-IDH1 ${ }^{R 132}$. As FIG. de 41B a 41F e de 42B a 42F mostram a evolução da captação dos contrastes injetados em todos os tempos de análise. Nos primeiros tempos de análise (de 15 min a 30min) há uma pequena captação no tumor, sendo que a partir de 1 h é possível verificar o aumento da ligação ao tumor, atingindo o melhor resultado às $2 \mathrm{~h}$ após a injeção em ambas as situações.
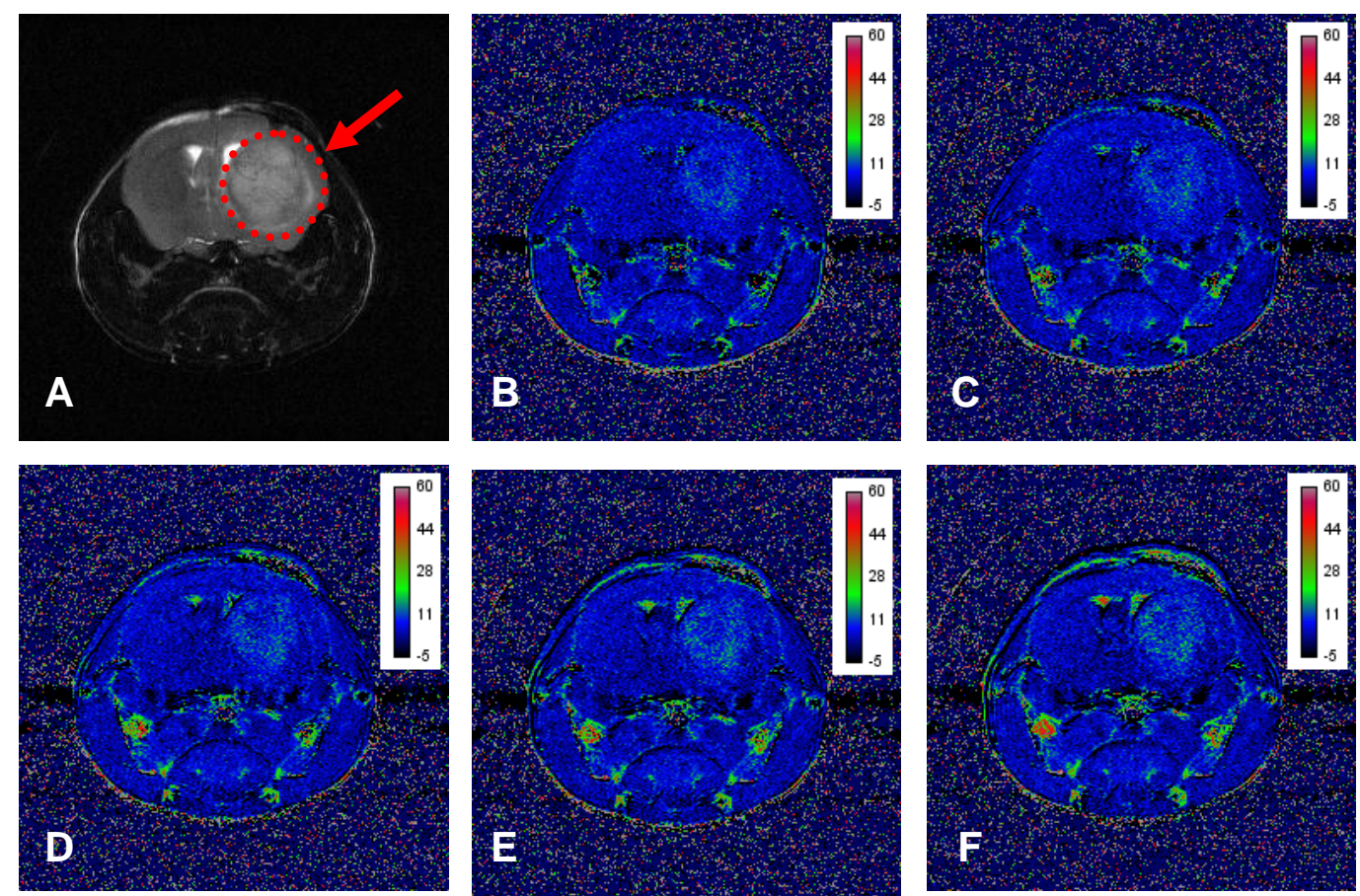

FIGURA 41 - Imagem de ressonância magnética de camundongos NOD-SCID inoculados com células de glioblastoma humano U87MG-IDH1 ${ }^{\mathrm{R} 132}$ e injetados com o contraste do conjugado NPM-HYNIC-PEG 4 -C(GX1); (A) Anatomia (RARE); Mapa de subtração em T2 (B) 0-15min; (C) 0-30min; (D) 0-1h; (E) 0-1h30; (F) 0-2h pós-injeção 

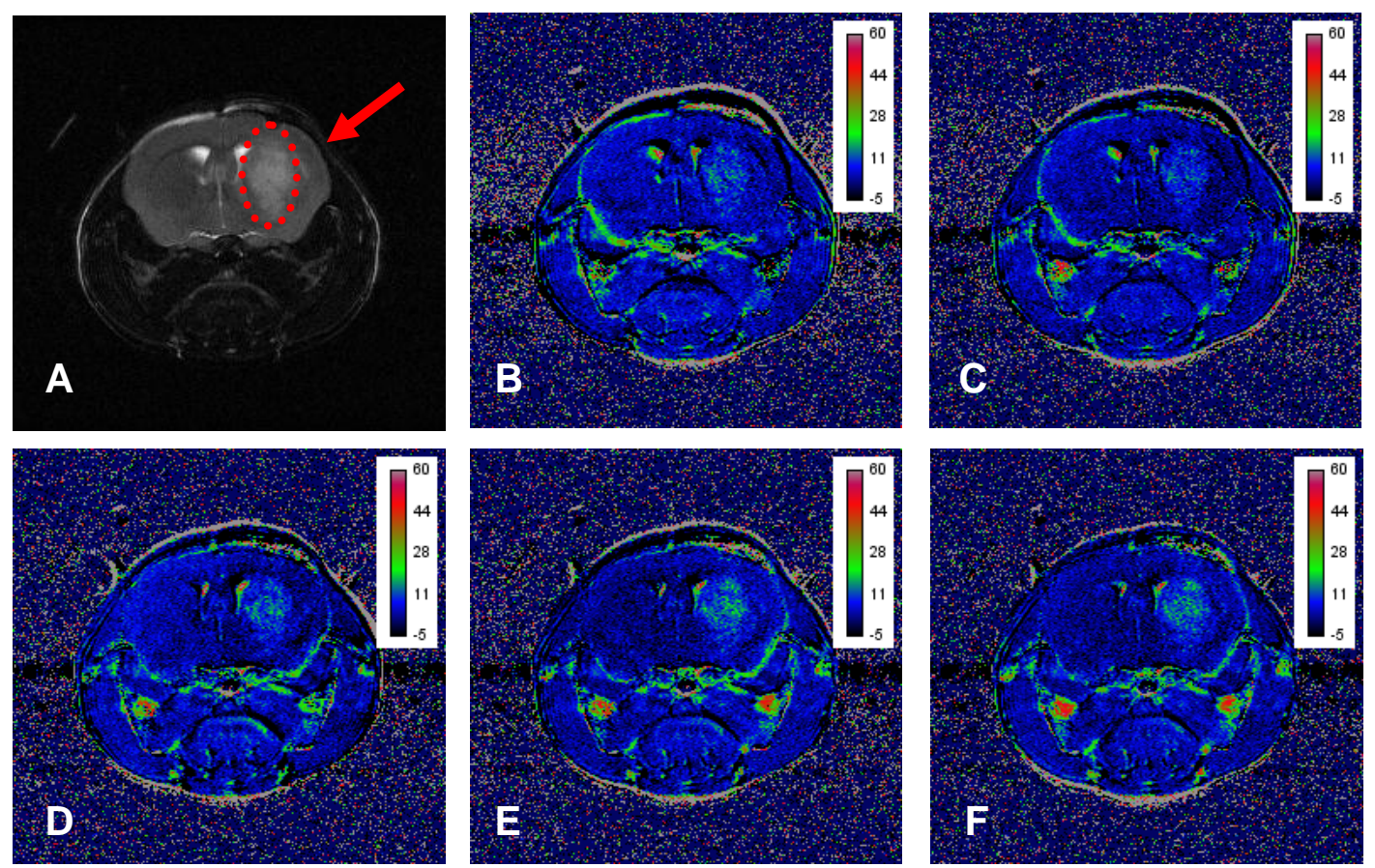

FIGURA 42 - Imagem de ressonância magnética de camundongos NOD-SCID inoculados com células de glioblastoma humano U87MG-IDH1 ${ }^{\mathrm{R} 132}$ e injetados com o contraste do conjugado NPM-HYNIC-E-[c(RGDfk)-c(GX1)]; (A) Anatomia (RARE); Mapa de subtração em T2 (B) 0-15min; (C) 0-30min; (D) 0-1h; (E) 01h30; (F) 0-2h pós-injeção

A FIG. 43 demonstra a quantificação dos valores T2 das captações obtidas nos tumores de células U87MG IDH1 ${ }^{\mathrm{R} 132}$ dos mesmos animais através das imagens de ressonância magnética.

Com os dois conjugados é possível visualizar a captação aumentando (devido à redução do sinal) ao longo do tempo, sendo que com o conjugado NPMHYNIC-E-[c(RGDfk)-c(GX1)] essa redução foi maior, indicando maior ligação do contraste às células tumorais, chegando a 15,84\% de captação e 12,39\% para o conjugado NPM-HYNIC-PEG $4-c(G X 1)$, porém sem diferença significativa ( $p>0,05)$. 


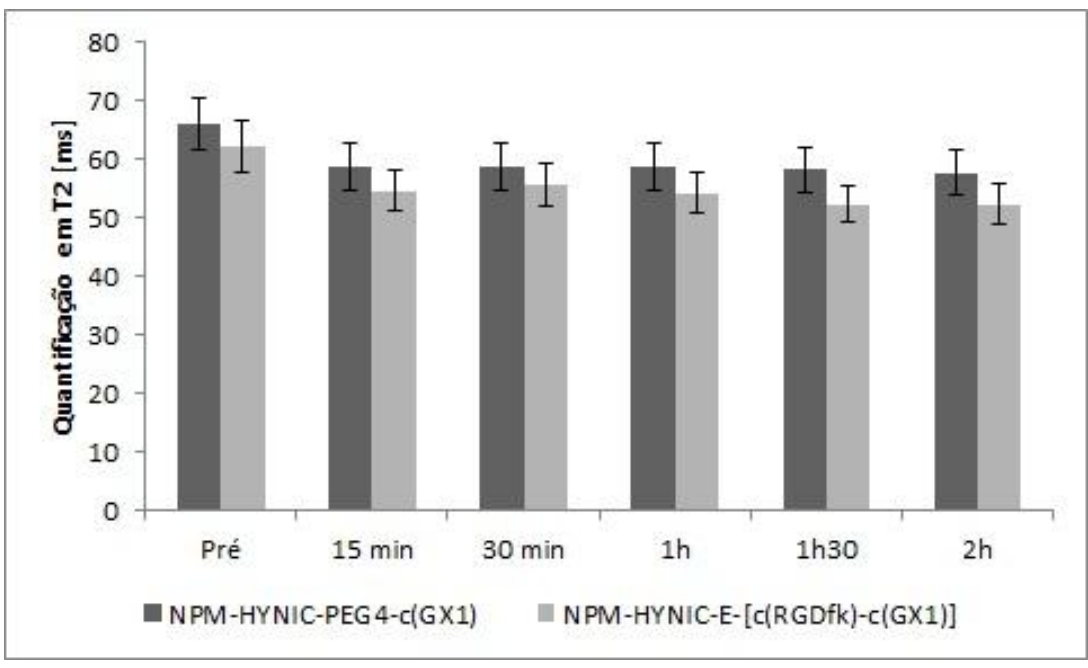

FIGURA 43 - Quantificação em T2 nos tumores dos animais portadores do tumor das células U87MG-IDH1 ${ }^{\mathrm{R} 132}$ obtida através das imagens de ressonância magnética com os contrastes conjugados NPM-HYNIC-PEG 4 -c(GX1) e NPM-HYNIC-E-[c(RGDfk)-c(GX1)]

Analisando todas as situações estudadas, os conjugados NPM-HYNICPEG $_{4}-\mathrm{c}(\mathrm{GX1}$ ) e NPM-HYNIC-E-[c(RGDfk)-c(GX1)] apresentaram resultados semelhantes nos tumores de células U87MG e U87MG-IDH1 ${ }^{\text {R132, }}$, porém, com exceção das células U87MG-IDH1 ${ }^{\mathrm{WT}}$, onde o conjugado NPM-HYNIC-PEG 4 $\mathrm{c}(\mathrm{GX} 1)$ apresentou um resultado melhor.

\subsection{Imagens Cintilográficas por SPECT/CT}

Foram realizadas as aquisições de imagens cintilográficas da cabeça dos animais em SPECT/CT do radiotraçador 99mTc-HYNIC-E-[C(RGDfk)-c(GX1)] no tempo de $1 \mathrm{~h}$ em tumores intracraniais de células U87MG, pois foi a situação que obteve o melhor desempenho nas avaliações prévias.

Foi possível visualizar o tumor nas posições coronal, sagital e axial dos animais sem bloqueamento, porém com pouca diferença de captação quando comparados aos tecidos adjacentes (FIG. 44). Na imagem do animal bloqueado com a adição de peptídeo frio (FIG. 45) é possível ver a diminuição na captação 
tumoral nos tecidos adjacentes, principalmente quando comparado a figura anterior. Entretanto, ainda é possível visualizar o tumor, demonstrando que sua captação não foi totalmente bloqueada.

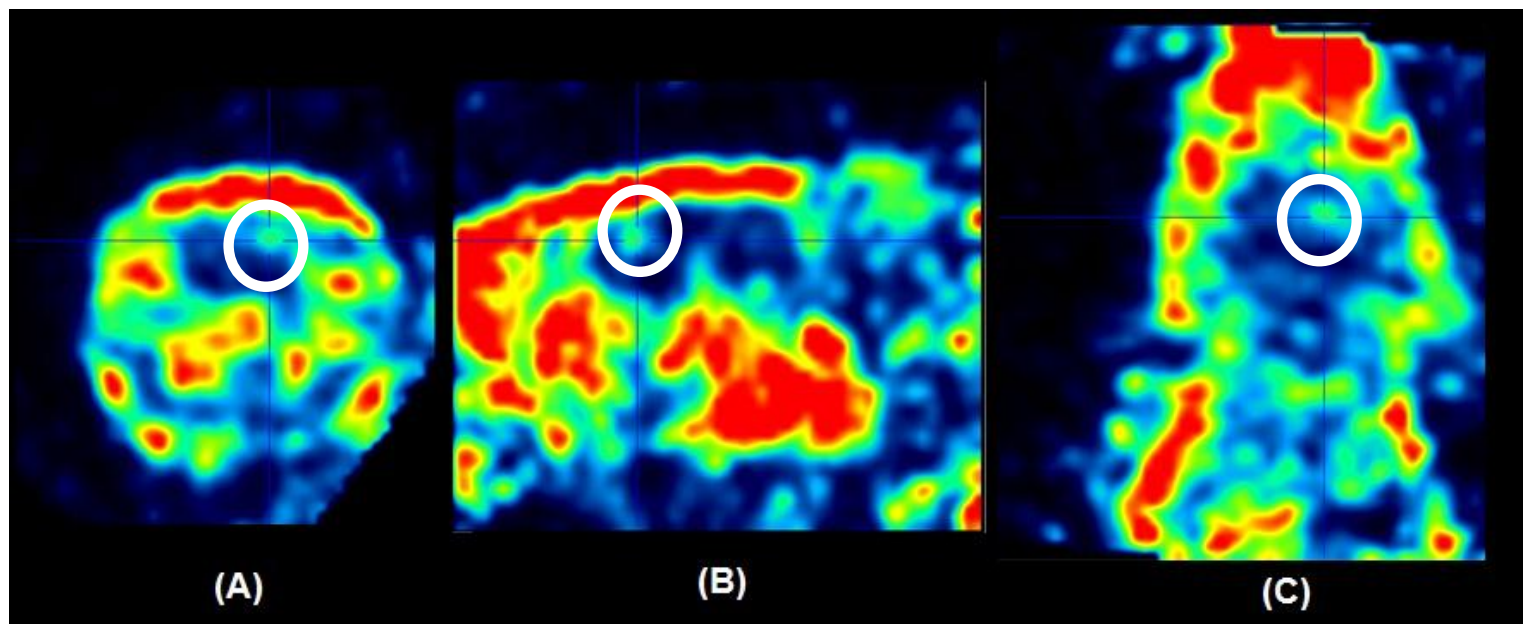

FIGURA 44 - Imagem de SPECT/CT de ratos Nude inoculados com células de glioma humano U87MG por cirurgia intracranial obtidas após $1 \mathrm{~h}$ da injeção do ${ }^{99 \mathrm{~m} T C} \mathrm{TC}$ HYNIC-E[c(RGDfk)-c(GX1)]; (A) Corte coronal; (B) Corte sagital e (C) Corte axial

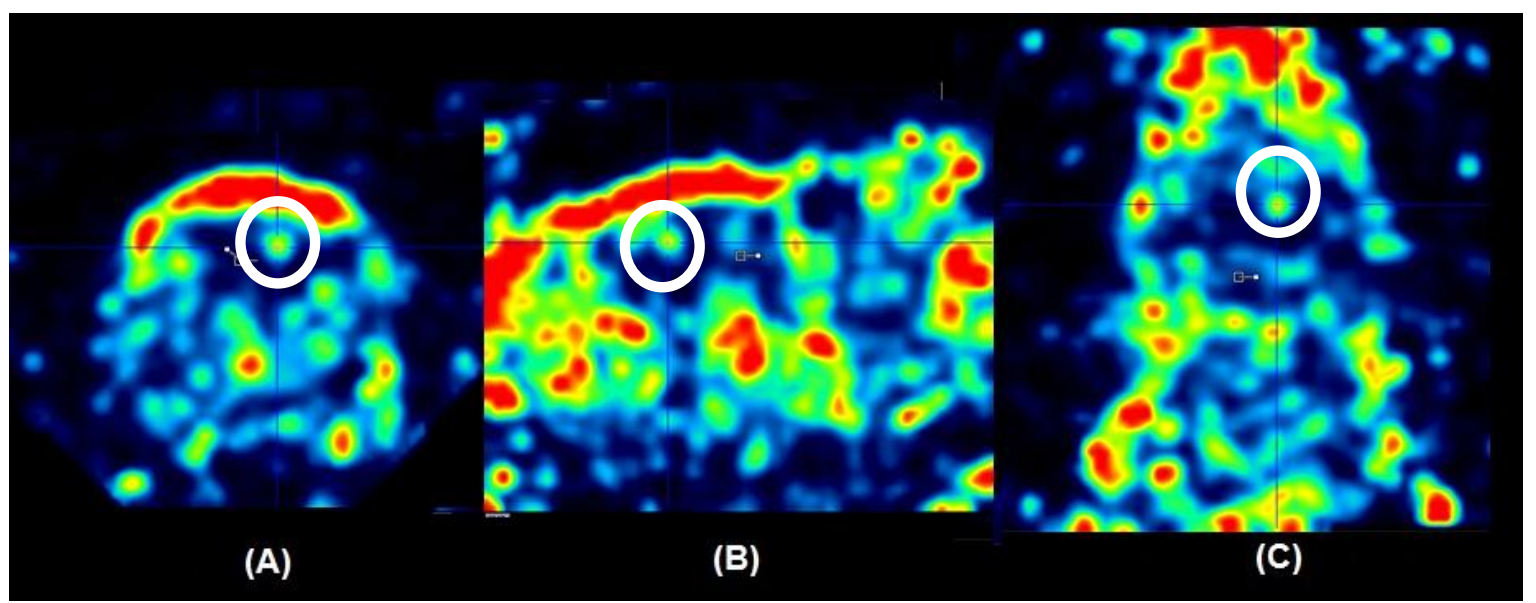

FIGURA 45 - Imagem de SPECT/CT com bloqueamento de ratos Nude inoculados com células de glioma humano U87MG por cirurgia intracranial obtidas após $1 \mathrm{~h}$ da injeção do ${ }^{99 m}$ Tc-HYNIC-E-[c(RGDfk)-c(GX1)]; (A) Corte coronal; (B) Corte sagital e (C) Corte axial 


\subsection{Teste do Campo Aberto}

Os parâmetros de total de entradas e distância percorrida são as medidas clássicas para avaliação da atividade locomotora dos animais (Campos e col., 2013). Os dados, apresentados nas FIG. 46 e FIG. 47, mostram uma tendência a diminuição dessa atividade nos animais com glioblastoma localizado na região cortical. O glioblastoma desses animais está circunscrito a região cortical motora primária e secundária (M1 e M2), sendo que prejuízos motores já são descritos na literatura após comprometimento desse local (Carmel e Martin, 2014; Hou e col., 2006). O acometimento do núcleo estriado também leva a déficit motor (Wang e col., 2014), entretanto, os animais não apresentaram essa alteração pelo tamanho do glioblastoma que foi restrito a uma pequena porção.

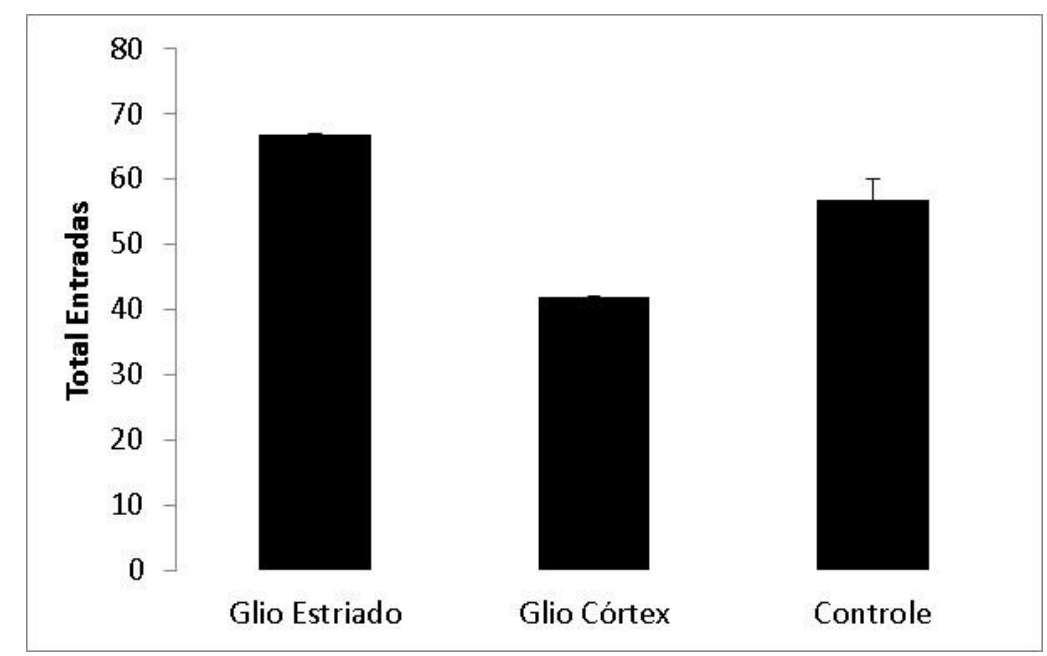

FIGURA 46 - Representação gráfica do total de entradas dos ratos Nude portadores de glioblastoma submetidos ao teste em campo aberto para avaliação comportamental 


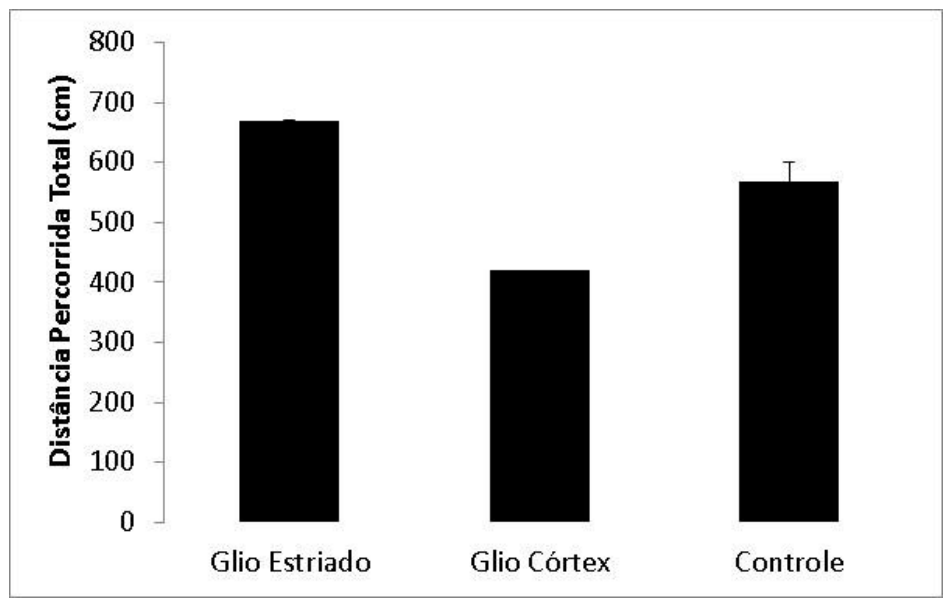

FIGURA 47 - Representação gráfica da distância percorrida total em cm dos ratos Nude portadores de glioblastoma submetidos ao teste em campo aberto para avaliação comportamental

O comportamento de levantamento (Rearing) é considerado um comportamento exploratório/investigatório que normalmente é aumentando em situações de aumento nos níveis de ansiedade, sendo que em estudos clínicos existe correlação entre aumento da ansiedade em pacientes acometidos por câncer (Beeker e col., 2014). Nos dados desse trabalho, observa-se um aumento da frequência e do tempo gasto nesse comportamento, com um aumento maior no grupo com tumor no estriado cerebral, quando em comparação com os outros grupos (FIG. 48 e FIG. 49). 


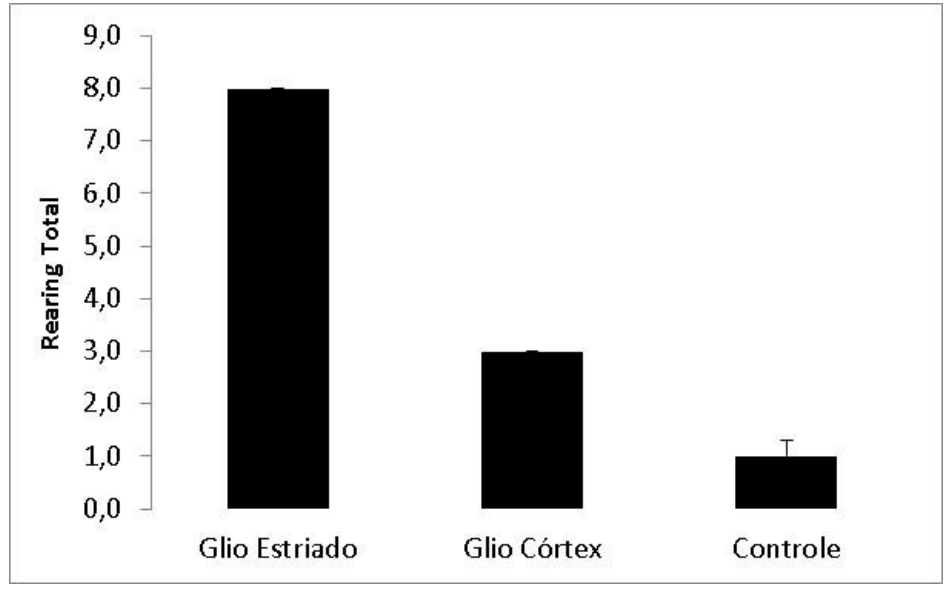

FIGURA 48 - Representação gráfica do rearing total dos ratos Nude portadores de glioblastoma submetidos ao teste em campo aberto para avaliação comportamental

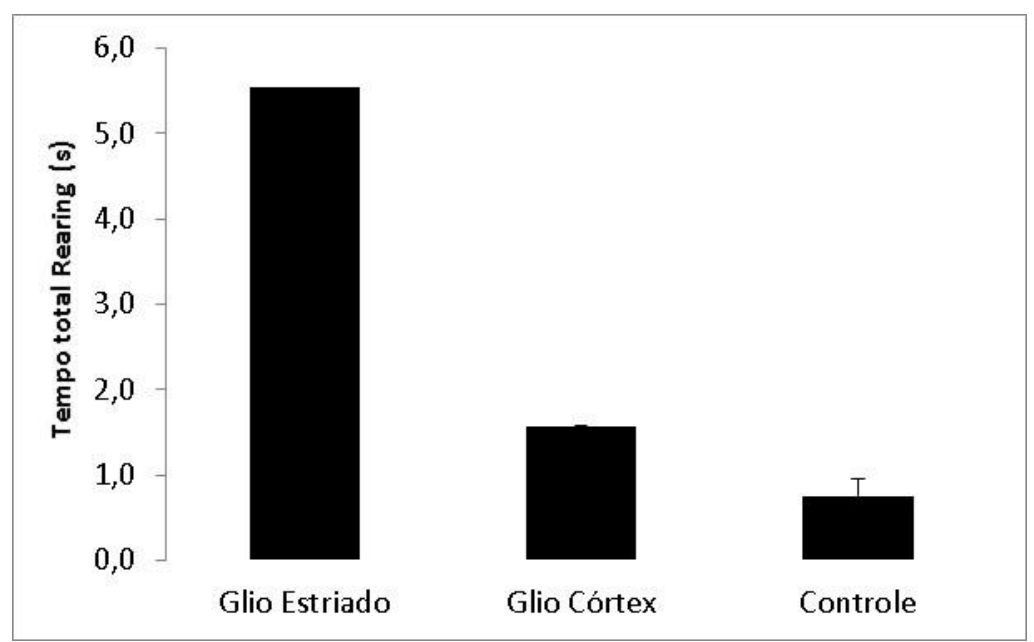

FIGURA 49 - Representação gráfica do tempo total de rearing em segundos dos ratos Nude portadores de glioblastoma submetidos ao teste em campo aberto para avaliação comportamental 


\subsection{Histologia}

Pelos estudos histológicos foi possível a confirmação do desenvolvimento dos tumores nos animais implantados por via estereotáxica, nos quais foram adquiridas as imagens em SPECT/CT do item 4.11. As FIG. 50 e FIG. 51 são referentes ao rato da FIG. 44, confirmando a presença de um tumor grande localizado na região do estriado cerebral.

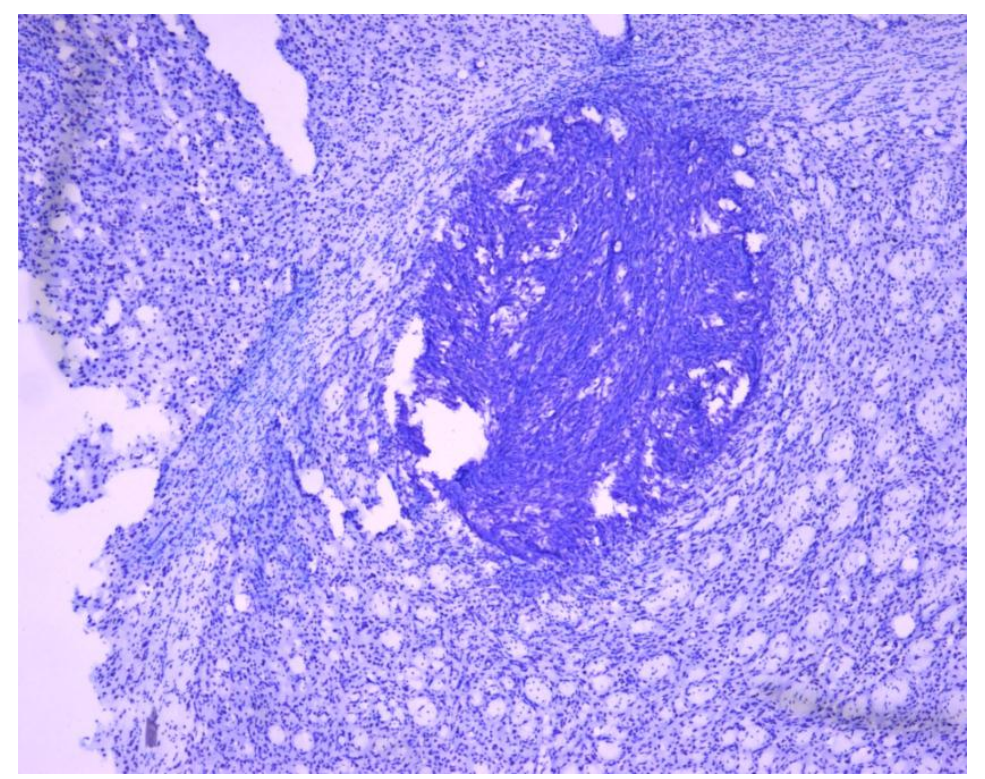

FIGURA 50 - Lâmina histológica com coloração de Nissl no aumento de 4x do cérebro de rato Nude com glioma inoculado intracranialmente e utilizados na aquisição de imagens por SPEC/CT sem bloqueamento

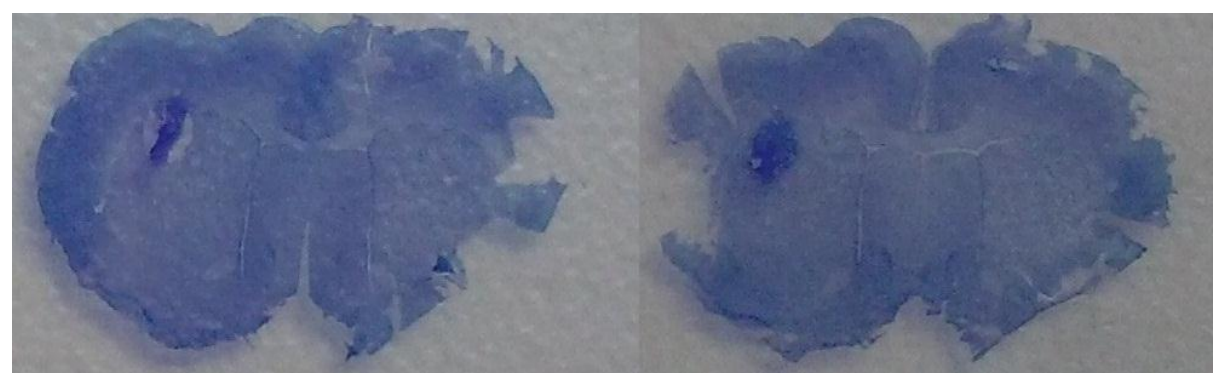

FIGURA 51 - Lâmina histológica com coloração de Nissl a olho nu do cérebro de rato Nude com glioma inoculado intracranialmente e utilizados na aquisição de imagens por SPEC/CT sem bloqueamento 
As FIG. 52 e FIG. 53 são referentes ao rato da FIG. 45, no qual foi injetado o radiotraçador com a adição de peptídeo frio, para efeito de bloqueamento. Foi possível a confirmação de desenvolvimento tumoral neste animal, localizado na região do córtex do cérebro, pois provavelmente as células tumorais subiram no momento da inoculação intracranial.

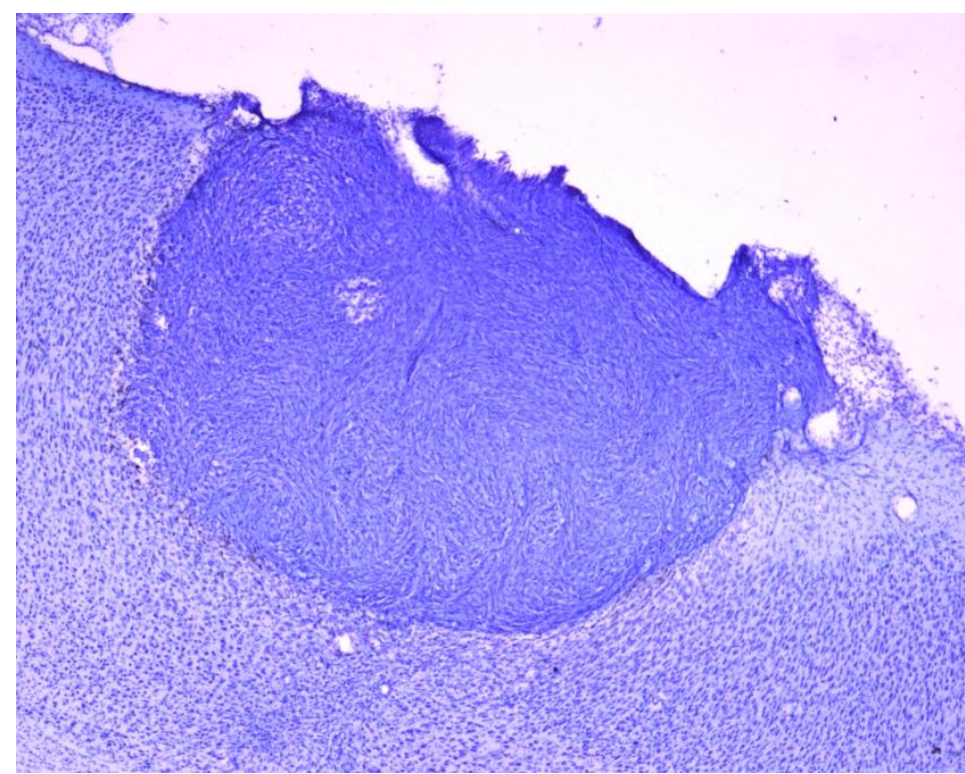

FIGURA 52 - Lâmina histológica com coloração de Nissl no aumento de 4x do cérebro de rato Nude com glioma inoculado intracranialmente e utilizados na aquisição de imagens por SPEC/CT com bloqueamento

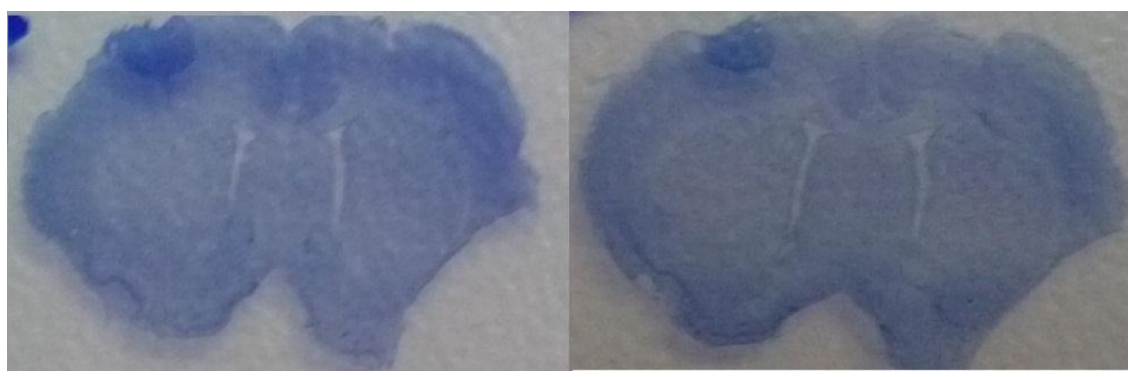

FIGURA 53 - Lâmina histológica com coloração de Nissl a olho nu do cérebro de rato Nude com glioma inoculado intracranialmente e utilizados na aquisição de imagens por SPEC/CT com bloqueamento 


\section{DISCUSSÃO}

O presente estudo visou o desenvolvimento de um novo radiotraçador, a partir de peptídeos radiomarcados, com alvo para processos angiogênicos em gliomas. Através do uso de duas sequências, os peptídeos RGD e GX1, visamos aumentar a especificidade do radiofármaco para atingir o alvo patológico e acumular em quantidade suficiente, enquanto preserva o tecido saudável. $O$ desenho de uma molécula com alvo duplo é uma abordagem atrativa, porque vários tipos de cânceres expressam simultaneamente múltiplos tipos de receptores (Liu e Wang, 2010).

Diferenças de características biológicas de RGD, linear e cíclico, já foram descritas antes (Kim e col., 2005; Kostidis e col., 2004; Metaferia e col., 2010; Verrier e col., 2002). O GX1 foi usado em sua forma cíclica desde os primeiros trabalhos (Chen e col., 2009; Hui e col., 2008; Zhi e col., 2004).

As sequências de peptídeos usadas nesse estudo e os espaçadores são diferentes, mas o quelante bifuncional (HYNIC) foi o mesmo. $O$ agente quelante bifuncional, assim como o espaçador, são comumente usados em procedimento de radiomarcação para melhorar a estabilidade. O quelante bifuncional ácido hidrazinonicotínico (HYNIC) já foi usado para radiomarcação de biomoléculas com ${ }^{99 \mathrm{~m} T c}$, e as características desse método de marcação já são bem conhecidas (Erfani e col., 2014; Faintuch e col., 2005; Guo e col., 2014; Meszaros e col., 2011). O polietilenoglicol (PEG) é um polímero altamente investigado para modificações covalentes em moléculas biológicas e o glutamato (E) foi usado na molécula heterodímera para possibilitar a ligação entre os dois peptídeos e o agente quelante.

Constam na literatura vários estudos com moléculas de RGD, usando diferentes quelantes, tais como o DTPA, HYNIC, DOTA, MAG2, MAG 3 , de maneira que o comportamento das moléculas seriam exclusivamente relacionadas as suas sequências de aminoácidos e conformação estrutural (Decristoforo e col., 2006; Liu e col, 2001; Oliveira e col., 2012; Shi e col., 2009b; van Hagen e col., 2000; Zhou e col., 2011b). Com a molécula de GX1, já foi usado o quelante DOTA, na marcação com cobre-64 (Chen e col., 2012a). 
O tecnécio é ainda o radionuclídeo para diagnósticos mais amplamente disponível e de fácil marcação, sem necessidade de purificação, fazendo com que traçadores marcados por ${ }^{99 \mathrm{mT} c}$ sejam adequados para produção em massa de kits que podem ser distribuidos e usados em hospitais e clínicas onde haja um gerador do radionuclídeo preente (Ebenhan e col., 2014a). Coligantes são necessários para completar a esfera de coordenação do núcleo de tecnécio, porque o HYNIC só pode ocupar uma ou duas posições no radionuclídeo (Faintuch e col., 2005). No grupo de diferentes coligantes, tricina e EDDA são os que tem a melhor eficiência de radiomarcação.

Pelo padrão de CLAE dos ${ }^{99 m}$ Tc-peptídeos conjugados mostrado na FIG. 13, somente um único pico foi observado para ambos traçadores, sugerindo que somente um único produto foi formado, com alta pureza radioquímica. Os valores de tempo de retenção e de coeficiente de partição foram bem parecidos para ambos conjugados. O pico similar no perfil de radio-CLAE entre eles, deve ser devido aos pesos moleculares, hidrofilicidade e estrutura semelhantes. Assim como também foi visualizado e confirmado pelo perfil na análise em UV e na análise de estabilidade em soro humano em vários tempos.

O coeficiente de partição é uma medida da lipofilicidade de um composto e é definido como a razão da concentração do mesmo, no equilíbrio, após dissolução em um sistema de duas fases, formadas por dois solventes imiscíveis, como por exemplo, a água e o octanol (Silva e Ferreira, 2003). Ele também é uma importante propriedade físico-química de um fármaco, pois a farmacocinética e biodistribuição in vivo do fármaco dependem da sua característica hidrofílica ou lipofílica (Kothari e col., 2003). Usualmente, o valor do coeficiente final é expresso em $\log P$, sendo que um composto lipofílico deve apresentar um coeficiente superior a 0,9. Quanto maior o valor do coeficiente de partição, maior a afinidade da substância pela fase orgânica. No entanto, substâncias hidrofílicas apresentam baixo $\log P$. Essa característica, em radiofarmácia, é favorável a uma depuração sanguínea e uma rápida excreção renal, importantes na visualização por imagem do órgão de interesse (Zhang e col., 2002).

Como já era esperado, o complexo 99mTC-HYNIC-PEG4-C(GX1) apresentou caráter hidrofílico $(\log P-2,51 \pm 0,04)$, sendo este resultado próximo 
ao obtido por Chen e col. (2012a) em suas marcações de GX1 marcados com ${ }^{64} \mathrm{Cu}(\log P-2,42 \pm$ 0,003). O 99mTc-HYNIC-E-[c(RGDfk)-c(GX1)] também apresentou caráter hidrofílico, porém menor $(\log P-2,25 \pm 0,07)$. Decristoforo e col. (2006) obtiveram resultados mais hidrofílicos ( $\log P$ em torno de $-3,5)$ com conjugados de HYNIC-RGD marcados com tecnécio-99m.

A vasculatura cerebral é diferente dos outros órgãos, pois possui a barreira hematoencefálica (BHE) que dificulta o acesso ao tecido cerebral de substâncias grandes e hidrofílicas (Deeken e Loscher, 2007) . Porém, nesse estudo o alvo são os receptores angiogênicos expressos nos vasos sanguíneos, desta maneira, não há a necessidade de atravessar e barreira, podendo assim ser mantida a característica hidrofílica, conhecida como vantajosa nos radiofármacos.

O sangue é composto por aproximadamente 7\% de protéinas. Essas proteínas exercem a função de transportar diferentes substâncias pela corrente sanguínea, como os fármacos, e para que isso ocorra, é necessário que essas substâncias se liguem às proteínas plasmáticas. Essa ligação é reversível e não específica, e depende de vários fatores, como $\mathrm{pH}$, carga, tamanho e afinidade (Ritschel e Kearns, 2009). A ligação às proteínas plasmáticas afeta diretamente a biodistribuição do radiofármaco aos tecidos de interesse. Portanto, é necessário determinar a extensão dessa ligação em qualquer fármaco novo, antes de sua utilização (Saha, 1998).

Através dos resultados de sangue total e ligação total ao plasma, é possível verificar que uma porcentagem mínima de radioatividade permaneceu no sangue em longos tempo, para ambos radiotraçadores, representando a ligação às proteínas plasmáticas, favorecendo os radiotraçadores que em sua maioria ficaram livres. A ligação às proteínas plasmáticas foi maior que o dobro para 0 traçador monômero, provavelmente devido à peguilação na molécula, levando à uma inibição significante da adsorção de proteínas, reconhecimento menor pelo sistema fagocitário, aumento do tamanho da molécula e redução da taxa de filtração glomerular (Denardo e col., 2003; Vonarbourg e col., 2006).

A biodistribuição de radiofármacos é essencial à determinação da sua eficácia e utilidade. Isto inclui a absorção, distribuição através dos tecidos, depuração sanguínea e excreção após a administração da droga. A excreção do radiofármaco faz-se por meio dos mecanismos existentes (por exemplo, excreção 
pulmonar, hepática e renal) e segue uma lei exponencial semelhante ao decaimento do radionuclídeo (Oliveira e col., 2006).

Os achados na avaliação da biodistribuição relacionados aos rins, fígados e intestinos, confirmam os valores de coeficiente de partição, mostrando uma alta hidrofilicidade como característica para os radioconjugados e sugerindo a via urinária como a via de excreção principal. Entretanto, uma porcentagem significante de radioatividade manteve-se no trato hepatobiliar. Um modelo ideal de biodistribuição, é aquele em que qualquer radioatividade não ligada ao tumor e/ou não-específica, seja rapidamente depurada do sangue e eficientemente excretada sem significante retenção por nenhum órgão normal ou não-alvo. Desde que a depuração hepatobiliar é necessariamente acompanhada por um relativamente baixo trânsito gastrointestinal da droga, antes que a radioatividade seja depurada do corpo, uma rota de excreção inteiramente renal do radiofármaco é desejada. Também, a redução da quantidade de radioatividade retida nos órgãos não-alvos e na circulação sanguínea são parâmetros importantes na determinação do tempo de aquisição das imagens cintilográficas (Schotellius e Wester, 2009).

Seguindo a rota de excreção dos conjugados radiomarcados em nosso estudo, observou-se que após os $5 \mathrm{~min}$ da administração do traçador, e de alta captação renal, há uma queda constante na atividade nos rins, corroborando com os resultados de depuração sanguínea e indicando a excreção de ambos radiofármacos. A depuração sanguínea foi rápida e a do GX1 foi tipicamente maior que a do RGD-GX1. A molécula maior pode ser a responsável pela excreção mais devagar do 99mTc-HYNIC-E-[c(RGDfk)-c(GX1)].

Uma baixa captação da radioatividade por todos os órgãos foi observada nos estudos de biodistribuição a partir de $2 \mathrm{~h}$ p.i. Os níveis de radioatividade encontrados no estômago (cerca de $2 \%$ ) em todos os tempos estudados, para ambos radioconjugados, indicam a estabilidade dos radiocomplexos frente a uma reoxidação.

Os peptídeos menores e mais hidrofílicos são geralmente removidos rapidamente do plasma pela filtração glomerular nos rins. A lipofilicidade normalmente seria vista como indesejável, pois seria esperado que 0 radiofármaco excretado fosse levado para o trânsito intestinal. No entanto, o 
metabolismo no trato gastrointestinal pode resultar em liberação do radionuclídeo na corrente sanguínea de uma forma na qual sofre eliminação renal (ListerJames, Moyer e Dean, 1997). Mas, considerando a alta captação dos rins para ambos conjugados, este evento não ocorre. Essa hidrofilicidade é importante como característica no transporte de drogas, porque afeta a maneira com que a droga vai alcançar o local de ação a partir do local de administração. Drogas altamente hidrofílicas podem se ligar a proteínas plasmáticas e essa ligação pode modificar as propriedades farmacocinéticas e a concentração no sangue (Stevenson e col., 2000 e 1994). Em cânceres, esse evento é menor, e a rápida depuração sanguínea confirma que isso não acontece para ambas as drogas (Svensson, 1986).

É importante ressaltar que o tempo de meia vida biológica de um radiofármaco está diretamente relacionado às suas propriedades estruturais bem como estabilidade do radiocomplexo in vivo. Portanto, uma rápida depuração de um fármaco em tempos precoces não demonstra ser um aspecto positivo, quanto ao seu tempo de circulação no organismo, e consequentemente ao seu tempo de acumulação nos sítios tumorais.

Dentre os parâmetros para determinação e escolha dos tempos que serão avaliados no modelo tumoral, as captações totais no sangue, ossos e músculo, representam um conjunto de fatores crucial para a boa aquisição de uma imagem cintilográfica. No entanto, as \%DI calculadas para sangue, músculo e osso totais (TAB. 3), indicam que a realização da avaliação em modelos tumorais seria mais adequada em tempos superiores aos $60 \mathrm{~min}$ p.i., onde a maior concentração da dose injetada (95\%) foi depurada do sangue, para ambos os radiomarcados.

A internalização é um importante mecanismo na comunicação intracelular, que compreende a degradação e a reciclagem da maioria dos peptídeos agonistas e seus receptores, resultando na acumulação celular do ligante. Embora seja um fenômeno altamente variável e dependente dos tipos e subtipos de receptores envolvidos, este mecanismo desempenha um papel fundamental na intensidade do sinal cintilográfico (Reubi, 2003).

O estudo de ligação às células endoteliais (HUVEC) foi realizado como controle em comparação às células tumorais de glioblastoma U87MG e T98G. 
Através desse estudo, foi demonstrado que os radiotraçadores ligam-se muito mais às células tumorais, do que às células endoteliais normais, confirmando a especificidade pelas células de glioblastoma. É importante considerar que a especificidade às células tumorais de glioblastoma reflete somente uma parte do potencial de ligação específica dos radiotraçadores ao tumor, pois seu alvo principal é a vasculatura tumoral, que somente pode ser reproduzida em um ambiente in vivo.

O perfil do ${ }^{99 m T c-H Y N I C-P E G} 4-\mathrm{C}(\mathrm{GX} 1)$ nas duas células foi bastante semelhante. Há um crescimento da ligação total às células com um pico em $1 \mathrm{~h}$ e depois decaindo até $2 \mathrm{~h}$, sendo que na linhagem celular U87MG os valores foram maiores do que os encontrados com a linhagem celular T98G $(p<0,05)$. Porém, em termos de ligação específica, não houve diferença significativa entre os resultados obtidos $(p>0,05)$ e na internalização total, foi observado um melhor resultado também nas células U87MG, quando comparada às células T98G $(p<0,05)$.

Analisando o 99mTc-HYNIC-E-[c(RGDfk)-c(GX1)] nas duas células também encontramos o mesmo perfil de ligação total, com um crescimento mais gradativo até às $2 \mathrm{~h}$ para a linhagem celular T98G. No caso das células U87MG, o crescimento foi mais acentuado nos últimos 30 min de incubação até às $2 \mathrm{~h}$, com destaque para a alta captação obtida. A ligação específica também foi maior $(p \leq 0,01)$, porém, na internalização não houve diferença significativa entre as células $(p>0,05)$.

Os estudos de ligação às células mostraram-se favoráveis ao conjugado 99mTc-HYNIC-E-[c(RGDfk)-c(GX1)] em células U87MG. Houve um aumento da ligação total, ligação específica e internalização do produto em relação ao aumento do tempo de incubação. Estes resultados corroboram com os estudos de biodistribuição em animais portadores de células tumorais. Tanto o conjugado 99mTc-HYNIC-E-[c(RGDfk)-c(GX1)] em células T98G, quanto o conjugado ${ }^{99 m} \mathrm{Tc}-\mathrm{HYNIC}-\mathrm{PEG}_{4}-\mathrm{c}(\mathrm{GX} 1)$, em ambas células tumorais, apresentaram desempenhos inferiores.

Os resultados de internalização confirmam que ambos radiotraçadores ligam-se tanto em receptores expressos em células como em vasos tumorais, pois houve uma captação em animais portadores de células tumorais maior do 
que os resultados obtidos nos estudos in vitro em células tumorais, como já descrito na literatura (Fukasawa e col., 2006; Ruoslahti e col., 2010; Zitzmann e col., 2002). Usar um composto com propriedades de penetração no tumor, que é o caso de pequenos peptídeos, e um receptor que é compartilhado pelo vaso tumoral e pelas células tumorais fornecem uma vantagem adicional à marcação tumoral para fins diagnósticos e terapêuticos.

Pelos resultados dos ensaios in vitro, concluiu-se que o pico de ligação do traçador ${ }^{99 m T c-H Y N I C-P E G} 4-\mathrm{C}(\mathrm{GX} 1)$, em ambas as células ocorreu aos $60 \mathrm{~min}$ após a incubação, diminuindo em tempos maiores. Com o 99mTc-HYNIC-E[c(RGDfk)-c(GX1)] , o pico de ligação ocorreu aos 120 min de incubação, também para ambas as células. Comparando o tempo estudado de $1 \mathrm{~h}$, o 99mTc-HYNIC$P_{E G}-c(G X 1)$ apresenta valores significantemente maiores do que o 99mTcHYNIC-E-[c(RGDfk)-c(GX1)] $(p<0,01)$ em ambas as células na ligação total.

Esse é um bom tempo para estudo em modelo animal tumoral, pois segundo os dados da biodistribuição feita em animais sadios, observou-se uma boa depuração sanguínea. Porém, esse tempo pode não favorecer o estudo com 99mTc-HYNIC-E-[c(RGDfk)-c(GX1)]. Por isso, para esse radiotraçador, a análise em animais portadores de células tumorais também foi conduzida no tempo de $2 h$.

Gliomas tendem a ser altamente vascularizados, uma característica que é crítica para o seu crescimento. Tem sido muito explorado o aumento da vasculatura de gliomas para a localização e diagnóstico destes tumores por angiografia e estudos contrastados que usa como vantagem a permeabilidade dos vasos. A proliferação vascular é um importante marcador na classificação histológica de gliomas (Daumas-Duport, 1992). O grau de vascularização tem sido mostrado como correlacionado com a classificação do tumor e sua agressividade, presumivelmente porque tumores com uma rápida taxa de crescimento requer um aumento de nutrientes e oxigênio (Plate e Mennel, 1995).

O desempenho do traçador RGD-GX1 foi superior ao GX1, com maior captação tumoral, maior razão tumor/sangue e tumor/músculo e maiores valores de bloqueamento, mostrando ser mais específico, principalmente para o glioblastoma U87MG. 
Chen e col. (2012a) estudaram a molécula do GX1 radiomarcada com ${ }^{64} \mathrm{Cu}$ em animais portadores de células tumorais U87MG e obtiveram captação tumoral de $6.46 \pm 0.29 \% \mathrm{ID} / \mathrm{g} 24 \mathrm{~h}$ p.i. Nos ensaios in vitro, o valor máximo de ligação $0,29 \%$ de toda a radioatividade colocada às $2 \mathrm{~h}$. A ligação total in vitro obtida no presente estudo, com o ${ }^{99 m}$ Tc-HYNIC-E-[c(RGDfk)-c(GX1)] em células U87MG, destaca-se perante esse trabalho.

Zhang e col. (2006) quantificaram os receptores de integrina $\alpha v \beta 3$ em diversas células tumorais, sendo que as células U87MG, de glioblastoma foram as que apresentaram maior número de receptores para o RGD (aproximadamente 128.000 sítios por células).

Os estudos de bloqueio dos receptores específicos, que são definidos como a quantidade da droga fria (peptídeo não-radiomarcado) que é administrada antes ou simultaneamente com o radiotraçador com a finalidade de bloquear os órgãos/tecidos, foram realizados (FIG. 29) e indicaram a especificidade dos produtos estudados quase em sua totalidade. A avaliação das razões tumor/órgãos não-alvos agem como fatores preditivos na aquisição das imagens cintilográficas, bem como para os estudos clínicos. Primordialmente, razões elevadas de tumor/sangue, tumor/músculo e tumor/osso são essenciais para uma boa visualização tumoral, já que correspondem a boa parte do peso corpóreo.

O tumor pode ser claramente visualizado nas imagens de gamacâmara dos animais portadores de células U87MG e T98G com ambos radiotraçadores, porém com destaque para as células U87MG com o traçador RGD-GX1. Pode ser visualizado também uma alta captação nos órgão de excreção e no sítio de injeção da droga, veia caudal. A alta radioatividade na bexiga, demonstrada em todas as imagens, indica a excreção urinária, corroborando portanto, com os dados obtidos na biodistribuição em camundongos portadores de tumor.

O isocitrato desidrogenase-1 (IDH1) é uma enzima localizada no citoplasma e nos peroxissomos, que catalisa a descarboxilação oxidativa do ácido isocítrico, tendo como produto alfa-cetoglutarato e dióxido de carbono, convertendo NAD para sua forma reduzida NADH. Mutações no IDH1 promovem o desenvolvimento de um grande número de malignidades (Cairns e Mak, 2013). 
Uma análise genômica completa do glioblastoma humano multiforme (GBM) em 2008 revelou que há uma mutação no sítio de ligação ativo do isocitrato desidrogenase-1 (IDH1) (sem perda de heterozigosidade) em $12 \%$ dos pacientes com glioblastoma (Yan e col., 2009). Investigações subsequentes confirmaram a presença de um ponto de mutação afetando a arginina no resíduo 132 (R132) da proteína do IDH1 (IDH1 ${ }^{\mathrm{R} 132}$ ) em > 70\% de gliomas de baixo grau (Yan e col., 2009). O resíduo R132 é conservado entre as espécies, provavelmente representando o local de ligação do substrato (Cohen, Holmen e Colman, 2013; Xu e col., 2004). O IDH1 ${ }^{R 132}$ parece ser em evento precoce no gliomagênese antes do aparecimento da mutação na p53 (Nobusawa e col., 2009), levando à especulação que isso contribui para a transformação maligna. A sobrevida global mediana entre os pacientes com astrocitoma anaplásico abrigando mutações no gene do IDH1 ou IDH2 é significantemente maior que nos pacientes sem essas mutações (65 vs 20 meses) (Yan e col., 2009). Similarmente, pacientes com glioblastoma com IDH1 ou IDH2 mutados tem uma sobrevida média de 31 meses vs 15 meses para pacientes com o tipo selvagem de IDH (IDH ${ }^{\mathrm{WT}}$ ) (Parsons e col., 2008, Yan e col., 2009). No entanto, gliomas são tumores heterogêneos tanto geneticamente como metabolicamente (Nikiforova e Hamilton, 2011), por isso é difícil de controlar as diferenças tumorais não relacionadas a mutação do IDH1 em pacientes.

Embora o peptídeo GX1 nunca tenha sido estudado conjugado com um contraste paramagnético para imagens de Ressonância Magnética, há alguns estudos com o peptídeo RGD. Liu e col. (2013) avaliaram um novo agente como contraste para obtenção de imagens de RM com especificidade para integrina avß3, o RGD-USPIO (partículas de óxido de ferro ultra pequenas e super paramagnéticas), que pode especificamente revelar o perfil angiogênico do câncer de pulmão em um scanner de RM 4.7T. Zhang e col. (2007) também estudaram o peptídeo RGD conjugado ao USPIO. Eles foram capazes de distinguir tumores que se diferenciavam pelo nível de expressão da integrina av $\beta 3$ e pelo perfil angiogênico, mesmo quando usando um scanner de RM padrão clínico de 1.5T. Park e col. (2008) descreveram o conjugado Gd-DOTA-RGD, como um potencial agente alvo para tumores hepatocelulares. 
Estudos em nanotecnologia tem levado ao desenvolvimento e síntese de várias nanopartículas magnéticas de óxido de ferro (NPM), que mudam o ambiente magnético dos prótons ao redor e alteram o sinal T1 e/ou T2 de uma maneira dependente da concentração, uma vez introduzidos nos tecidos do corpo (Akhtari e col., 2012; Akhtari e col., 2008; Islam e Harisinghani, 2009; Molday, 1984; Muldoon e col., 2005).

Analisando todos os achados experimentais dos peptídeos em estudo conjugados com as NPM, NPM-HYNIC-PEG 4 -C(GX1) e NPM-HYNIC-E-[c(RGDfk)$\mathrm{c}(\mathrm{GX1})]$, ambos obtiveram resultados similares com as células tumorais U87MG e U87MG-IDH1 ${ }^{\text {R132}}$, enquanto que para as células U87MG-IDH1 ${ }^{\text {WT }}$ somente o NPMHYNIC-PEG4-c(GX1) alcançou sucesso na ligação.

Houve mais captação com as células U87MG do que com as células U87MG mutantes. Tumores com mutação IDH1 ${ }^{\mathrm{R} 132}$ sofrem áreas grandes de necroses macroscópicas, atingindo até $40-50 \%$ de seu volume inteiro (Lazovic e col., 2012). É concebível que diferenças de crescimento e tamanho podem subjazer tais padrões, assim como a proliferação do tumor mutante mais rápido poderia superar a angiogênese indispensável que suporta a viabilidade celular (Altman e col., 2007; Jain e col., 2007; Pope e col., 2012). As lesões da mutação IDH1 podem também resultar em aumento nas espécies reativas de oxigênio e intensificar a resposta oxidativa. O crescimento tumoral desordenado ligado a ativação sustentada do inibidor do ciclo celular pode seguir, induzindo apoptose e necrose (Hamptom e Orrenius, 1997; Li e col., 2013; Ramsey e Sharpless, 2006; Takahashi e col., 2006).

A opção de um modelo ortotópico de glioma, embora tecnicamente complicado, é dotado de vantagens quando comparado ao modelo de heterotransplante, por imitar precisamente o ambiente cerebral tumoral (Fei e col., 2010). As imagens atuais de RM carecem de um padrão homogêneo no tumor devido à distribuição dos novos vasos tenderem a serem irregulares. Apesar de tal dificuldade, o desenvolvimento de agentes de contrastes para RM que atravessem a BHE e acumulem no tumor poderiam nutrir a habilidade de identificar gliomas, incluindo tumores pequenos e aqueles que infiltram os tecidos cerebrais adjacentes normais. 
Devido à problemas técnicos, não foi possível a realização da implantação ortotópica das células tumorais em camundongos para a aquisição em SPECT. Por isso, foram utilizados ratos nude atímicos, que são bastante similares aos camundongos e muito utilizados como modelo animal para tumores (Ruggeri e Camp, 2014). Os estudo em animais com tumor ortotópico foram

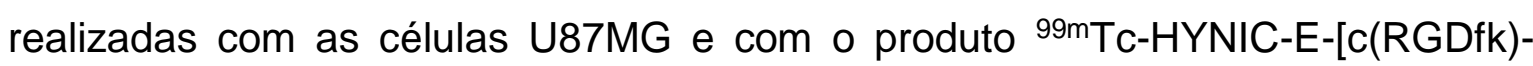
$c(G X 1)]$, que foi a situação com a melhor captação tumoral nos estudos prévios.

A imagem molecular tem aumentado os processos de investigação de várias doenças e se tornado uma ferramenta essencial no campo da oncologia, tanto para a pesquisa como na clínica (Higgins e Pomper, 2011). Outra vantagem desse tipo de imagem é a habilidade de promover uma avaliação tridimensinal de todo o órgão ou corpo, ajudando na correlação de todo o processo da doença (Ebenhan e col., 2014b).

Foi possível a visualização do tumor pelas imagens de SPECT/CT e o desenvolvimento dos tumores nesses animais foi confirmada pelas análises histológicas. A análise do comportamento animal se mostrou alterada nos parâmetros de rearing, principalmente para o animal com tumor localizado na região do estriado cerebral, quando comparados ao grupo controle. Porém, nas análises de locomoção, os animais não apresentaram comprometimento das funções. 


\section{CONCLUSÕES}

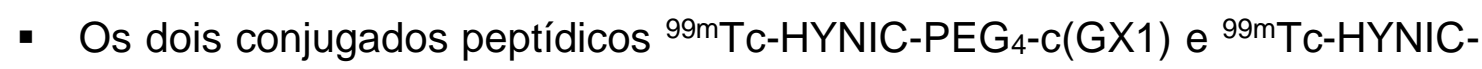
$\mathrm{E}-[\mathrm{c}(\mathrm{RGDfk})-\mathrm{c}(\mathrm{GX} 1)]$ foram marcados com tecnécio-99m, e obtiveram alta pureza radioquímica.

- Ambos demonstraram serem hidrofílicos com valores de $\log \mathrm{P}$ negativos e estáveis em soro humano até $4 \mathrm{~h}$, com acentuada excreção renal e rápida depuração sanguínea.

- Os dois conjugados radiomarcados ${ }^{99 m T C-H Y N I C-P E G} 4-c(G X 1)$ e ${ }^{99 m T C-}$ HYNIC-E-[c(RGDfk)-c(GX1)] demonstraram melhor ligação nas células de glioblastoma U87MG, sendo que para o primeiro radiotraçador isto ocorreu após 1 hora e com o segundo, após 2 horas de incubação.

- O composto ${ }^{99 m T C-H Y N I C-E-[c(R G D f k)-c(G X 1)] ~ a p r e s e n t o u ~ a ~ m e l h o r ~}$ captação tumoral em animais comparado ao ${ }^{99 m T c-H Y N I C-P E G} 4-c(G X 1)$ em células de glioblastoma humano U87MG.

- Com os estudos de ressonância magnética no ambiente cerebral, foi comprovada a ligação específica dos conjugados peptídicos ao tumor, sendo que o melhor tempo de análise é o de $2 \mathrm{~h}$ para ambos os conjugados na célula de glioblastoma humano U87MG.

- Nas imagens moleculares do cérebro obtidas pelo SPECT foi confirmada a captação do composto ${ }^{99 m}$ Tc-HYNIC-E-[c(RGDfk)-c(GX1)] pelas células tumorais de glioma humano U87MG.

- O radiotraçador 99mTc-HYNIC-E-[C(RGDfk)-c(GX1)] apresentou superioridade em todos os estudos realizados, confirmando as vantagens da inovadora ideia de uma molécula heterodímera, mostrando-se como um radiofármaco promissor para o diagnóstico de glioma e encorajando estudos clínicos futuros. 


\section{REFERÊNCIAS BIBLIOGRÁFICAS}

ABRAMS, M.J.; JUWEID, M.; TENKATE, C.I.; SCHWARTZ D.A.; HAUSER M.M.; GAUL F.E. Technetium-99m human polyclonal IgG radiolabeled via the hydrazino nicotinamide derivative for imaging focal sites of infection in rats. J. Nucl. Med., v.31, p.2022-2028, 1990.

ACHILEFU, S. Lighting up tumors with receptor-specific optical molecular probes. Technol. Cancer Res. Treat., v.3, n.4, p.393-409, 2004.

AKHTARI, M.; BRAGIN, A.; COHEN, M.; MOATS, R.; BRENKER, F.; LYNCH, M.D.; VINTERS, H.V.; ENGEL, J. JR. Functionalized magnetonanoparticles for MRI diagnosis and localization in epilepsy. Epilepsia, v.49, p.1419-1430, 2008.

AKHTARI, M.; BRAGIN, A.; MOATS, R.; FREW, A.; MANDELKERN, M. Functionalized magnetonanoparticles in imaging brain neuronal activity using MRI. Brain Topogr., v.25, n.4, p.374-88, 2012.

ALAM, I.S.; WITNEY, T.H.; TOMASI, G.; CARROLL, L.; TWYMAN, F.J.; NGUYEN, Q.D.; ABOAGYE, E.O. Radiolabeled RGD Tracer Kinetics Annotates Differential av $\beta 3$ Integrin Expression Linked to Cell Intrinsic and Vessel Expression. Mol. Imaging Biol., v.16, n.4, p.558-66, 2014.

ALBELDA, S.M.; METTE, S.A.; ELDER, D.E.; STEWART, R.; DAMJANOVICH, L.; HERLYN, M.; BUCK, C.A. Integrin distribution in maliganant melanoma: association of the $\beta 3$ subunit with tumor progression. Cancer Res., v.50, p.67576764, 1990.

ALBERTO, R.; SCHIBLI, R.; WAIBEL, R.; ABRAM, U.; SCHUBIGER, A.; Basic aqueous chemistry of $[\mathrm{M}(\mathrm{OH}) 3(\mathrm{CO}) 3]+(\mathrm{M}=\mathrm{Re}, \mathrm{Tc})$ directed towards radiopharmaceutical application. Coord. Chem. Rev., v.190-192, p.901-919, 1999.

ALTMAN, D.A.; ATKINSON, D.S.Jr.; BRAT, D.J. Best cases from the AFIP: glioblastoma multiforme. Radiographics, v.27, n.3, p.883-888, 2007.

ANSELONI, V. Z.; BRANDÃO, M. L. Ethopharmacological analysis of behavior of rats using variations of the elevated plus-maze. Behavioural Pharmacology, v.8, p.533-540, 1997.

BABICH, J.W; FISCHMAN, A.J. Effect of "co-ligand" on the biodistribution of 99mTc-labeled hydrazino nicotinic acid derivatized chemotactic peptides. Nucl. Med. Biol., v.22, n.1, p.25-30, 1995.

BANERJEE, S.; PILLAI, M.R.A.; RAMAMOORTHY, N. Evaluation of Tc-99m in diagnostic radiopharmaceuticals. Semin. Nucl. Med., v.31, n.4, p.260-277, 2001.

BANERJEE, S.R.; MARESCA, K.P.; FRANCESCONI, L.; VALLIANT, J.; BABICH, J.W.; ZUBIETA, J. New directions in the coordination chemistry of $99 \mathrm{mTC}$ : a 
reflection on technetium core structures and a strategy for new chelate design. Nucl. Med. Biol., v.32, p.1-20, 2005.

BATTLE, M.R.; GOGGI, J.L.; ALLEN, L.; BARNETT, J.; MORRISON, M.S. Monitoring tumor response to antiangiogenic sunitinib therapy with ${ }^{18} \mathrm{~F}$-fluciclatide, an ${ }^{18} \mathrm{~F}$-labeled alphaVbeta3-integrin and alphaV beta5-integrin imaging agent. $\mathbf{J}$. Nucl. Med., v.52, p.424-430, 2011.

BEEKERS, N.; HUSSON, O.; MOLS, F.; VAN EENBERGEN, M.; VAN DE POLLFRANSE, L.V. Symptoms of Anxiety and Depression Are Associated With Satisfaction With Information Provision and Internet Use Among 3080 Cancer Survivors: Results of the PROFILES Registry. Cancer Nurs. 2014 Sep 14. DOI: 10.1097/NCC.0000000000000184

BEER, A.J.; GROSU, A.L.; CARLSEN, J.; KOLK, A.; SARBIA, M.; STANGIER, I.; WATZLOWIK, P.; WESTER, H.J.; HAUBNER, R.; SCHWAIGER, M. [18F]galactoRGD positron emission tomography for imaging of alphavbeta3 expression on the neovasculature in patients with squamous cell carcinoma of the head and neck. Clin. Cancer Res., v.13, p.6610-6616, 2007.

BEER, A.J.; LORENZEN, S.; METZ, S.; HERRMANN, K.; WATZLOWIK, P.; WESTER, H.J.; PESCHEL, C.; LORDICK, F.; SCHWAIGER, M. Comparison of integrin alphaVbeta3 expression and glucose metabolism in primary and metastatic lesions in cancer patients: a PET study using 18F-galacto-RGD and 18F-FDG. J. Nucl. Med., v.49, n.1, p.22-29, 2008.

BEER, A.J.; SCHWAIGER, M. PET imaging of $\alpha \mathrm{v} \beta 3$ expression in cancer patients. Methods Mol. Biol, v.;680, p.183-200, 2011.

BENEZRA, M.; PENATE-MEDINA, O.; ZANZONICO, P.B.; SCHAER, D.; OW, H.; BURNS, A.; DESTANCHINA, E.; LONGO, V.; HERZ, E.; IYER, S.; WOLCHOK, J.; LARSON, S.M.; WIESNER, U.; BRADBURY, M.S. Multimodal silica nanoparticles are effective cancer-targeted probes in a model of human melanoma. J. Clin. Invest., v.121, p.2768-2780, 2011.

BOYD, R. E. Technetium-99m Generators - The Available Options. Int. J. Appl. Radiat. Isot., v.33, n.10, p.801- 809, 1982.

BRACK, S.S.; DINKELBORG, L.M.; NERI, D. Molecular targeting of antiogenesis for imaging and therapy. Eur. J. Nucl. Med. Mol. Imaging, v.31, p.1327-1341, 2004.

CAI, H.; CONTI, P.S. RGD-based PET tracers for imaging receptor integrin av $\beta 3$ expression. J. Labelled Compd. Radiopharm., v.56, p.264-279, 2013.

CAI, W., GAMBHI, S., CHEN, X. Multimodality tumor imaging targeting integrin $\alpha_{v} \beta_{3}$. BioTechniques, v.39, p.S6-S17, 2005.

CAI, W.; SHIN, D.W.; CHEN, K.; GHEYSENS, O.; CAO, Q.; WANG, S.X.; GAMBHIR, S.S.; CHEN, X. Peptide-labeled near-infrared quantum dots for imaging tumor vasculature in living subjects. Nano Lett., v.6, p.669-676, 2006. 
CAIRNS, R.A., MAK, T.W. Oncogenic isocitrate dehydrogenase mutations: mechanisms, models, and clinical opportunities. Cancer Discov., v.3, n.7, p.730741, 2013.

CAMPOS, A.C.; FOGAÇA, M.V.; AGUIAR, D.C.; GUIMARÃES, F.S. Animal models of anxiety disorders and stress. Rev. Bras. Psiquiatr., v.35, Suppl.2, p.S101-11, 2013.

CARMEL, J.B.; MARTIN, J.H. Motor cortex electrical stimulation augments sprouting of the corticospinal tract and promotes recovery of motor function. Front. Integr. Neurosci., p.8:51, 2014.

CASCINI, G.L.; CUCCURULLO, V.; TAMBURRINI, O.; ROTONDO, A.; MANSI, L. Peptide imaging with somatostatin analogues: more than cancer probes. Cur. Radiopharm., v.6, p.36-40, 2013.

CASTEL, G.; CHTÉOUI, M.; HEYD, B.; TORDO, N. Phage Display of Combinatorial Peptide Libraries: Application to Antiviral Research. Molecules, v.16, p.3499-3518, 2011.

CHEN, B.; CAO, S.; ZHANG, Y.; WANG, X.; LIU, J.; HUI, X.; WAN, Y.; DU, W.; WANG, L.; WU, K.; FAN, D. A novel peptide (GX1) homing to gastric cancer vasculature inhibits angiogenesis and cooperates with TNF alpha in anti-tumor therapy. BMC Cell Biol., v.10, n.63, 2009.

CHEN, K.; CONTI, P.S. Target-specific delivery of peptide-based probes for PET imaging. Adv. Drug Deliv. Rev., v.62, p.1005-1022, 2010.

CHEN, K.; SUN, X.; NIU, G.; MA, Y.; YAP, L.P.; HUI, X.; WU, K.; FAN, D.; CONTI, P.S.; CHEN, X. Evaluation of 64Cu labeled GX1: a phage display peptide probe for PET imaging of tumor vasculature. Mol Imaging Biol., v.14, n.1, p.96-105, 2012 A.

CHEN, K.; YAP, L.P.; PARK, R.; HUI, X.; WU, K.; FAN, D.; CHEN, X.; CONTI, P.S. A Cy5.5-labeled phage-displayed peptide probe for near-infrared fluorescence imaging of tumor vasculature in living mice. Amino Acids., v.42, n. 4, p.1329-1337, 2012 B.

CHEN, X.; PARK, R.; HOU, Y.; KHANKALDYYAN, V.; GONZALES-GOMEZ, I.; TOHME, M.; BADING, J.R.; LAUG, W.E.; CONTI, P.S. MicroPET imaging of brain tumor angiogenesis with 18F-labeled PEGylated RGD peptide. Eur. J. Nucl. Med. Mol. Imaging, v.31, p.1081-1089, 2004 A.

CHEN, X.; PARK, R.; SHARINIAN, A. H.; BADING, J.R.; CONTI, P.S.; Pharmacokinetics and tumor retention of 125 -labeled RGD peptide are improved by PEGylation. Nucl. Med. Biol., v.31, n.1, p.11-19, 2004 B.

CHEN, X.; PARK, R.; SHARINIAN, A. H.; TOHME, M.; KHANKALDYAN, V.; BOZORGZADEH, M.H.; BADING, J.R.; MOATS, R.; LANG, W.E.; CONTI, P.S.; ${ }^{18} \mathrm{~F}$-labebled RGD peptide: initial evaluation for imaging brain tumor angiogenesis. Nucl. Med. Biol., v.31, n.2, p.179-189, 2004 C. 
CHOI, D.S.; JIN, H.E.; YOO, S.Y.; LEE, S.W. Cyclic RGD Peptide Incorporation on Phage Major Coat Proteins for Improved Internalization by HeLa Cells. Bioconjug Chem., v.25, n.2, p.216-23, 2014.

CISTARO, A.; QUARTUCCIO, N.; VESCO, S.; PAGANI, M.; FANIA, P.; DONATI, L.; NOBILI, F.M.; DUCA, S.; CARRARA, G.; VALENTINI, M.C. Positron emission tomography. Ophthalmology, v.119, n.7, p.1496-7.e1, 2012.

COHEN, A.L., HOLMEN, S.L., COLMAN, H. IDH1 and IDH2 mutations in gliomas. Curr. Neurol. Neurosci. Rep., v.13, n.5, p.345, 2013.

CUCCURULLO, V.; CASCINI, G.L.; MANSI, L. Structural, pathophysiological and clinical aspects of diagnostic imaging in breast recurrence: the breast after treatment. Q. J. Nucl. Med. Mol. Imag., v.57, p. 322-331 2013.

CUCCURULLO, V.; CASCINI, G.L.; TAMBURRINI, O.; ROTONDO, A.; MANSI, L. Bone metastases radiopharmaceuticals: an overview. Cur. Radiopharm., v. 6, p. 41-47, 2013.

D'ANDREA, L.D.; DEL GATTO, A.; PEDONE, C.; BENEDETTI, E. Peptide-based molecules in angiogenesis. Chem. Biol. Drug Des., v.67, p.115-26, 2006.

DAUMAS-DUPORT, C. Histological grading of gliomas. Curr. Opin. Neurol. Neurosurg., v.5, p.924-31, 1992.

DECRISTOFORO C.; FAINTUCH B.L.; REY A.; GUGGENBERG E. von; RUPPRICH M.; HERNANDEZ I.G.; TEODORO R.; HAUBNER R. [ $\left.{ }^{99 m} T c\right]$ HYNICRGD for imaging integrin avb3 expression. Nucl. Med. Biol., v.33, p.945-952, 2006.

DECRISTOFORO, C.; HERNANDEZ GONZALEZ, I.; CARLSEN, J.; RUPPRICH, M.; HUISMAN, M.; VIRGOLINI, I.; WESTER, H.J.; HAUBNER, R. ${ }^{68} \mathrm{Ga}$ - and ${ }^{111} \mathrm{In}-$ labelled DOTA-RGD peptides for imaging of alphavbeta3 integrin expression. Eur. J. Nucl. Med. Mol. Imaging, v.35, n.8, p.1507-1515, 2008.

DECRISTOFORO, C.; MATHER, S. 99mTc-Technetium-Labelled Peptide-HYNIC Conjugates: Effects of Lipophilicity and Stability on Biodistribution. Nucl. Med. Biol., v.26, n.4, p.389-396, 1999.

DECRISTOFORO, C.; SANTOS, I.; PIETZSCH, H.J.; KUENSTLER, J.U.; DUATTI, A.; SMITH, C.J.; REY, A.; ALBERTO, R.; VON GUGGENBERG, E.; HAUBNER, $R$. Comparison of in vitro and in vivo properties of [99mTc]cRGD peptides labeled using different novel Tc-cores. Q. J. Nucl. Med. Mol. Imag., v.51, p. 33-41, 2007.

DEEKEN, J.F.; LOSCHER, W. The blood-brain barrier and cancer: transporters, treatment, and Trojan horses. Clin. Cancer Res., v.13, p.1663-1674, 2007.

DENARDO, S.J.; YAO, Z.; LAM, K.M.; SONG, A.; BURKER, P.A.; MERICK, G.R.; LAMBORN, K.R.; O'DONNELL, R.T.; DENARDO, G.L. Effect of molecular size of pegylated peptide on the pharmacokinetics and tumor targeting in lymphomabearing mice. Clin. Cancer Res.,v.1, n.9, p.38545-38645, 2003. 
DESGROSELLIER, J.S.; CHERESH, D.A. Integrins in cancer: biological implications and therapeutic opportunities. Nat. Rev. Cancer, v.10, p.9-22, 2010.

DEUTSCHER, S.L. Phage display in molecular imaging and diagnosis of cancer. Chem. Rev., v.110, p.3196-3211, 2010.

DHERMAIN, F.G.; HAU, P.; LANFERMANN, H.; JACOBS, A.H.; VAN DEN BENT, M.J. Advanced MRI and PET imaging for assessment of treatment response in patients with gliomas. Lancet Neurol., v.9, n.9, p. 906-20, 2010.

DIJKGRAAF, I.; KRUIJTZER, A.W.; LIU, S.; SOEDE, A.C.; OYEN, W.J.G.; CORSTENS, F. H. M.; LISKAMP, R. M. J.; BOERMAN, O;C.; Improved targeting of the avb3 integrin by multimerisation of RGD peptides. Eur. J. Nucl. Med. Mol. Imaging, v.34, n.2, p.267-273, 2007.

DILWORTH, J.R.; PARROT, S.J. The biomedical chemistry of thecnetium and rhenium. Chem. Soc. Rev., v.27, p.43-55, 1998.

DOBRUCKI, L.W.; SINUSA, A.J.; Imaging angiogenesis. Curr. Opin. Biotechnol., v.18, p.90-96, 2007.

D'ONOFRIO, N.; CARAGLIA, M.; GRIMALDI, A.; MARFELLA, R.; SERVILLO, L.; PAOLISSO, G.; BALESTRIERI, M.L. Vascular-homing peptides for targeted drug delivery and molecular imaging: Meeting the clinical challenges. Biochim.

Biophys. Acta, v.1846, n.1, p. 1-12, 2014.

DUATTI, A. Role of ${ }^{99 m}$ Tc in diagnostic imaging. In: Technetium-99m Radiopharmaceuticals: Status and Trends: IAEA Radioisotopes and Radiopharmaceuticals, Series n.1. Vienna: International Atomic Energy Agency, 2009.

EBENHAN, T.; GHEYSENS, O.; KRUGER, H.G.; ZEEVAART, J.R.; SATHEKGE, M.M. Antimicrobial Peptides: Their Role as Infection-Selective Tracers for Molecular Imaging. Biomed. Res. Int., v.2014, p.867381, 2014 B.

EBENHAN. T.; CHADWICK, N.; SATHEKGE, M.M.; GOVENDER, P.; GOVENDER, T.; KRUGER, H.G.; MARJANOVIC-PAINTER, B.; ZEEVAART, J.R. Peptide synthesis, characterization and $68 \mathrm{Ga}$-radiolabeling of NOTAconjugated ubiquicidin fragments for prospective infection imaging with PET/CT. Nucl. Med. Biol., v.41, n.5, p.390-400, 2014 A.

EGLI, A.; ALBERTO, R.; TANNAHILL, L.; SCHIBLI, R.; ABRAM, U., SCHAFFLAND, A.; WAIBEL, R.; TOURWÉ, D., JEANNIN, L ; ITERBEKE, K.; SCHUBIGER, P. A. Organometallic ${ }^{99 m}$ Tc-aquaion labels peptide to an unprecedented high specific activity. J. Nucl. Med., v.40, p.1913-1917, 1999.

EOLI, M.; SILVANI, A.; POLLO, B.; BIANCHESSI, D.; MENGHI, F.; VALLETTA, L.; BROGGI, G.; BOIARDI, A.; BRUZZONE, M.G.; FINOCCHIARO, G. Molecular markers of gliomas: a clinical approach. Neurol. Res., v. 28, n.5, p. 538-541, 2006. 
ERFANI, M.; SHAMSAEI, M.; MOHAMMADBAGHERY, F.; SHIRMARDI, S.P. Synthesis and evaluation of a (99m) Tc-labeled tubulin-binding agent for tumor imaging. J. Labelled Comp. Radiopharm., v.57, n.6, p. 419-424, 2014.

FAINTUCH, B.L.; SANTOS, R.L.S.R.; SOUZA, A.L.F.M.; HOFFMAN, T.J.; GREELEY, M.; SMITH, C.J.; ${ }^{99 m}$ Tc-HYNIC-Bombesin (7-14) $\mathrm{NH}_{2}$ : Radiochemical Evaluation with Co-ligands EDDA (EDDA=Ethylenediamine-N,N'-diacetic Acid), Tricine, and Nicotinic Acid. Synth. React. Inorg. M., v.35, p 43-51, 2005.

FAINTUCH, B.L.; SANTOS, R.L.S.R.; TEODORO, R.; MURAMOTO, E.; MORGANTI, L.; NUNES, I.V.S.; OKAMOTO, M.R.Y. Labeling of small biomolecules using novel technetium-99m cores: results of a coordinated research project 2003-2006, International Atomic Energy Agency (IAEA)Technical reports series, ISSN 0074-1914; n.459, Vienna, 2007.

FALCIONI, R.; CIMINO, L.; GENTILESCHI, M.P.; CIMINO, L.; GENTILESCHI, M.P.; D'AGNANO, I.; ZUPI, G.; KENNEL, S.J.; SACCHI, A. Expression of $\beta 1, \beta 3$, $\beta 4$, and $\beta 5$ integrins by human lung carcinoma cells of different histotypes. Exp. Cell Res., v.210, p.113-122, 1994.

FEI, X.F.; ZHANG, Q.B.; DONG, J.; DIAO, Y.; WANG, Z.M.; LI, R.J.; WU, Z.C.; WANG, A.D.; LAN, Q.; ZHANG, S.M.; HUANG, Q. Development of clinically relevant orthotopic xenograft mouse model of metastatic lung cancer and glioblastoma through surgical tumor tissues injection with trocar. J. Exp. Clin. Cancer Res., v.29, n.1, p. 84, 2010.

FICHNA, J.; JANECKA, A. Synthesis of Target-Specific Radiolabeled Peptides for Diagnostic Imaging. Bioconjug. Chem., v.14, p.3-17, 2003.

FOLKMAN J. Seminars in Medicine of the Beth Israel Hospital, Boston. Clinical applications of research on angiogenesis. N. Engl. J. Med., v.333, p.1757$1763,1995$.

FOLKMAN J. Tumor angiogenesis: therapeutic implications. $\boldsymbol{N}$. Engl. J. Med., v. 285, p.1182-1186, 1971.

GAERTNER, F.C.; KESSLER, H.; WESTER, H.J.; SCHWAIGER, M.; BEER, A.J. Radiolabelled RGD peptides for imaging and therapy. Eur. J. Nucl. Med. Mol. Imaging, v.39, p.126-138, 2012.

GANDOMKAR, M.; NAJAFI, R.; SHAFIEI, M.; MAZIDI, M.; GOUDARZI, M.; MIRFALLAH, S.H.; EBRAHIMI, F.; HEYDARPOR, H.R.; ABDIE, N. Clinical evaluation of antimicrobial peptide [(99m)Tc/Tricine/HYNIC(0)]ubiquicidin 29-41 as a human-specific infection imaging agent. Nucl. Med. Biol., v.36, n.2, p.199-205, 2009.

GARCÍA-GARAYOA, E.; MAES, V.; BLÄUENSTEIN, P.; BLANC, A.; HOHN, A.; TOURWÉ, D.; SCHUBIGER, P.A. Double-stabilized neurotensin analogues as potential radiopharmaceuticals for NTR-positive tumors. Nucl. Med. Biol., v.33, n.4, p.495-503, 2006. 
GASPARINI, G.; BROOKS, P.C.; BIGANZOLI, E.; VERMEULEN, P.B.; BONOLDI, E.; DIRIX, L.Y.; RANIERI, G.; MICELI, R.; CHERESH, D.A. Vascular integrin avß3: a new prognostic indicator in breast cancer. Clin. Cancer Res., v.4, n.11, p.26252634, 1998.

GAUTAM, A.; KAPOOR, P.; CHAUDHARY, K.; KUMAR, R.; RAGHAVA, G.P. Tumor Homing Peptides as Molecular Probes for Cancer Therapeutics, Diagnostics, and Theranostics. Curr. Med. Chem., v.21, n.21, p. 2367-2391, 2014.

GILAD, G.M.; SHILLER, I. Differences in open-field behavior and in learning tasks between two rat strains differing in their reactivity to stressors. Behav. Brain Res., v.32, p.89-93, 1989.

GOLDMAN, S.; PIROTTE, B.J. Brain tumors. Methods Mol. Biol. v.727, p.291315, 2011.

GOTTSCHALK, K.E.; KESSLER, H. The structures of integrins and in-tegrinligand complexes: Implications for drug design and signal transduction. Angew. Chem. Int. Ed. Engl., v.41, p.3767-3774, 2002.

GUEDES, AFBD. Estudo de marcadores de diagnóstico e prognóstico em gliomas. 2010. Dissertação (Mestrado). Universidade de Trás-os-Montes e Alto Douro, Vila, Portugal.

GUO, W.; HINKLE, G.H.; LEE, R.J. 99mTc-HYNIC-folate: A Novel ReceptorBased Targeted Radiopharmaceutical for Tumor Imaging. J. Nucl. Med., v.40, p.1563-1569, 1999.

GUO, Z.; ZHANG, P.; SONG, M.; WU, X.; LIU, C.; ZHAO, Z.; LU, J.; ZHANG, X. Synthesis and preliminary evaluation of novel $99 \mathrm{mTc}$-labeled folate derivative via click reaction for SPECT imaging. Appl. Radiat. Isot., v.14, n. 91C, p. 24-30, 2014.

HAMPTON, M.B.; ORRENIUS, S. Dual regulation of caspase activity by hydrogen peroxide: implications for apoptosis. FEBS Lett., v. 414, n. 3, p. 552-556, 1997.

HANAHAN. D.; WEINBERG R. A., The hallmarks of cancer. Cell., v.100, p.57-70, 2000.

HEPPELER, A.; FROIDEVAUX, S.; EBERLE, A.N.; MAECKE, H.R. Receptor targeting for tumour localisation and therapy with radiopeptides. Curr. Med. Chem., v,7, p.971-994, 2000.

HIGGINS, L.J.; POMPER, M.G. The evolution of imaging in cancer: current state and future challenges. Seminars in Oncology, v. 38, n.1, p. 3-15, 2011.

HNATOWICH, D.J.; MARDIRIOSSIAN, G.; RUSCOWSKI, M.; FORGARASI, M.; VIRZI, F.; WINNARD, P. Directly and indirectly technetium-99m labeled antibodies: A comparison of in vitro and animal in vivo properties. J. Nucl. Med., v.34, p.109-119, 1993. 
HNATOWICH, D.J.; WINNARD, P.; VIRZI, F.; FORGARASI, M.; SANO, T.; SMITH, C.L.; RUSCOWISKI, M. Technetium-99m labeling of DNA oligonucleotides. J. Nucl. Med., v.36, p.2306-2314, 1995.

HOU, B.L.; BRADBURY, M.; PECK, K.K.; PETROVICH, N.M.; GUTIN, P.H.; HOLODNY, A.I. Effect of brain tumor neovasculature defined by rCBV on BOLD fMRI activation volume in the primary motor cortex. Neuroimage., v.32, n.2, p.489-497, 2006.

HU, H.; YIN, J.; WANG, M.; LIANG, C.; SONG, H.; WANG, J.; NIE, Y.; LIANG, J.; WU, K. GX1 targeting delivery of rmhTNFa evaluated using multimodality imaging. Int. J. Pharm., v.461, n. 1-2, p.181-191, 2014.

HUI, X.; HAN, Y.; LIANG, S.; LIU, Z.; LIU, J.; HONG, L.; ZHAO, L.; HE, L.; CAO, S.; CHEN, B.; YAN, K.; JIN, B.; CHAI, N.; WANG, J.; WU, K.; FAN, D. Specific targeting of the vasculature of gastric cancer by a new tumor-homing peptide CGNSNPKSC. J. Control. Release, v.131, p.86-93, 2008.

IMAM, S.K. Molecular nuclear imaging: the radiopharmaceuticals. Cancer Biother. Radiopharm., v. 20, p. 163-172, 2005.

ISLAM, T.; HARISINGHANI, M.G. Overview of nanoparticle use in cancer imaging. Cancer Biomark., v.5, p.61-67, 2009.

JAIN, R.K.; CARMELIET, P. SnapShot: Tumor angiogenesis. Cell, v.149, p.14081408 e1401, 2012.

JAIN, R.K.; DI TOMASO, E.; DUDA, D.G.; LOEFFLER, J.S.; SORENSEN, A.G.; BATCHELOR, T.T. Angiogenesis in brain tumours. Nat. Rev. Neurosci., v.8, n.8, p. 610-622, 2007.

JANSSEN, M.L.; OYEN, W.J.; DIJKGRAAF, I.; MASSUGER, L.F.; FRIELINK, C.; EDWARDS, D.S.; RAJOPADHYE, M.; BOONSTRA, H.; CORSTENS, F.H.; BOERMAN, O.C. Tumor targeting with radiolabeled alpha(v)beta(3) integrin binding peptides in a nude mouse model. Cancer Res., v.62, p. 6146-6151, 2002.

JIN, H.; VARNER, J. Integrins: roles in cancer development and as treatment targets. Br J Cancer, v.90, p.561-565, 2004.

JURISSON, S.; BERNING, D.; JIA, W.; MA, D. Coordination Compounds in Nuclear Medicine. Chem. Rev., v.93, p.1137-1156, 1993.

JURISSON, S.S.; LYDON, J.D. Potencial technetium small molecule radiopharmaceutical. Chem. $\boldsymbol{R e v . , ~ v . 9 9 , ~ p . 2 2 0 5 - 2 2 1 8 , ~} 1999$.

KENNY, L.M.; COOMBES, R.C.; OULIE, I.; CONTRACTOR, K.B.; MILLER, M.; SPINKS, T.J.; MCPARLAND, B.; COHEN, P.S.; HUI, A.M.; PALMIERI, C.; OSMAN, S.; GLASER, M.; TURTON, D.; AL-NAHHAS, A.; ABOAGYE, E.O. Phase I trial of the positron-emitting Arg-Gly-Asp (RGD) peptide radioligand 18FAH111585 in breast cancer patients. J. Nucl. Med.,v. 49, n.6, p. 879-886, 2008. 
KIM, J.; HONG, S.Y.; PARK, H.S.; KIM, D.S.; LEE, W. Structure and function of RGD peptides derived from disintegrin proteins. Mol. Cells., v.19, n.2, p.205-11, 2005.

KIM, Y.H.; JEON, J.; HONG, S.H.; RHIM, W.K.; LEE, Y.S.; YOUN, H.; CHUNG, J.K.; LEE, M.C.; LEE, D.S.; KANG, K.W.; NAM, J.M. Tumor targeting and imaging using cyclic RGD-PEGylated gold nanoparticle probes with directly conjugated iodine-125. Small., v.7, p.2052-2060, 2011.

KITSON, S.L.; CUCCURULLO, V.; MOODY, T.S. MANSI, L. Radionuclide antibody-conjugates, a targeted therapy towards cancer. Cur. Radiopharm., v.6, p.57-71, 2013.

KOK, R.J., SCHRAA, A.J., BOS, E.J., MOORLAG, H.E., ASGEIRSDOTTIR, S.A., EVERTS, M., MEIJER, D.K.F., MOLEMA, G. Preparation and functional evaluation of RGD-modified proteins as alpha(v)beta(3) integrin directed therapeutics.

Bioconjugate Chem., v.13,n.1, p.128-135, 2002.

KOPECKY, M., SEMECKY, V., TREJTNAR, F., LAZNICEK, M., LAZNICKOVA, A., NACHTIGAL, P., DECRISTOFORO, C., MATHER, S. J., MÄCKE, H.R. Analysis of accumulation fo ${ }^{99 m}$ Tc-octreotide and ${ }^{99 m}$ Tc-EDDA-HYNIC-Tyr ${ }^{3}$-octreotide in the rat kidneys. Nucl. Med. Biol., v.31, p. 231-239, 2004.

KORDE, A.; PANDEY, U.; BANERJEE, S.; DEV SARMA, H.; MUKHERJEE, A.; VENKATESH, M. Preparation and biological studies of $\left({ }^{125}\right)$ I-DOTA-TATE. Appl. Radiat. Isot., v.65, n.6, p.687-690, 2007.

KOSTIDIS, S.; STAVRAKOUDIS, A.; BIRIS, N.; TSOUKATOS, D.; SAKARELLOS, C.; TSIKARIS, $\mathrm{V}$. The relative orientation of the Arg and Asp side chains defined by a pseudodihedral angle as a key criterion for evaluating the structure-activity relationship of RGD peptides. J. Pept. Sci., v.10, n.8, p.494-509, 2004.

KOTHARI, K.K.; RAGHURAMAN, K., PILLARSETTY, N.K.; HOFFMAN, T.J.; OWEN, N.K.; KATTI, K.V.; VOLKERT, W.A. Syntheses, in vitro and in vivo characterization of a $99 \mathrm{~m} \mathrm{Tc}$-(I)-tricarbonyl-benzylamino-dihydroxymethyl phosphine $\left(\mathrm{NP}_{2}\right)$ chelate. Appl. Radiat. Isot, v.58, p.543-549, 2003.

KOWALSKY, R.J.; FALEN, S.W. Radiopharmaceuticals in Nuclear Pharmacy and Nuclear Medicine. 2. ed. American Pharmacists Association, Washington DC, 2004.

LAPERRIERE, N.; ZURAW, L.; CAIRNCROSS, G. Radiotherapy for newly diagnosed malignant glioma in adults: a systematic review. Radiother. Oncol., v.64, n.3, p.259-273, 2002.

LAWS, E.R.Jr.; SHAFFREY, M.E. The inherent invasiveness of cerebral gliomas: implications for clinical management. Int. J. Dev. Neurosci., v.17, n.5-6, p. 413420, 1999.

LAZOVIC, J.; SOTO, H.; PICCIONI, D.; LOU, J.R.; LI, S.; MIRSADRAEI, L.; YONG, W.; PRINS, R.; LIAU, L.M.; ELLINGSON, B.M.; CLOUGHESY, T.F.; LAI, A.; POPE, W.B. Detection of 2-hydroxyglutaric acid in vivo by proton magnetic 
resonance spectroscopy in U87 glioma cells overexpressing isocitrate dehydrogenase-1 mutation. Neuro Oncol., v.14, n.12, p.1465-1472, 2012.

LEE, S., XIE, J., CHEN, X. Peptide-based probes for targeted molecular imaging. Biochem., v.49, n.7, p.1364-1376, 2010.

LEE, H.Y.; LI, Z.; CHEN, K.; HSU, A.R.; XU, C.; XIE, J.; SUN, S.; CHEN, $X$. PET/MRI dual-modality tumor imaging using arginine-glycine-aspartic (RGD)conjugated radiolabeled iron oxide nanoparticles. J. Nucl. Med., v.49, p.13711379, 2008.

LI, S.; CHOU, A.P.; CHEN, W.; CHEN, R.; DENG, Y.; PHILLIPS, H.S.; SELFRIDGE, J.; ZURAYK, M.; LOU, J.J.; EVERSON, R.G.; WU, K.C.; FAULL, K.F.; CLOUGHESY, T.; LIAU, L.M.; LAI, A. Overexpression of isocitrate dehydrogenase mutant proteins renders glioma cells more sensitive to radiation. Neuro Oncol., v.15, n.1, p.57-68, 2013.

LI, Z., CAI, W., CAO, Q., CHEN, K., WU, Z., HE, L., CHEN, X. ${ }^{64} \mathrm{Cu}$-labeled tetrameric and octameric RGD peptide for small-animal PET of tumor av $\beta 3$ integrin expression. J. Nucl. Med., v.48, n.7 p.1162-1171, 2007.

LI, Z.B., WU, Z., CHEN, K., RYU, E.K., CHEN, X. ${ }^{18}$ F-labeled BBN-RGD Heterodimer for Prostate Cancer Imaging. J. Nucl. Med., v.49, p.453-461, 2008.

LISTER-JAMES, J.; MOYER, B.R.; DEAN, R.T. Pharmacokinetic considerations in the development of peptide-based imaging agents. Q. J. Nucl. Med., v.41, n.2, p.111-118, 1997.

LIU, C.; LIU, D.B.; LONG, G.X.; WANG, J.F.; MEI, Q.; HU, G.Y.; QIU, H.; HU, G.Q. Specific targeting of angiogenesis in lung cancer with RGD-conjugated ultrasmall superparamagnetic iron oxide particles using a 4.7T magnetic resonance scanner. Chin. Med. J. (Engl)., v.126, n.12, p.2242-2247, 2013.

LIU, G.; WESCOTT, C.; SATO, A.; WANG, Y.; LIU, N.; ZHANG, Y.M.; RUSCKOWSKI, M.; HNATOWICH, D.J. Nitriles form mixed-coligand complexes with ${ }^{99 m}$ Tc-HYNIC-peptide. Nucl. Med. Biol., v.29, p.107-113, 2002.

LIU, S.; CHEUNG, E.; RAJOPADHYE, M.; ZIEGLER, M.C.; EDWARDS, D.S. ${ }^{90}$ Yand ${ }^{177} \mathrm{Lu}$-labeling of a DOTA-conjugated vitronectin receptor antagonist for tumor therapy. Bioconj. Chem., v.12, p.559-568, 2001.

LIU, S.; EDWARDS, D.S. ${ }^{99 m}$ Tc-labeled small peptides as diagnostic radiopharmaceuticals. Chem. Rev., v.99, p.2235-2268, 1999.

LIU, S.; KIM, Y.S., HSIEH, W.Y., SREERAMA, S.G.; Coligant effect on the solution stability, biodistribution and metabolism of the $99 \mathrm{mTc}$-labeled cyclic RGDfK tetramer. Nucl. Med. Biol., v.35, p.111-121, 2008.

LIU, S.; ROBINSON, S.P.; EDWARD, D.S. Integrin avb3 directed radiopharmaceuticals for tumor imaging. Drugs of the Future, v.28, n.6, p. 551564, 2003. 
LIU, Z.; SHI, J.; JIA, B.; LIU, Y.; ZHAO, H.; LI, F.; TIAN, J.; CHEN, X.; LIU, S.; WANG, F. Two (90)-Labeled Multimeric RGD Peptides RGD4 and 3PRGD2 for Integrin Targeted Radionuclidee Therapy. Mol. Pharm., v.8, n.2, p.591-599, 2011. LIU, Z.; WANG, F. Dual-targeted molecular probes for cancer imaging. Curr. Pharm. Biotechnol., v.11, p.610-619, 2010.

LIU, Z.; YAN, Y.; CHIN, F.T.; WANG, F.; CHEN, X. Dual integrin and gastrinreleasing peptide receptor targeted tumor imaging using 18F-labeled PEGylated RGD-bombesin heterodimer 18F-FB-PEG3-Glu-RGD-BBN. J. Med. Chem., v.52, n.2, p.425-432, 2009.

LOUIS, D.N.; OHGAKI, H.; WIESTLER, O.D.; CAVENEE, W.K.; BURGER, P.C.; JOUVET, A.; SCHEITHAUER, B.W.; KLEIHUES, P. The 2007 WHO classification of tumours of the central nervous system. Acta Neuropathol., v.114, p.97-109, 2007.

MAINA, T.; NIKOLOPOULOU, A.; STATHOPOULOU, E.; GALANIS, A.S.; CORDOPATIS, P.; NOCK, B.A. [99mTc]Demotensin 5 and 6 in the NTS1-Rtargeted imaging of tumours: synthesis and preclinical results. Eur. J. Nucl. Med. Mol. Imaging, v.34, n.11, p.1804-1814, 2007.

MANSI L. Ich bin ein Molekularmediziner (how much CT and nuclear medicine in molecular CT?) Eur. J. Nucl. Med.Mol. Imaging, v.36, n.3, p.531-532, 2009.

MARQUES, F.L.N.; OKAMOTO, M.R.Y.; BUCHPIGUEL, C.A. Alguns aspectos sobre geradores e radiofármacos de Tecnécio-99m e seus controles de qualidade. Radiol. Bras., v.34, n.4, p.233-239, 2001.

MEITAR, D.; CRAWFORD, S.E.; RADEMAKER, A.W.; COHN, S.L. Tumor angiogenesis correlates with metastatic disease, $\mathrm{N}$-myc-amplification, and poor outcome in human neuroblastoma. J Clinical Oncol., v.14, p.405-414, 1996.

MELO, F. H. M.; JUNQUEIRA, M. S.; CHAMMAS, R., Mecanismos de Invasão e metástases. In: BRENTANI, M.M; KOWALSKI, L.P.; COELHO, F.R.G., Bases da Oncologia, 2 ed., Editora Marina e Tedmedd Editora, São Paulo, v. 2, p.201-226, 2003.

MESZAROS, L.K.; DOSE, A.; BIAGINI, S.C.; BLOWER, P.J. Synthesis and evaluation of analogues of HYNIC as bifunctional chelators for technetium. Dalton Trans., v.40, n.23, p.6260-6267, 2011.

METAFERIA, B.B.; RITTLER, M.; GHEEYA, J.S.; LEE, A.; HEMPEL, H.; PLAZA, A.; STETLER-STEVENSON, W.G.; BEWLEY, C.A.; KHAN, J. Synthesis of novel cyclic NGR/RGD peptide analogs via on resin click chemistry. Bioorg. Med. Chem. Lett., v.20, n.24, p.7337-7340, 2010.

MOLDAY, H.S. (1984) US Pat 2,452,773.

MORALES M.A.A.; DUCONGÉ J.; ALVAREZ-RUIZ D.; BECQUER-VIART M.L.A.; NUÑEZ-GANDOLFF G.; FERNÁNDEZ E.; CABALLERO-TORRES I.; IZNAGAESCOBAR N. Humanized Versus Murine Anti-Human Epidermal Growth Factor 
Receptor Monoclonal Antibodies for Immunoscintigrafhic Studies. Nucl. Med. Biol., v.27, p.199-206, 2000.

MUKHERJEE, A.; PANDEY, U.; CHAKRAVARTY, R.; SARMA, H.D.; DASH, A. Development of single vial kits for preparation of (68)Ga-labelled peptides for PET imaging of neuroendocrine tumours. Mol. Imaging Biol., v.16, n.4, p.550-557, 2014.

MULDOON, L.L.; SANDOR, M.; PINKSTON, K.E.; NEUWELT, E.A. Imaging, distribution, and toxicity of superparamagnetic iron oxide magnetic resonance nanoparticles in the rat brain and intracerebral tumor. Neurosurgery, v.57, p.785796, 2005.

NIKIFOROVA, M.N.; HAMILTON, R.L. Molecular diagnostics of gliomas. Arch. Pathol. Lab. Med., v.135, n.5, p.558-568, 2011.

NISHINO, M.; JAGANNATHAN, J.P.; KRAJEWSKI, K.M.; O'REGAN, K.; HATABU, H.; SHAPIRO, G.; RAMAIYA, N.H. Personalized tumor response assessment in the era of molecular medicine: cancer-specific and therapy-specific response criteria to complement pitfalls of RECIST. AJR Am. J. Roentgenol., v.198, n.4, p.737-745, 2012.

NOBUSAWA, S.; WATANABE, T.; KLEIHUES, P.; OHGAKI, H. IDH1 mutations as molecular signature and predictive factor of secondary glioblastomas. Clin.

Cancer Res., v.15, n.19, p.6002-6007, 2009.

OBENAUS, E.R; EDREIRA, M.M.; CRUDO, J.L. Análogos de Somatostatina marcados com ${ }^{99 m}$ Tc. Comision Nacional de Energia Atômica. Centro Atômico Ezeiza. Unidad de Actividad Radioquímica,Radiofármacos, 1999.

OGAWA, M.; HATANO, K.; OISHI, S.; KAWASUMI, Y.; FUJII, N.; KAWAGUCHI, M.; DOI, R.; IMAMURA, M.; YAMAMOTO, M.; AJITO, K.; MUKAI, T.; SAJI, H.; ITO, K. Direct electrophilic radiofluorination of a cyclic RGD peptide for in vivo alpha(v)beta3 integrin related tumor imaging. Nucl. Med. Biol., v.30, p.1-9, 2003.

OHGAKI, H.; KLEIHUES, P. Genetic alterations and signaling pathways in the evolution of gliomas. Cancer Sci., v.100, n.12, p. 2235-2241, 2009.

OKARVI, S. M. Synthesis, radiolabeling and in vitro and in vivo characterization of a technetium-99m-labeled alpha-M2 peptide as a tumor imaging agent. J. Peptide Res., v.63, p.460-468, 2004.

OKARVI, S.M. Peptide-based radiopharmaceutical and cytotoxic conjugates:

Potencial tools against cancer. Cancer Treatment Reviews, v.34, p.13-26, 2008.

OLIVEIRA, É.A.; FAINTUCH, B.L.; NÚÑEZ, E.G.; MORO, A.M.; NANDA, P.K.; SMITH, C.J. Radiotracers for different angiogenesis receptors in a melanoma model. Melanoma Res., v.22, n.1, p.45-53, 2012.

OLIVEIRA, R.; SANTOS, D.; FERREIRA, D.; COELHO, P. VEIGA, F. Preparações radiofarmacêuticas e suas aplicações. Rev. Bras. Ciênc. Farmac., v.42, n.2, p.151-65, 2006. 
ONG, B.Y.; RANGANATH, S.H.; LEE, L.Y.; LU, F.; LEE, H.S.; SAHINIDIS, N.V.; WANG, C.H. Paclitaxel delivery from PLGA foams for controlled release in postsurgical chemotherapy against glioblastoma multiforme. Biomaterials., v.30, p.3189-3196, 2009.

OSTROM, Q.T.; GITTLEMAN, H.; FARAH, P.; ONDRACEK, A.; CHEN, Y.; WOLINSKY, Y.; KRUCHKO, C.; BARNHOLTZ-SLOAN, J.S. CBTRUS Statistical Report: Primary Brain and Central Nervous System Tumors Diagnosed in the United States 2006-2010. Neuro Oncol., v.15 (sup 2), p. ii1 - ii56, 2013.

PARK, J.A.; LEE, J.J.; JUNG, J.C.; YU, D.Y.; OH, C.; HA, S.; KIM, T.J.; CHANG, Y. Gd-DOTA conjugate of RGD as a potential tumor-targeting MRI contrast agent. Chembiochem, v.9, p. 2811-2813, 2008.

PARSONS, D.W., JONES, S., ZHANG, X., LIN, J.C., LEARY, R.J., ANGENENDT, P., MANKOO, P., CARTER, H., SIU, I.M., GALLIA, G.L., OLIVI, A., MCLENDON, R., RASHEED, B.A., KEIR, S., NIKOLSKAYA, T., NIKOLSKY, Y., BUSAM, D.A., TEKLEAB, H., DIAZ, L.A. JR, HARTIGAN, J., SMITH, D.R., STRAUSBERG, R.L., MARIE, S.K., SHINJO, S.M., YAN, H., RIGGINS, G.J., BIGNER, D.D., KARCHIN, R., PAPADOPOULOS, N., PARMIGIANI, G., VOGELSTEIN, B., VELCULESCU, V.E., KINZLER, K.W. An integrated genomic analysis of human glioblastomamultiforme. Science, v.321, n.5897, p.1807-1812, 2008.

PIERSCHBACHER, M. D., RUOSLAHTI, E. The cell attachment activity of fibronectin can be duplicated by small fragments of the molecule. Nature, v. 309, p.30-33, 1984.

PLACHCINSKA, A.; MIKOLAJCZAK, R.; MAECKE, H.; KOZAK, J.; MICHALSKI, A.; RZESZUTEK, K.; KUSMIEREK, J. Efficacy of 99mTc-EDDA/HYNIC-TOC scintigraphy in differential diagnosis of solitary pulmonary nodules. Cancer Biother. Radiopharm., v.19, n.5, p. 613-620, 2004.

PLATE, K.H., MENNEL, H.D. Vascular morphology and angiogenesis in glial tumors. Exp. Toxicol. Pathol., v.47, p.89-94, 1995.

PLATE, K.H.; BREIER, G.; MILLAUER, B.; ULLRICH, A.; RISAU, W. Upregulation of vascular endothelial growth factor and its cognate receptors in a rat glioma model of tumor angiogenesis. Cancer Res., v.53, p.5822-5827, 1993

PLATE, K.H.; SCHOLZ, A.; DUMONT, D.J. Tumor angiogenesis and antiangiogenic therapy in malignant gliomas revisited. Acta Neuropathol., v.124, p.763-775, 2012.

POPE, W.B.; PRINS, R.M.; ALBERT THOMAS, M.; NAGARAJAN, R.; YEN, K.E.; BITTINGER, M.A.; SALAMON, N.; CHOU, A.P.; YONG, W.H.; SOTO, H.; WILSON, N.; DRIGGERS, E.; JANG, H.G.; SU, S.M.; SCHENKEIN, D.P.; LAI, A.; CLOUGHESY, T.F.; KORNBLUM, H.I.; WU, H.; FANTIN, V.R.; LIAU, L.M. Non-invasive detection of 2-hydroxyglutarate and other metabolites in IDH1 mutant glioma patients using magnetic resonance spectroscopy. J. Neurooncol., v.107, n.1, p.197-205, 2012. 
PRICE, E.W.; ORVIG, C. Matching chelators to radiometals for radiopharmaceuticals. Chem. Soc. Rev., v.43, n.1, p.260-290, 2014.

PSIMADAS, D.; BOUZIOTIS, P.; GEORGOULIAS, P.; VALOTASSIOU, V.; TSOTAKOS, T.; LOUDOS, G. Radiolabeling approaches of nanoparticles with (99m) Tc. Contrast Media Mol. Imaging, v.8, p.333-339, 2013.

RAMSEY, M.R.; SHARPLESS, N.E. ROS as a tumour suppressor? Nat. Cell. Biol., v.8, n.11, p.1213-1215, 2006.

RENNEN, H.J.J.M., VAN EERD, J.E., OYEN, W.J.G., CORSTENS, F.H.M., EDWARDS, D.S., BOERMAN, O.C. Effects of Coligand Variation on the In Vivo Characteristics of Tc-99m-Labeled Interleukin-8 in Detection of Infection. Bioconj. Chem., v.13, n.2, p.370-377, 2002.

REUBI, J.C. Peptide receptors as molecular targets for cancer diagnosis and therapy. Endocr. Rev., v.24, p.389-427, 2003.

REUBI, J.C. Regulatory peptide receptors as molecular targets for cancer daignosis and therapy. Q. J. Nucl. Med., v.41, p.63-70, 1997.

RICCABONA, G.; DECRISTOFORO, C. Peptide targeted imaging of cancer. Cancer Biother Radiopharm, v.18, p.675-87, 2003.

RIEMENSCHNEIDER, M.J.; JEUKEN, J.W.; WESSELING, P.; REIFENBERGER, G. Molecular diagnostics of gliomas: state of the art. Acta Neuropathol., v.120, n.5, p.567-584, 2010.

RITSCHEL, W.A; KEARNS, G.L. Definitions and nomenclature. In: (Ed.). Handbook of basic pharmacokinectis including clinical applications. Washington American Pharmacists Association, 2009. Cap.1, p.1-11.

ROMERO, Thiago. Radiofármacos: produção deverá aumentar com novo acelerador.Inovação Uniemp, Campinas, v. 2, n. 2, jun. 2006

RUGGERI, B.A.; CAMP, F. Animal models of disease: pre-clinical animal models of cancer and their applications and utility in drug discovery. Biochem.

Pharmacol., v.87,p.150-161, 2014.

RUOSLAHTI, E. Specialization of tumour vasculature. Nat. Rev. Cancer., v.2, n.2, p.83-90, 2002.

RUOSLAHTI, E.; SANGEETA, N.; BHATIA, S.N.; SAILOR, M.J. Targeting of drugs and nanoparticles to tumors. J. Cell Biol., v.188, n.6, p.759-768, 2010.

SAHA, G.B. Fundamentals of nuclear pharmacy. Springer, 1998. p. 34-170.

SCHNELL, O.; KREBS, B.; WAGNER, E.; ROMAGNA, A.; BEER, A.J.; GRAU, S.J.; THON, N.; GOETZ, C.; KRETZSCHMAR, H.A.; TONN, J.C.; GOLDBRUNNER, R.H. Expression of integrin av $\beta 3$ in gliomas correlates with tumor grade and is not restricted to tumor vasculature. Brain Pathol., v.18, p.37886, 2008. 
SCHOTTELIUS, M.; WESTER, H.J. Molecular imaging targeted receptor Methods, v.48, p.161-177, 2009.

SEGRÈ, E.; WU, C.S. Some Fission Products of Uranium. Physical Review, v.57, n.6, p.552, 1940.

SENGUPTA, S.; CHATTOPADHYAY, N.; MITRA, A.; RAY, S.; DASGUPTA, S.; CHATTERJEE, A. Role of avß3 integrin receptors in breast tumor. J. Exp. Clin. Cancer Res., v.20, p.585-590, 2001.

SHI, J.; KIM, Y.S.; ZHAI, S.; LIU, Z.; CHEN, X.; LIU, S. Improving tumor uptake and pharmacokinetics of (64)Cu-labeled cyclic RGD peptide dimers with Gly(3) and PEG(4) linkers. Bioconjug. Chem., v.20, n.4, p.750-759, 2009 A.

SHI, J.; WANG, L.; KIM, Y.S.; ZHAI, S.; JIA, B.; WANG, F.; LIU, S. 99mTcO(MAG2-3G3-dimer): a new integrin alpha(v)beta(3)-targeted SPECT radiotracer with high tumor uptake and favorable pharmacokinetics. Eur. J. Nucl. Med. Mol. Imaging, v.36, n.11, p.1874-1884, 2009 B.

SIEGEL, R.; NAISHADHAM, D., JEMAL, A. Cancer statistics, 2013. CA Cancer J. Clin., v.63, p.11-30, 2013.

SIGNORE, A.; ANNOVAZZI, A.; CHIANELLI, M.; CORSETTI, F.; WIELE, C.V.; WATHERHOUSE,R.N.; SCOPINARO, F. Peptide radiopharmaceuticals for siagnosis and terapy. Eur. J. Nucl. Med., v.28 p.1555-1565, 2001.

SILVA, L. R.; FERREIRA, M. M. C. Estudo do Coeficiente de Partição octanolágua de bifenilas policloradas (PCBs) utilizando parâmetros topológicos. Química Nova, v.26, n.3, p. 312-318, 2003.

SMITH, G.P. Filamentous fusion phage: Novel expression vectors that display cloned antigens on the virion surface. Science, v.228, p.1315-1317, 1985.

SMITH, J. W., CHERESH, D.A. The arg-gly-asp binding domain of the vitronectin receptor: photoaffinity crosslinking implicates amino acid residues $61-203$ of the $B$ subunit. J. Biol. Chem., v.263, p.18726-18731, 1988.

SMITH-JONES, P. M.; STOLZ, B.; ALBERT, R.; KNECHT, H.; BRUNS, C. Synthesis, biodistribution and renal handling of various chelate-somatostatin conjugates with metabolizable linking groups. Nucl. Med. Biol. v.24, n.8, p.761769, 1997.

SONG, K.M.; LEE, S.; BAN, C. Aptamers and their biological applications.

Sensors (Basel)., v.12, n.1, p.612-631, 2012.

SOURIAU, C.; HUA, T.; LEFRANC, M.; WEILL, M. Présentation à la surface de phages filamenteux: Les multiples applications du phage display.

Médecine/Sciences, v.14, p.300-309, 1998. 
STEVENSON, D.; MILLER, S.; WILSON, I.D. Extraction Methods in Organic Analysis. 1ed. England: Editora Sheffield Acad. Press, 2000.

STEVENSON, D.; WILSON, I.D. 1 ed. Sample preparation for Biomedical and Environmental Analysis. New York: Editora Plenum, 1994.

STUPACK, D.G.; PUENTE, X.S.; BOUTSABOUALOY, S.; STORGARD, C.M.; CHERESH, D. A. Apoptosis of adherent cells by recruitment of caspase- 8 to unligated integrins. J. Cell Biol., v.155, p.459-470, 2001.

SU, Z.F.; HE, J.; RUSCKOWSKI, M.; HNATOWICH, D.J. In vitro cell studies of technetium-99m labeled RGD-HYNIC peptide, a comparison of tricine and EDDA as co-ligands. Nucl. Med. Biol., v.30, p.141-149, 2003.

SUGAHARA, K.N.; TEESALU, T.; KARMALI, P.P.; KOTAMRAJU, V.R.; AGEMY, L.; GIRARD, O.M.; HANAHAN, D.; MATTREY, R.F.; RUOSLAHTI, E. Tissue penetrating delivery of compounds and nanoparticles into tumors. Cancer Cell, v.16, p. 510-520, 2009.

SUTCLIFFE-GOULDEN, J.L.; O'DOHERTY, M.J.; MARSDEN, P.K.; HART, I.R.; MARSHALL, J.F.; BANSAL, S.S. Rapid solid phase synthesis and biodistribution of ${ }^{18} \mathrm{~F}$-labelled linear peptides. Eur. J. Nucl. Med. Mol. Imag., v.29, p.754-759, 2002.

SVENSSON, C.K.; WOODRUFF, M.N.; BAXTER, J.G.; LALKA, D. Free drug concentration monitoring in clinical practice. Rationale and current status. Clin. Pharmacokinet., v.11, n.6, p.450-460, 1986.

TAKAHASHI, A.; OHTANI, N.; YAMAKOSHI, K.; IIDA, S.; TAHARA, H.; NAKAYAMA, K.; NAKAYAMA, K.I.; IDE, T.; SAYA, H.; HARA, E. Mitogenic signalling and the p16INK4a-Rb pathway cooperate to enforce irreversible cellular senescence. Nat. Cell Biol., v.8, n.11, p.1291-1297, 2006.

UEBERBERG, S.; SCHNEIDER, S. Phage library-screening: a powerful approach for generation of targeting-agents specific for normal pancreatic islet-cells and islet-cell carcinoma in vivo. Regul. Pept., v.160, n.1-3, p.1-8, 2010.

VAN DEN BENT, M.J.; VOGELBAUM, M.A.; WEN, P.Y.; MACDONALD, D.R.; CHANG, S.M. End point assessment in gliomas: novel treatments limit usefulness of classical Macdonald's Criteria. J. Clin. Oncol., v.27, p.2905-2908, 2009.

VAN DER LAKEN, C.J.; BOERMAN, O.C.; OYEN, W.J.G.; VAN DER VEM, M.T.P.; EDWARDS, D.S.; BARRETT, J.A.; VAN DER MEER, J.W.M.; CORSTENS, F.H.M. Technetium-99m-labeled chemotactic peptides in acute infection and sterile inflammation. J. Nucl. Med., v.38, p.1310-1315, 1997.

VAN HAGEN P.M.; BREEMAN, W.A.; BERNARD, H.F.; SCHAAR, M.; MOOIJ, C.M.; SRINIVASAN, A.; SCHMIDT, M.A.; KRENNING, E.P.; DE JONG, M. Evaluation of a radiolabeled cyclic DTPA-RGD analog for tumor imaging and radionuclide therapy. Int. J. Cancer (Radiat. Oncol. Invest.), v.90, p.186-198, 2000. 
VANLIĆ-RAZUMENIC, N.; PETROVIC, J.; GORKIC, D. Biochemical studies of the renal radiopharmaceutical compound dimercaptosuccinate. IV. Interaction of 99mTc-DMS and 99Tc-DMS complexes with blood serum proteins. Eur. J. Nucl. Med., v.9, n.8, p.370-373, 1984.

VERRIER, S.; PALLU, S.; BAREILLE, R.; JONCZYK, A.; MEYER, J.; DARD, M.; AMÉDÉE, J.Function of linear and cyclic RGD-containing peptides in osteoprogenitor cells adhesion process. Biomaterials, v.23, n.2, p.585-596, 2002.

VEULENS, A.N.; RODRÍGUEZ, R. G protein coupled receptors as targets for drug design. Biotec. Apl., v.26, p.24-33, 2009.

VONARBOURG, A.; PASSIRANI, C.; SAULNIER, P.; BENOIT, J.P. Parameters influencing the stealthiness of colloidal drug delivery systems. Biomaterials, v.27, n.24, p.4356-4373, 2006.

WANG, E.S.; ZHANG, X.P.; YAO, H.B.; WANG, G.; CHEN, S.W.; GAO, W.W.; YAO, H.J.; SUN, Y.R.; XI, C.H.; JI, Y.D. Tetranectin knockout mice develop features of Parkinson disease. Cell Physiol. Biochem., v.34, n.2, p.277-87, 2014.

WANG, L., SHI, J., KIM, Y.S., ZHAI, S., JIA, B., ZHAO, H., LIU, Z., WANG, F., CHEN, X., LIU, S. Improving tumor targeting capability and pharmacokinetics of 99mTc-labeled cyclic RGD dimers with PEG4 linkers. Mol. Pharm., v.6, p.231245, 2009.

WANG, Y.; LIU, G.; HNATOWICH, D. J. Methods for MAG3 conjugation and 99mTc radiolabeling of biomolecules. Nature Protocols, v.1, p.1477-1450, 2006.

WEEKS, M. E. The discovery of the elements. XX. Recently discovered elements". J. Chem. Education, v.10, n.3, p.161-170, 1993.

WEINER R.E.; THAKUR M.L. Radiolabeled Peptides in Oncology: role in diagnosis and treatment. Biodrugs., v.19, n.3, p.145-163, 2005.

WESTER, H.J.; KESLLER, H. Molecular targeting with peptides or peptidepolymer conjugates: Just a question of size? J. Nucl. Med., v.46, n.12, p.19401945, 2005.

WU, H.; CHEN, H.; PAN, D.; MA, Y.; LIANG, S.; WAN, Y.; FANG, Y. Imaging Integrin av 33 and NRP-1 Positive Gliomas with a Novel Fluorine-18 Labeled RGD-ATWLPPR Heterodimeric Peptide Probe. Mol. Imaging Biol. 2014 Jul 8. DOI 10.1007/s11307-014-0761-0.

WU, Y.; ZHANG, X.Z.; XIONG, Z.M.; CHENG, Z.; FISHER, D.R.; LIU, S. MicroPET imaging of glioma av-integrin expression using 64Cu labeled tetrametric RGD peptide. J. Nucl. Med., v.56, p.1707-1718, 2005.

WU, Z.; LI, Z.B.; CAI, W.; HE, L.; CHIN, F.T.; LI, F.; CHEN, X. 18F-labeled miniPEG spacered RGD dimer (18F-FPRGD2): synthesis and microPET imaging of alphavbeta3 integrin expression. Eur. J. Nucl. Med. Mol. Imaging, v.34, n.11, p.1823-1831, 2007. 
XU, X.; ZHAO, J.; XU, Z.; PENG, B.; HUANG, Q.; ARNOLD, E.; DING, J.

Structures of human cytosolic NADP-dependent isocitrate dehydrogenase reveal a novel self-regulatory mechanism of activity. J. Biol. Chem., v.279, n.32, p.3394633957, 2004.

XUE L.Y.; NOUJAIM A.A.; SYKES T.R.; WOO T.K.; PENG Z.; Studies on Metabolism of Directly Labeled ${ }^{99 m}$ Tc-antibody in Mice. Q. J. Nucl. Med., v.40, n.4, p.341-350, 1996.

YAN, H., PARSONS, D.W., JIN, G., MCLENDON, R., RASHEED, B.A., YUAN, W., KOS, I., BATINIC-HABERLE, I., JONES, S., RIGGINS, G.J., FRIEDMAN, H., FRIEDMAN, A., REARDON, D., HERNDON, J., KINZLER, K.W., VELCULESCU, V.E., VOGELSTEIN, B., BIGNER, D.D. IDH1 and IDH2 mutations in gliomas. $\boldsymbol{N}$. Engl. J. Med., v.360, n.8, p.765-773, 2009.

YANG, J.; GUO, H.; GALAZZI, F.; BERWICK, M.; PADILLA, R.S.; MIAO, Y. Evaluation of a Novel Arg-Gly-Asp-Conjugated r-Melanocyte Stimulating Hormone Hybrid Peptide for Potential Melanoma Therapy. Bioconjugate Chem., v.20, p.1634-1642, 2009.

YANG, J.; GUO, H.; MIAO, Y. Technetium-99m-labeled Arg-Gly-Asp-conjugated alpha-melanocyte stimulating hormone hybrid peptides for human melanoma imaging. Nucl. Med. Biol., v.37, n.8, p.873-883, 2010.

YI, M.; RUOSLAHTI, E. A fibronectin fragment inhibits tumor growth, angiogenesis, and metastasis. Proc. Natl Acad. Sci. USA, v.98, p.620-624, 2001.

ZERROUQI, A.; VAN MEIR, E.G. A conspiracy of glioma and endothelial cells to invade the normal brain. Onco. Target., v.2, p.1-4, 2011.

ZHANG H.; CHEN J.; WALDHERR C.; HINNI K.; WASER B.; REUBI J.C.; MAECKE, H.R. Synthesis and evaluation of bombesin derivatives on the basis of pan-bombesin peptides labeled with indium-111, lutetium-177, and yttrium-90 for targeting bombesin receptor-expressing tumors. Cancer Res., v.64, n.18, p.67076715, 2004.

ZHANG, C.; JUGOLD, M.; WOENNE, E.C.; LAMMERS, T.; MORGENSTERN, B.; MUELLER, M.M.; ZENTGRAF, H.; BOCK, M.; EISENHUT, M.; SEMMLER, W.; KIESSLING, F. Specific targeting of tumor angiogenesis by RGD-conjugated ultrasmall superparamagnetic iron oxide particles using a clinical 1.5-T magnetic resonance scanner. Cancer Res., v.67, p.1555-1562, 2007.

ZHANG, J.B; WANG, X.B.; LI, C.Y. Synthesis and biodistribution of a new 99mTc nitrido complex for cerebral imaging. Nucl. Med. Biol., v.29, p.665-669, 2002.

ZHANG, X.; XIONG, Z.; WU, Y.; CAI, W.; TSENG, J.R.; GAMBHIR, S.S.; CHEN, $X$. Quantitative PET imaging of tumor integrin alphavbeta3 expression with 18FFRGD2. J. Nucl. Med., v.47, n.1, p.113-121, 2006

ZHANG, Y.M.; LIU, N.; ZHU, Z.H.; RUSCKOWSKI, M.; HNATOWITCH, D.J. Influence of different chelators (HYNIC, MAG 3 and DTPA) on tumor cell 
accumulation and mouse biodistribution of technetium-99m labeled to antisense DNA. Eur. J. Nucl. Med., v.27, n. 11, p. 1700-1707, 2000.

ZHI, M.; WU, K.C.; DONG, L.; HAO, Z.M.; DENG, T.Z.; HONG, L.; LIANG, S.H.; ZHAO, P.T.; QIAO, T.D.; WANG, Y.; XU, X.; FAN, D.M. Characterization of a specific phage-displayed peptide binding to vasculature of human gastric cancer. Cancer Biol. Ther., v.3, p.1232-1235, 2004.

ZHOU, Y.; CHAKRABORTY, S.; LIU, S. Radiolabeled Cyclic RGD Peptides as Radiotracers for Imaging Tumors and Thrombosis by SPECT. Theranostics, v.1, p.58-82, $2011 \mathrm{~A}$.

ZHOU, Y.; KIM, Y.S.; CHAKRABORTY, S.; SHI, J.; GAO, H.; LIU, S. (99m)TcLabeled Cyclic RGD Peptides for Noninvasive Monitoring of Tumor Integrin $\alpha(v) \beta(3)$ Expression. Mol Imaging, v.10, n.5, p.386-397, 2011 B.

ZITZMANN, S.; EHEMANN, V.; SCHWAB, M. Arginine-glycine-aspartic acid (RGD)-peptide binds to both tumor and tumor-endothelial cells in vivo. Cancer Res., v.62, p.5139-5143, 2002.

ZURITA, A.J.; TRONCOSO, P.; CARDO-VILA, M.; LOGOTHETIS, C.J.;

PASQUALINI, R.; ARAP, W. Combinatorial screenings in patients: the interleukin11 receptor alpha as a candidate target in the progression of human prostate cancer. Cancer Res., v.64, p.435-439, 2004. 